\title{
MATURAÇÃO E CONSERVAÇÃO DO TANGOR 'MURCOTE' (Citrus reticulata Blanco x $C$. sinensis Osbeck) E DA LIMA ÁCIDA 'TAHITI' (Citrus latifolia Tanaka) SOB EFEITO DE BIORREGULADORES
}

\author{
SILVIO TAVARES
}

\begin{abstract}
Tese apresentada à Escola Superior de Agricultura "Luiz de Queiroz", Universidade de São Paulo, para obtenção do título de Doutor em Agronomia, Área de Concentração: Fitotecnia.
\end{abstract}

P I R A C I C A B A

Estado de São Paulo - Brasil

Junho - 2003 


\title{
MATURAÇÃO E CONSERVAÇÃO DO TANGOR 'MURCOTE' (Citrus reticulata Blanco x $C$. sinensis Osbeck) E DA LIMA ÁCIDA 'TAHITI' (Citrus latifolia Tanaka) SOB EFEITO DE BIORREGULADORES
}

\author{
SILVIO TAVARES \\ Engenheiro Agrônomo \\ Orientador: Prof. Dr. PAULO ROBERTO DE CAMARGO E CASTRO

\begin{abstract}
Tese apresentada à Escola Superior de Agricultura "Luiz de Queiroz", Universidade de São Paulo, para obtenção do título de Doutor em Agronomia, Área de Concentração: Fitotecnia.
\end{abstract}

P I R A C I C A B A

Estado de São Paulo - Brasil

Junho -2003 
Dados Internacionais de Catalogação na Publicação (CIP) DIVISÃO DE BIBLIOTECA E DOCUMENTAÇÃO - ESALQ/USP

\section{Tavares, Silvio}

Maturação e conservação do tangor "Murcote" (C itrus retic ula ta Blanco $\times$ C. sinensis Osbeck) e da lima ácida 'Tahiti' (C itrus la tifolia Tanaka) sob efeito de biorreguladores/ Silvio Tavares. - - Piracicaba, 2003.

115 p. : il.

Tese (doutorado) - Escola Superior de Agricultura Luiz de Queiroz, 2003. Bibliografia.

1. Conservação de a limentos 2. Limão-Taiti 3. Maturação 4.

Reguladorde crescimento vegetal 5. Senescência pós-colheita 6. Tangerina Murcote I. Título

CDD 634.31 
Aos meus filhos Pedro e Thiago

À minha esposa Elisabete, pelo apoio e dedicação e,

... A todos àqueles que lutam ou sonham por um mundo melhor,

\section{OFEREÇO}

Ao meu amigo e Mestre

Dr. Antonio Augusto Lucchesi

(In memorian) 


\section{AGRADECIMENTOS}

Ao nosso Deus Pai, Deus Filho e Espírito Santo pelas graças recebidas todos os dias desta caminhada.

Ao Departamento de Produção Vegetal (ESALQ/USP), pela oportunidade oferecida para a realização deste trabalho.

À Coordenadoria de Aperfeiçoamento de Pessoal e Ensino Superior - CAPES, pelo apoio financeiro concedido para a realização deste trabalho.

Ao Professor Paulo R. C. Castro, pelo exemplo e orientação, amizade e incentivo, durante todo o período de trabalho e aprendizagem.

Ao professor Ricardo Alfredo Kluge, pela amizade, sugestões e críticas durante a redação deste trabalho.

Aos docentes da ESALQ/USP, por compartilharem seus conhecimentos durante este período de minha formação.

Aos amigos Chryz, Graça e Mineirinho pelo apoio na instalação e avaliação dos ensaios e Alexandre Vendemiatti pelas fotografias e companheirismo.

Aos colegas de curso Chryz, Rafael, Elvis, Ilana, Carol, Cecília, Saly, Stella e Mônica pelo companheirismo e amizade. 
A Maria Cristina Clemente Furlan, Eliana Maria Garcia e Luciane Aparecida Lopes pela amizade e apoio, durante o período do curso. 


\section{SUMÁRIO}

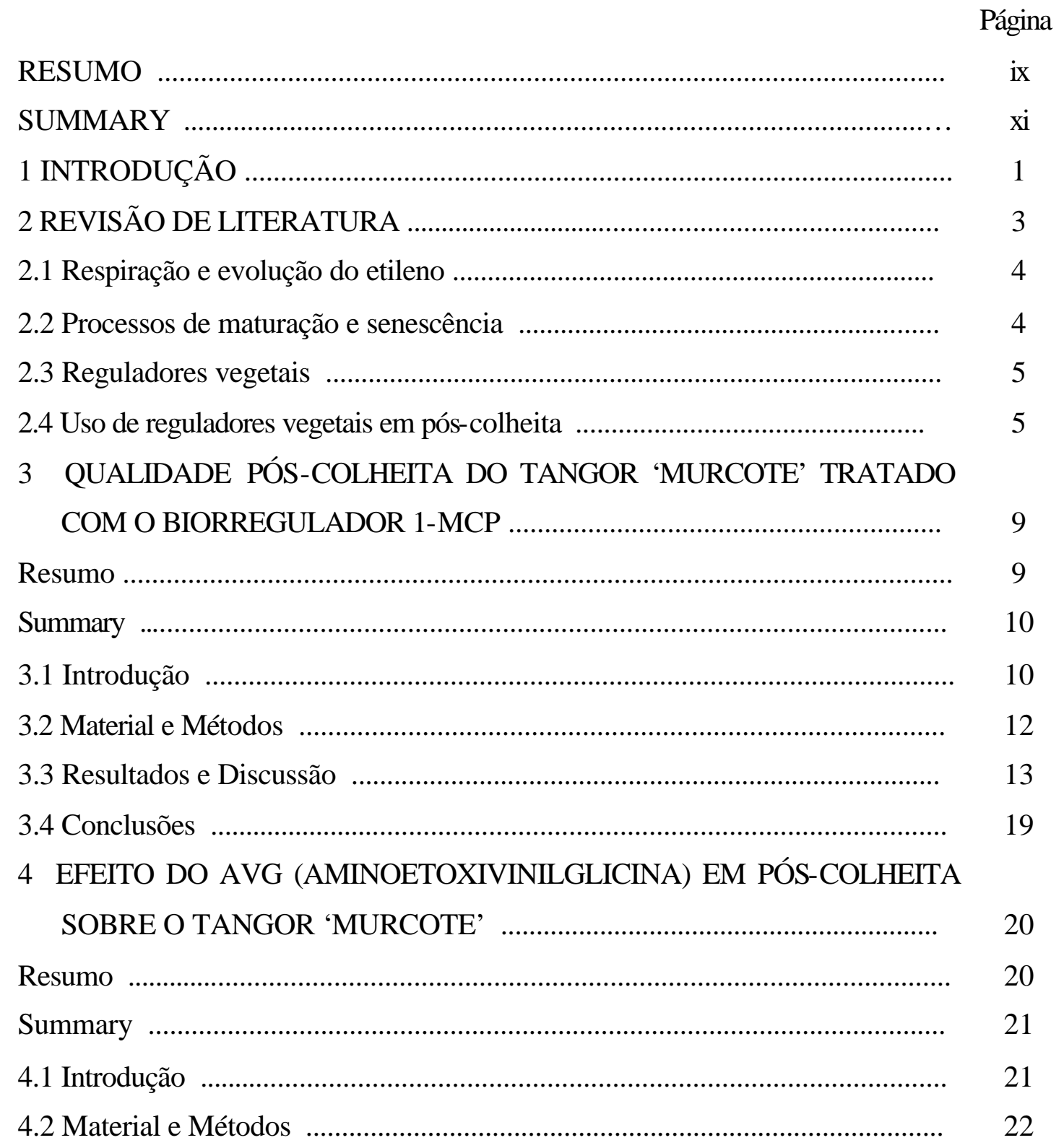


4.3 Resultados e Discussão .................................................................................. 23

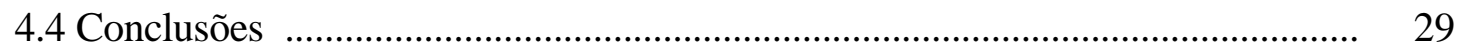

5 MATURAÇÃO E CONSERVAÇÃO DE TANGOR 'MURCOTE' TRATADO COM BIORREGULADORES ........................................................................ 30

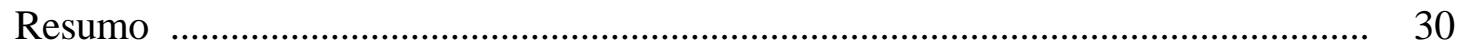

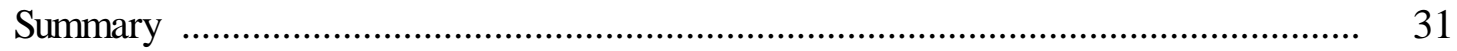

5.1 Introdução ................................................................................................. 31

5.2 Material e Métodos ............................................................................................. 34

5.3 Resultados e Discussão .............................................................................. $\quad 35$

5.4 Conclusões

6 CONSERVAÇÃO PÓS-COLHEITA DA LIMA ÁCIDA 'TAHITI' TRATADA COM 1-METILCICLOPROPENO …………............................................... 42

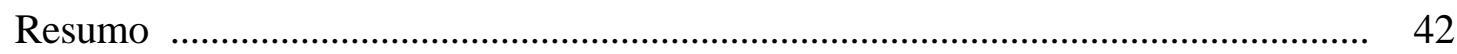

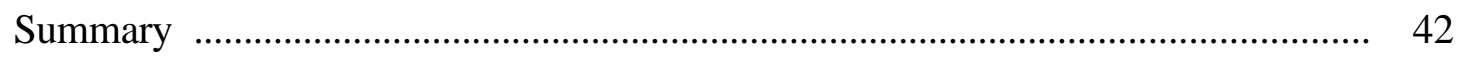

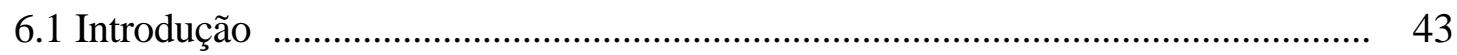

6.2 Material e Métodos .................................................................................... 45

6.3 Resultados e Discussão ................................................................................... 46

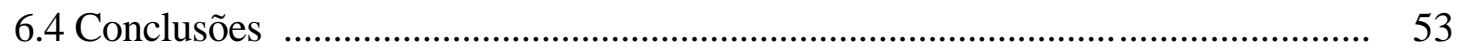

7 EFEITO DE AMINOETOXIVINILGLICINA (AVG) NA CONSERVAÇÃO PÓS-COLHEITA DA LIMA ÁCIDA 'TAHITI' .............................................. 54

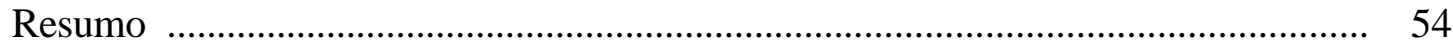

Summary …................................................................................................. 54

7.1 Introdução .................................................................................................... 55

7.2 Material e Métodos ……….......................................................................... 57

7.3 Resultados e Discussão ...................................................................................... 58

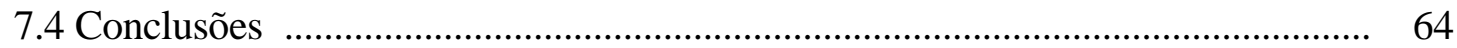

8 EFEITO DE GA $\mathrm{DA}_{3}$ E SUA COMBINAÇÃO COM 1-MCP E AVG, NA QUALIDADE PÓS-COLHEITA DA LIMA ÁCIDA 'TAHITI' ........................ 65

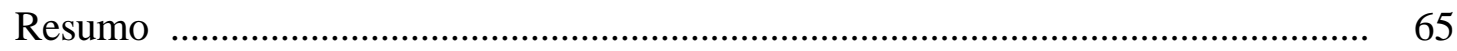

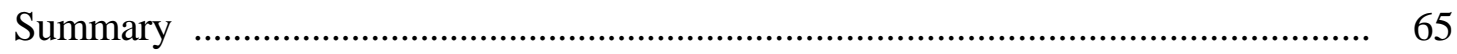




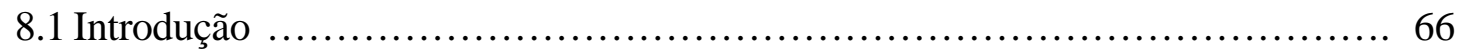

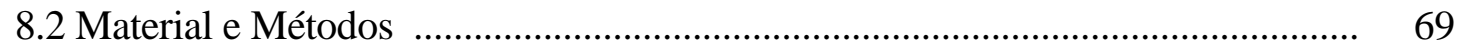

8.3 Resultados e Discussão .................................................................................. $\quad 70$

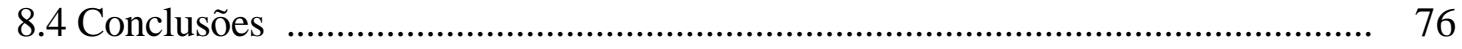

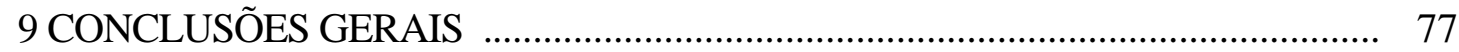

9.1 Tangor 'Murcote' .................................................................................................. 7

9.2 Lima ácida ‘Tahiti’ ........................................................................................... 77

9.3 Combinações de biorreguladores em pós-colheita ................................................ 77

REFERÊNCIAS BIBLIOGRÁFICAS ............................................................ 79

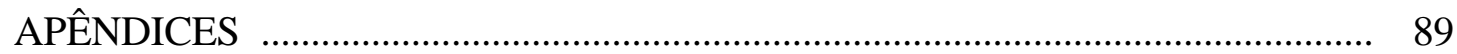




\section{MATURAÇÃO E CONSERVAÇÃO DO TANGOR 'MURCOTE' (Citrus reticulata Blanco x C. sinensis Osbeck) E DA LIMA ÁCIDA 'TAHITI' (Citrus latifolia Tanaka) SOB EFEITO DE BIORREGULADORES}

Autor: SILVIO TAVARES

Orientador: Prof. Dr. PAULO ROBERTO DE CAMARGO E CASTRO

\section{RESUMO}

Os trabalhos foram conduzidos no Laboratório de Fisiologia Pós-Colheita do Departamento de Ciências Biológicas da ESALQ-USP, no período de agosto de 2001 a agosto de 2002. Verificaram-se os efeitos isolados do regulador vegetal ácido giberélico, 1-metilciclopropeno e aminoetoxivinilglicina, e também nas combinações de 1-MCP com GA3 e AVG com $\mathrm{GA}_{3}$, em pós-colheita de tangor 'Murcote' e de lima ácida 'Tahiti'. A escolha das variedades ocorreu em função do seu potencial, tanto para o mercado interno, quanto para a exportação de frutas frescas. As concentrações utilizadas foram: $20 \mathrm{mg} \mathrm{L}^{-1}$ de $\mathrm{GA}_{3}$; 0,1, 0,5 e 1,0 $\mu \mathrm{L} \mathrm{L}^{-1}$ de 1-MCP; 10, 50 e $100 \mathrm{mg} \mathrm{L}^{-1}$ de AVG e as combinações de $0,5 \mu \mathrm{L} \mathrm{L}^{-1}$ de 1-MCP com $20 \mathrm{mg} \mathrm{L}^{-1}$ de $\mathrm{GA}_{3}$ e $50 \mathrm{mg} \mathrm{L}^{-1}$ de AVG com $20 \mathrm{mg} \mathrm{L}^{-1}$ de $\mathrm{GA}_{3}$, além do controle. Aplicoutse o 1-MCP através da exposição dos frutos ao gás durante $12 \mathrm{~h}$ em caixas herméticas a $20{ }^{\circ} \mathrm{C}$. O AVG e o $\mathrm{GA}_{3}$ foram aplicados submergindo os frutos em solução aquosa contendo as devidas concentrações, durante um minuto. Nas combinações, o $\mathrm{GA}_{3}$ foi aplicado após os tratamentos com 1 MCP ou AVG. O delineamento experimental adotado foi inteiramente casualizado, em 
esquema fatorial para verificar a ação do 1-MCP e do AVG em tangor 'Murcote'e na lima 'Tahiti'.

Para as combinações de $1-\mathrm{MCP}+\mathrm{GA}_{3}$ e do $\mathrm{AVG}+\mathrm{GA}_{3}$, utilizou-se o delineamento experimental inteiramente casualizado com parcelas subdivididas no tempo. Determinou-se a evolução da coloração na casca $\left(L, C^{*} e h^{0}\right)$, os níveis de sólidos solúveis totais ( ${ }^{\circ}$ Brix), acidez titulável total (\%), vitamina $\mathrm{C}$, perda de massa (\%), quantidade de suco (\%) e taxa respiratória dos frutos sob refrigeração e após 3 dias a $25{ }^{\circ} \mathrm{C}$. Os resultados foram submetidos à análise de regressão. O 1-MCP não tem efeito sobre a coloração de casca, em aplicações tardias em tangor 'Murcote'. A concentração de $0,5 \mu \mathrm{L} \mathrm{L}^{-1}$ foi suficiente para reduzir a taxa respiratória e o consumo de vitamina $\mathrm{C}$. As características físico-químicas mantiveram-se adequadas para o consumo durante 45 dias de armazenamento refrigerado. O AVG aplicado em pós-colheita realçou a intensidade da cor na casca de tangor 'Murcote', diminuiu o consumo de sólidos solúveis totais, a taxa respiratória e não afetou a acidez titulável. As combinações de 1 MCP e AVG com GA3 não tiveram efeitos na coloração da casca do tangor 'Murcote', após estágio avançado de pigmentação na casca. As combinações também não afetaram o nível de acidez titulável, vitamina $\mathrm{C}$, a perda de massa e a taxa respiratória do tangor 'Murcote'. Com relação à lima ácida 'Tahiti', o tratamento com 1-MCP a 0,5 ou 1,0 $\mu \mathrm{L}$ $\mathrm{L}^{-1}$ atrasou mudanças na coloração da casca (croma e ângulo de cor), promoveu maior teor de sólidos solúveis totais e diminuiu a amplitude de variação do ratio. O AVG não impediu a mudança na cor da casca, porém diminuiu o consumo de SST e de ATT; não afetou a taxa respiratória e o nível de vitamina C. A combinação do 1-MCP+GA3 retardou a evolução na mudança da cor de casca durante 60 dias. O nível de vitamina $\mathrm{C}$ manteve-se elevado. Não houve alterações na taxa respiratória e na quantidade de suco nos frutos da lima ácida 'Tahiti'. 


\section{MATURATION AND CONSERVATION OF 'MURCOTT' TANGOR (Citrus reticulata Blanco $\mathrm{x}$ C. sinensis Osbeck) AND 'TAHITI' LIME (Citrus latifolia Tanaka) UNDER BIOREGULATORS ACTION}

Author: SILVIO TAVARES

Adviser: Prof. Dr. PAULO ROBERTO DE CAMARGO E CASTRO

\section{SUMMARY}

The experiments were conducted from August 2001 to August 2002 in the postharvest Physiology Laboratory, Department of Biology, ESALQ-USP. It was checked the isolated effect of gibberellic acid, 1-methylcyclopropene and aminoethoxyvinilglycine, and also the combinations of $1 \mathrm{MCP}$ with $\mathrm{GA}_{3}$ and AVG with $\mathrm{GA}_{3}$, on 'Murcott' tangor and 'Tahiti' lime post-harvest. The cultivars were chosen because of their potential, both for the internal market as for fresh fruit exportation. The following concentrations were applied: $\mathrm{GA}_{3}$ at $20 \mathrm{mg} \mathrm{L}^{-1} ; 1-\mathrm{MCP}$ at $0.1,0.5$ and $1.0 \mu \mathrm{L}$ $\mathrm{L}^{-1}$; AVG at 10,50 and $100 \mathrm{mg} \mathrm{L}^{-1}$ and the combinations of $1 \mathrm{MCP}$ at $0.5 \mu \mathrm{L} \mathrm{L}^{-1}$ with $\mathrm{GA}_{3}$ at $20 \mathrm{mg} \mathrm{L}^{-1}$ and $\mathrm{AVG}$ at $50 \mathrm{mg} \mathrm{L}^{-1}$ with $\mathrm{GA}_{3}$ at $20 \mathrm{mg} \mathrm{L}^{-1}$, and the control. The fruits were exposed to $1-\mathrm{MCP}$ gas during $12 \mathrm{~h}$ in hermetic boxes at $20{ }^{\circ} \mathrm{C}$. AVG and $\mathrm{GA}_{3}$ were applied dipping the fruits, for a minute, in solutions with the mentioned concentrations. In combinations, $\mathrm{GA}_{3}$ was applied after the treatments with 1-MCP or AVG. The experimental design was totally randomized factorial to check the action of 1-MCP and AVG on 'Murcott' tangor and 'Tahiti' lime. For the combinations of 1- 
$\mathrm{MCP}+\mathrm{GA}_{3}$ and $\mathrm{AVG}+\mathrm{GA}_{3}$, totally randomized design was used with time subdivided parcels.

It was determined the evolution in the peel color $\left(\mathrm{L}, \mathrm{C}^{*}\right.$ e $\left.\mathrm{h}^{\mathrm{O}}\right)$, the levels of total soluble solids ( ${ }^{\circ}$ Brix), total titriable acidity (\%), vitamin C, mass loss (\%), juice content (\%) and respiratory rate of the fruits under cold storage and after 3 days at $25{ }^{\circ} \mathrm{C}$. The results were submitted to regression analysis. 1-MCP doesn't have any effect on the peel color, in late application, on tangor 'Murcott'. The 1-MCP at $0.5 \mu \mathrm{L} \mathrm{L}^{-1}$ was enough to reduce the respiratory rate and the waste of $\mathrm{C}$ vitamin. The physic-chemical characteristics were kept suitable for the consumption during 45 days of cold storage. The AVG, in postharvest application, enhanced the peel color intensity of 'Murcott' tangor, decreased the waste of total soluble solids, the respiratory rate and didn't affect the total titrable acidity. The combinations of 1-MCP and AVG with $\mathrm{GA}_{3}$ didn't have any effect on the peel color of 'Murcott' tangor, after an advanced stage of peel coloration. The combinations didn't affect the levels of total titrable acidity, $\mathrm{C}$ vitamin, mass loss and respiratory rate of 'Murcott' tangor. In relation to 'Tahiti' lime, the treatment with 1MCP at 0.5 or $1.0 \mu \mathrm{L} \mathrm{L}^{-1}$ delayed changes in the peel color (color croma and angle), promoted higher concentration of total soluble solids and decreased the range of ratio variation. The AVG didn't prevent peel color change, however it decreased the waste of TSS and of TTA; it didn't affect the respiratory rate and the level of $\mathrm{C}$ vitamin. The combination of $1-\mathrm{MCP}+\mathrm{GA}_{3}$ delayed the evolution in the change of peel color during 60 days. The level of $\mathrm{C}$ vitamin was kept high. There weren't changes in the respiratory rate and in juice content 'Tahiti' lime. 


\section{INTRODUÇÃO}

A pós-colheita de frutas e hortaliças tem despertado grande interesse nos últimos anos, devido principalmente ao aumento na produção e na demanda, aos estímulos oferecidos às exportações e ànecessidade de um abastecimento regular do mercado.

O Brasil é um dos maiores produtores mundiais de frutas, alcançando em torno de 35 milhões de toneladas por ano. Entretanto, apresenta um dos maiores índices de perdas em pós-colheita, estimado em 30\% (Chitarra \& Chitarra, 1990; Bleinroth et al., 1992). Estas perdas ocorrem em função de inúmeros fatores, tais como, colheita e transporte inadequados; ausência de classificação; falta de cadeia de frio; embalagens e falta de tratamentos auxiliares, como o uso de reguladores vegetais que retardam os processos relacionados à maturação e senescência dos frutos em pós-colheita. As exportações do tangor 'Murcote' e da lima ácida 'Tahiti' representam apenas $1 \%$ deste volume (FNP 2002). A diferença de preço entre as diferentes classes pode variar até $46 \%$, em média.

As frutas apresentam diferentes graus de perecibilidade e sua capacidade de armazenamento é influenciada pela respiração e produção de etileno; duração da fase de desenvolvimento, fatores genéticos e diferenças morfológicas e fisiológicas.

O armazenamento das frutas não deve ser entendido como um método de melhoria da qualidade, mas sim, como uma alternativa para a manutenção da mesma, objetivando o prolongamento do período de comercialização, regularização no abastecimento e, conseqüentemente, maiores rendimentos aos produtores.

A refrigeração tem sido o método de conservação mais utilizado em pós-colheita, entretanto, em alguns casos, somente a baixa temperatura pode ser insuficiente para a preservação da qualidade das frutas. Assim, a utilização de técnicas auxiliares à 
refrigeração vem alcançando bons resultados. $\mathrm{O}$ uso de reguladores vegetais na agricultura tem demonstrado grande potencial para o aumento da produtividade ou na conservação pós-colheita de frutos e hortaliças, embora ainda não seja uma prática rotineira em culturas com bom nível tecnológico.

Aumentos na produção e no consumo de frutas frescas, aliados às exportações, requerem estudos direcionados à fisiologia e à tecnologia pós-colheita que tenham por objetivo a redução das perdas dos produtos colhidos e o prolongamento do período de armazenamento e comercialização. Portanto, existe a necessidade de se compreender os fatores biológicos envolvidos na deterioração das frutas, bem como adotar ou criar tecnologias de pós -colheita para retardar a senescência e manter a qualidade das frutas. 


\section{REVISÃO DE LITERATURA}

A origem do tangor 'Murcote' é desconhecida. O nome Murcote está relacionado ao do viveirista Charles Murcott Smith, que obteve as primeiras plantas em Bayview, na Flórida, Estados Unidos por volta de 1922. Acredita-se que essa variedade é resultante do programa de melhoramento do Departamento de Agricultura dos Estados Unidos. Os frutos têm a forma achatada, com aproximadamente vinte sementes e massa média de 140 g. A casca é de cor laranja vívido, com espessura fina, aderente e vesículas de óleo em nível. Seu suco é abundante, em média $48 \%$ da massa do fruto, com teores médios de sólidos solúveis de $12,6{ }^{\circ}$ Brix, acidez titulável $-0,92 \%$ e ratio de 13,7 . Seus frutos são destinados aos mercados interno e externo para consumo ao natural, alcançando preços excepcionais em certas épocas do ano, sendo também utilizados na indústria de suco concentrado. O cultivar apresenta frutos de maturação tardia, sendo a colheita a partir de meados de julho a outubro (Figueiredo, 1991).

A lima ácida 'Tahiti' (Citrus latifólia Tanaka), conhecida entre os consumidores brasileiros como limão Tahiti, é uma espécie de citros, originária da Califórnia, Estados Unidos. Surgiu a partir de sementes de limão introduzidas do Tahiti. Seus frutos são de forma ovalada, normalmente não apresentam sementes e com peso médio de $70 \mathrm{~g}$; sua casca é de cor verde amarelada, espessura fina e vesículas de óleo deprimidas. Seu suco representa quase $50 \%$ da massa do fruto, com níveis médios de $9{ }^{\circ}$ Brix, acidez de $6 \%$ e ratio de 1,5. Destina-se os frutos para o consumo ao natural, nos mercados interno e externo ou para suco concentrado (Figueiredo, 1991). 
Atualmente, tornou-se de consumo diário, devido as suas propriedades benéficas, seja como condimento e aromatizante na culinária ou ainda pelo seu valor alimentar.

\subsection{Respiração e evolução do etileno}

A respiração é o processo central na pós-colheita de frutas e hortaliças (Moretti et al., 2000). Os produtos orgânicos como carboidratos, ácidos e lipídeos são convertidos a $\mathrm{CO}_{2}$, água e compostos ricos em energia. A respiração é um dos principais fatores relacionados ao potencial de longevidade dos frutos, após a colheita e está intimamente ligada à temperatura e à concentração de gases disponíveis aos mesmos (Wills et al., 1981; Chitarra \& Chitarra, 1990; Kader, 1992).

Os frutos cítricos apresentam um padrão respiratório do tipo não climatérico, onde não há elevação na taxa respiratória e também do etileno produzido, portanto, considera-se não existir a fase de amadurecimento (McMurchie et al., 1972; Oetiker \& Yang, 1995). Aplicação de giberelinas em frutos de laranja retarda sua perda de clorofila e inibe especificamente o amaciamento do tecido. A benziladenina também inibe a perda de clorofila em alguns frutos. Os efeitos da citocinina no desverdecimento podem refletir sua habilidade em inibir a senescência, sobre a ação dos eventos da maturação (Roberts \& Hooley, 1988).

\subsection{Processos de maturação e senescência}

A maturação e senescência são estágios sequienciais que ocorrem durante a vida útil de um fruto (Kluge et al., 2002). A maturação é o estádio do desenvolvimento do fruto que coincide com a maturação fisiológica. A maturação fisiológica refere-se ao estádio do desenvolvimento, em que o fruto continuará a sua ontogenia, mesmo que destacado da planta (Awad, 1993). A senescência vem a ser o conjunto de processos que ocorrem após a maduração, culminando com o colapso dos tecidos da fruta tornando-a imprópria para o consumo.

Os frutos podem ser classificados em climatéricos e não climatéricos, com base no fato de exibirem ou não, um climatério respiratório durante a maturação. Os frutos climatéricos podem ser induzidos à maturação pela exposição ao etileno, enquanto que 
os não-climatéricos mostram geralmente pequena resposta ao gás. Nos frutos climatéricos, a maturação é acompanhada por um aumento na produção de etileno (Yang \& Hoffman, 1984). As modificações bioquímicas que levam à maturação em frutos climatéricos incluem aumentos na atividade de enzimas responsáveis pela biossíntese de etileno, degradação da parede celular e acúmulo de pigmento. Uma das mais evidentes séries de mudanças que se verificam nos frutos em maturação envolve as alterações nos pigmentos.

\subsection{Reguladores vegetais}

Reguladores vegetais são compostos sintéticos, que a baixas concentrações, promovem, modificam ou inibem processos morfológicos e fisiológicos das plantas, os quais aplicados exogenamente possuem ações similares aos grupos de hormônios vegetais conhecidos. Os grupos de hormônios vegetais envolvem as auxinas, giberelinas, citocininas, retardadores, inibidores e etileno (Castro \& Vieira, 2001).

\subsection{Uso de biorreguladores em pós-colheita}

A presença do etileno acelera a senescência, promovendo a mudança de coloração em casca de frutos cítricos (Fuchs \& Cohen, 1969; Goldschmidt et al., 1977; Mota et al., 1997). O etileno induz a síntese de novos mRNAs e proteínas (Christoffersen \& Laties, 1982). Sítios receptores de etileno foram isolados e parcialmente purificados (Sisler \& Blankenship, 1993). O etileno promove várias respostas fisiológicas e tem sido demonstrado que a indução específica ocorre ao nível de expressão gênica e essas mudanças seriam mediadas pelo etileno ligado à proteína.

O etileno pode ser adicionado ou removido do ambiente de armazenamento dos frutos. Sua síntese pode ser promovida ou inibida e sua ação acelerada, reduzida ou inibida (Figura 1). Os reguladores vegetais desempenham papel importante durante certos estágios do desenvolvimento do fruto e são utilizados em pós-colheita.

A descoberta da metionina como precursora do etileno levou à identificação do ácido amino-oxiacético (AOA) e da aminoetoxivinilglicina (AVG), como inibidores da 
sua síntese. Normalmente, esses compostos reduzem, mas não inibem completamente a ação do etileno (Abeles et al., 1992).

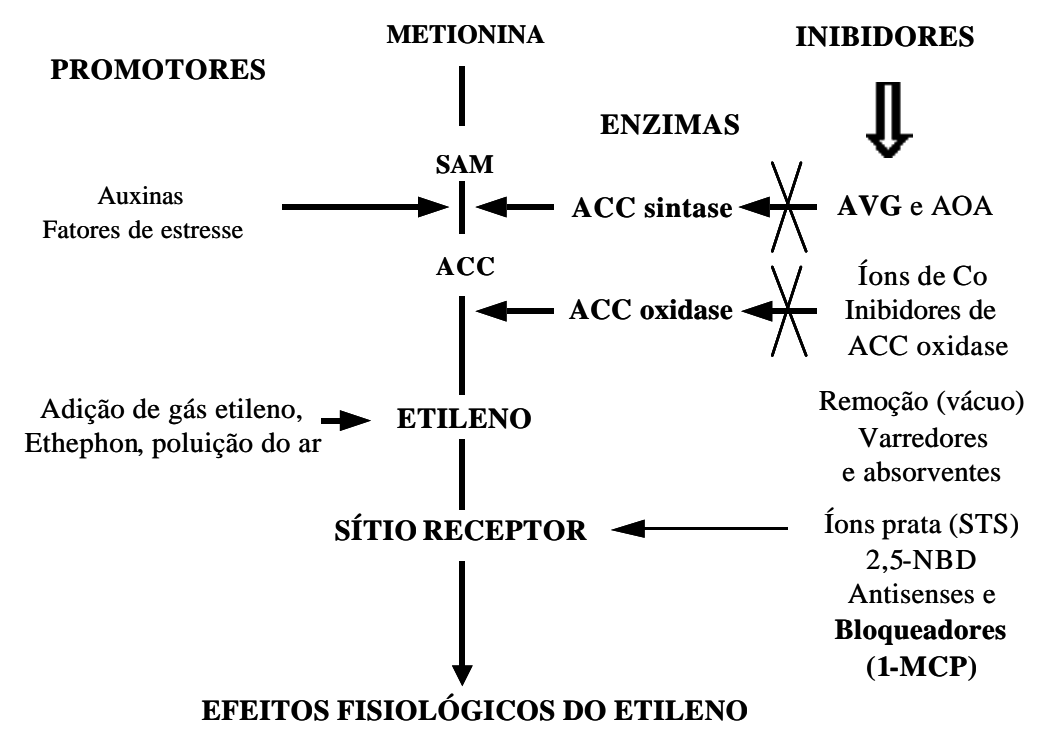

Figura 1 - Opções disponíveis para a manipulação da produção e atividade do etileno. Adaptado de Abeles et al. (1992)

As enzimas envolvidas na biossíntese do etileno são a ACC sintase e a ACC oxidase (Adams \& Yang, 1979). A ação da ACC sintase foi reprimida com $100 \mathrm{mM}$ de AVG, diminuindo significamente a conversão de S-adenosilmetionina (SAM) para ácido 1-carboxilíco-1-aminociclopropano (ACC) e também a evolução de etileno nos tecidos de grapefruit, sugerindo que para frutos não climatéricos, a síntese de etileno pode ser regulada por um processo de auto-inibição ao nível de expressão gênica (Mullins et al., 1999).

Wills et al. (1999) relataram a importância de se manter baixos níveis de etileno para atrasar a senescência de frutos não climatéricos e de vegetais, uma vez que, produtos analisados apresentavam $60 \%$ de prolongamento na vida pós-colheita, quando armazenados em ambientes com teores abaixo de $0,005 \mu \mathrm{L} \mathrm{L}^{-1}$ de etileno, quando comparados com o nível limite para a sua ação $\left(0,1 \mu \mathrm{L} \mathrm{L}^{-1}\right)$. 
A giberelina é um hormônio relacionado a juvenilidade (Dilley, 1969). Desta forma, a sua aplicação exógena retarda processos ligados à maturação e a senescência, incluindo a degradação da clorofila (Agusti et al., 1988; Schechter et al., 1989; Ludford, 1995). Nas frutas cítricas imaturas predomina a cor verde e durante o amadurecimento, ocorre a degradação das clorofilas e síntese de pigmentos denominados carotenóides (Baldwin, 1994). O ácido giberélico é muito usado para retardar mudanças na coloração de casca de lima ácida 'Tahiti' (Barros et al., 1991; Silva \& Donadio, 1997; Spósito et al., 2000; Mizobutsi et al., 2000). O uso de giberelinas, também está relacionado a aplicações em pré-colheita para laranjas (Goldschmidt et al., 1977; Davies et al, 1997; Damián \& Monter, 1999) e também para tangerinas e híbridos (Garcia et al., 1986; Agusti et al., 1988; El-Otmani \& Coggins, 1991; Garcia et al., 1992; Pozo et al., 2000).

O 1-MCP (1-metilciclopropeno) é um composto gasoso e tem demonstrado ser um eficiente inibidor da ação de etileno, devido ao fato de se ligar ao sítio receptor de etileno, atuando como antagonista. O 1-MCP apresenta grande potencial de uso comercial para o controle da maturação de frutas e hortaliças e da senescência em flores (Sisler \& Serek, 1997). Embora os citros apresentem apenas um sistema de produção de etileno (Vendrell \& Palomer, 1997), isso não significa que não ocorre interferência do etileno sobre a maturação do fruto. Goldschmidt (1997), considerou que o etileno, mesmo em baixas concentrações em frutos não climatéricos, está relacionado a eventos ligados à maturação, como a degradação de clorofilas da casca. Constatourse que 1MCP aumentou o tempo de conservação de morangos (Ku et al., 1999) e retardou o amadurecimento em frutos climatéricos como banana (Jiang et al., 1999), maçã (Fan \& Mattheis, 1999), abacate (Kluge et al., 2002) e pêssego (Kluge \& Jacomino, 2002). Geralmente, 1-MCP reduz ou atrasa o início da elevação da taxa respiratória, como encontrado em morango (Tian et al., 2000). Entretanto, o 1-MCP não teve efeito na taxa respiratória em nectarinas (Dong et al., 2001) e damasco (Dong et al., 2002). A taxa respiratória em brocoli foi inibida por 1-MCP na faixa de $0-1 \mu \mathrm{L} \mathrm{L^{-1 }}$ (Fan \& Mattheis, 2000 a).

O efeito de 1-MCP sobre o teor de acidez total titulável é variável de acordo com a cultura. O 1-MCP atrasou o declínio no teor de ácido ascórbico em abacaxi (Selvarajah 
et al., 2001), preveniu a queda de acidez em cenouras (Fan \& Mattheis, 2000b), tomate (Wills \& Ku, 2002) e ameixas (Dong et al., 2002). O 1-MCP não afetou o teor de acidez em laranjas 'Shamouti' (Porat et al., 1999). Encontrou-se alto teor de sólidos solúveis em abacaxí (Selvarajah et al., 2001), mamão (Hofman et al., 2001) e maçãs (Fan \& Mattheis, 1999) tratadas com 1-MCP. Entretanto, laranjas, ameixas e mangas não foram afetadas por 1-MCP, no teor de sólidos solúveis (Porat et al., 1999; Hofman et al., 2001; Dong et al., 2002). Tratamentos com 1-MCP em laranjas não afetaram a perda de massa (Porat et al., 1999), enquanto houve um atraso de perda de massa em abacate (Jeong et al., 2002).

O AVG (aminoetoxivinilglicina) inibe a conversão enzimática de SAM (Sadenosilmetionina) para ACC (ácido 1-carboxílico-1-aminociclopropano), sendo o cobalto e o ácido ascórbico, inibidores da conversão subseqüente de ACC para etileno (Wenzel et al., 1995). O AVG é largamente utilizado na indústria da maçã, prevenindo a produção interna de etileno, não tendo efeito contra o etileno externo. Aplicação de AVG $88 \mathrm{mg} \mathrm{L}^{-1}$ em pré-colheita não afetou a coloração da casca e o teor de sólidos solúveis em maçã 'Delicious' (Byers, 1997; Greene, 1997). Utilizando-se a mistura de GA 100-150 mg L L e AVG 100-150 mg L $\mathrm{m}^{-1}$ em pré-colheita, Ju et al., (1999) prolongaram por quatro semanas, a comercialização de pêssegos 'Feicheng' com a inibição da maturação dos frutos na planta. Um atraso no amadurecimento de pêras 'Packham's Triumph' foi obtido com AVG aplicado em pré-colheita (Munhoz \& Luis, 1998). Hu et al. (1999) testaram o AVG em uvas, com o objetivo de evitar queda de bagas. 


\section{QUALIDADE PÓS-COLHEITA DO TANGOR 'MURCOTE' TRATADO COM O BIORREGULADOR 1-MCP}

\section{Resumo}

A conservação de tangor 'Murcote' (Citrus reticulata Blanco $x$ C. sinensis Osbeck), sob baixa temperatura permite prolongar seu período de maturação comercial. A utilização de biorreguladores permite aumentar a vida útil de frutos cítricos submetidos à refrigeração. $\mathrm{O}$ objetivo deste trabalho foi verificar o efeito da aplicação de 1-metilciclopropeno sobre a manutenção das características físicas e físico-químicas de tangor 'Murcote' sob refrigeração a $9{ }^{\circ} \mathrm{C}$. O 1-MCP foi aplicado nas concentrações 0 ; 0,$1 ; 0,5$ e $1,0 \mu \mathrm{L} \mathrm{L}^{-1}$. Os frutos foram expostos ao gás com $1-\mathrm{MCP}$ por $12 \mathrm{~h}$ a $20{ }^{\circ} \mathrm{C} \mathrm{em}$ câmaras herméticas. Em seguida, foram armazenados durante 15, 30, 45 e 60 dias a $9^{\circ} \mathrm{C}$ $\pm 1{ }^{\circ} \mathrm{C}$ e umidade relativa de $90 \pm 5 \%$. Cera (Sparcitrus) diluída em água na proporção de 1:3 foi utilizada para diminuir a perda de água. A intensidade de cor (croma), ângulo de cor $\left(\mathrm{h}^{\mathrm{o}}\right)$ na casca, taxa respiratória, teor de sólidos solúveis totais, acidez total titulável, teor de ácido ascórbico e porcentagem de suco em frutos de 'Murcote' foram avaliados. Os resultados apresentados permitiram concluir que a aplicação de 1-MCP 0,5 $\mu \mathrm{L} \mathrm{L}^{-1}$ : a) mantém a qualidade pós-colheita dos frutos de 'Murcote' armazenados sob refrigeração a $9 \pm 1{ }^{\circ} \mathrm{C}$ até 45 dias; b) diminui a taxa respiratória; c) reduz a perda de acidez; d) aumenta a percentagem de suco e retarda o consumo de ácido ascórbico.

Termos de indexação: Citrus reticulata, maturação, conservação, biorreguladores, póscolheita. 


\section{POST-HARVEST QUALITY OF 'MURCOTE' MANDARYN HYBRID TREATED WITH BIOREGULATOR 1-MCP}

\section{Summary}

The storage of 'Murcott' tangor (Citrus reticulata Blanco $x$ C. sinensis Osbeck), under low temperature allows the comercialization period to be extended. The use of bioregulators has helped to extend fruit shelf life. The objective of this research was to verify the effect of 1-MCP (1-methylcyclopropene) upon the quality of 'Murcott' tangor cold stored. The 1-MCP was applied at $0 ; 0,1 ; 0,5$ and $1,0 \mu \mathrm{L} \mathrm{L}^{-1}$. The fruits were stored for a period of $15,30,45$ and 60 days at $9 \pm 1^{\circ} \mathrm{C}$ and $90 \pm 5 \% \mathrm{RH}$, after being exposed to 1 -MCP for $12 \mathrm{~h}\left(20^{\circ} \mathrm{C}\right)$. Wax treatment was used to decrease fruit weight loss. The results show that the qualities of 'Murcott' tangor were maintained during cold storage at $9 \pm 1{ }^{\circ} \mathrm{C}$ for 45 days with $1-\mathrm{MCP}$ at $0,5 \mu \mathrm{L} \mathrm{L}^{-1}$. The respiratory rate, acidity tritiable and ascorbic acid were reduced and the percentage of juice was increased.

Index terms: Citrus reticulata, maturation, conservation, bioregulators, postharvest.

\subsection{Introdução}

Os frutos, em geral, são adquiridos pelo consumidor em função das características externas como tamanho uniforme e coloração brilhante da casca. O tangor 'Murcote' (Citrus reticulata Blanco $x$ C. sinensis Osbeck) é classificado como sendo não climatérico, por apresentar baixa taxa respiratória e baixa produção de etileno. $\mathrm{O}$ desejável nos frutos cítricos, com exceção dos limões, é a predominância da cor alaranjada. Os pigmentos carotenóides, responsáveis pela coloração da casca, ocorrem nos cromoplastos das células do flavedo. Nas frutas cítricas imaturas predomina a cor verde e durante o amadurecimento, ocorre a degradação das clorofilas, começando a predominar os pigmentos amarelos da casca. Estes continuam a aumentar, mesmo após o completo desaparecimento da clorofila (Chitarra, 1979; Baldwin, 1994). Além da coloração da casca, é importante também a textura ou firmeza da casca dos frutos. 
A conservação do tangor 'Murcote', sob baixa temperatura, prolonga seu período de conservação. Entretanto, a perda da coloração da casca é fator determinante na decisão de compra pelo consumidor. Valores de $\mathrm{h}\left({ }^{\circ}\right)$ mais próximos de $90\left(^{\circ}\right)$ representam frutos mais amarelos, à medida que tendem a $0\left(^{\circ}\right)$, tornam-se mais alaranjados e maturos. $\mathrm{O}$ croma define a intensidade da cor, assumindo valores próximos a zero para cores neutras (cinzas) e ao redor de 60 para cores vívidas (McGuire, 1992).

As condições ambientais para a conservação refrigerada de tangor 'Murcote' são com temperaturas entre $2-10{ }^{\circ} \mathrm{C}$ e umidade relativa (UR) entre 85 e $95 \%$. Nessas condições, os frutos podem ser armazenados por 4 a 8 semanas, como recomendam Ismail \& Wilhite (1991). Tratamentos com biorreguladores têm sido utilizados em frutos cítricos e outros, com o objetivo de manter sua aparência externa e também suas características físico-quimicas.

O 1-MCP (1-metilciclopropeno) é um composto gasoso que tem demonstrado ser um eficiente inibidor da ação de etileno. Ele se liga ao sítio receptor de etileno, atuando como antagonista. Apresenta grande potencial no uso comercial para o controle da maturação e senescência de frutas e hortaliças, e da senescência de flores (Sisler \& Serek, 1997). Embora os citros apresentem apenas um sistema de produção de etileno (endógeno), diferente dos frutos climatéricos, onde existe a produção autocatalítica de etileno (Vendrell \& Palomer, 1997), isso não significa que não ocorre interferência do etileno sobre a maturação do fruto. Goldschmidt (1997) considerou que o etileno, mesmo em baixas concentrações em frutos não climatéricos, está relacionado aos processos ligados à maturação, como a degradação de clorofilas da casca. Constatou-se que 1-MCP aumentou o tempo de conservação de morangos (Ku et al., 1999) e retardou o amadurecimento em frutos climatéricos como banana (Jiang et al., 1999), maçã (Fan \& Mattheis, 1999), abacate (Kluge et al., 2002) e pêssego (Kluge \& Jacomino, 2002). Geralmente o 1-MCP reduz ou atrasa o início da elevação da taxa respiratória, como observado em morango (Tian et al., 2000). Entretanto o 1-MCP não teve efeito na taxa respiratória em nectarinas (Dong et al., 2001) e damasco (Dong et al., 2002). A taxa respiratória em brocoli foi inibida por 1-MCP na faixa de $0-1 \mu \mathrm{L} \mathrm{L}^{-1}$ (Fan \& Mattheis, 2000 a). 
O efeito de 1-MCP sobre o teor de acidez total titulável é variável, de acordo com a cultura. Este biorregulador atrasou o declínio no teor de ácido ascórbico em abacaxi (Selvarajah et al., 2001), preveniu a queda de acidez em cenouras (Fan \& Mattheis, 2000b), tomate (Wills \& Ku, 2002) e ameixas (Dong et al., 2002). O 1-MCP não afetou o teor de acidez em laranjas 'Shamouti' (Porat et al., 1999). Encontrou-se alto teor de sólidos solúveis em abacaxí (Selvarajah et al., 2001), mamão (Hofman et al., 2001) e maçãs (Fan \& Mattheis, 1999) tratadas com 1-MCP. Entretanto, laranjas, ameixas e mangas não foram afetadas por 1-MCP, no teor de sólidos solúveis (Porat et al., 1999; Hofman et al., 2001; Dong et al., 2002). Tratamentos com 1-MCP em laranjas não afetaram a perda de massa (Porat et al., 1999), enquanto houve um atraso de perda de massa em abacate (Jeong et al., 2002).

O objetivo deste trabalho foi determinar o efeito do 1-MCP em tangor 'Murcote' visando retardar sua senescência após a colheita e aumentar o seu período de conservação.

\subsection{Material e Métodos}

Frutos de tangor 'Murcote' colhidos em pomar comercial localizado no município de Mogi-Mirim, SP, foram transportados para o Laboratório de Pós-Colheita do Departamento de Produção Vegetal da ESALQ/USP. Foram utilizados frutos sadios, colhidos na altura do peito, apresentaram em média $71,6^{\circ}$ de ângulo de cor $\left(\mathrm{h}^{\circ}\right.$ ) e 59,28 unidades de croma caracterizando a coloração inicial da casca e classificados na classe C4 (CQH/Ceagesp, 2001). O suco de vinte frutos apresentava no início do experimento, um teor de sólidos solúveis totais de $12,8{ }^{\circ}$ Brix e acidez total titulável de $0,83 \%$. Após a seleção, os frutos foram submetidos a exposição ao gás 1-metilciclopropeno (1-MCP) nas concentrações de $0 ; 0,1 ; 0,5$ e $1,0 \mu \mathrm{L} \mathrm{L}^{-1}$. A aplicação de 1-MCP foi realizada em caixas herméticas, com capacidade para 188,0 litros, utilizando-se o produto comercial SmartFresh $^{\mathrm{TM}}$, na forma pó molhável, contendo 0,14\% de i.a. de 1-metilciclopropeno. Aos frascos contendo 1-MCP, foram adicionados $20 \mathrm{~mL}$ de água destilada aquecida a 50 ${ }^{\circ} \mathrm{C}$. Após completa dissolução, os frascos foram abertos no interior das câmaras, expondo os frutos ao gás durante $12 \mathrm{~h}$ sob temperatura de $20{ }^{\circ} \mathrm{C}$. 
Após esse período, a cera (Sparcitrus) diluída em água, na proporção de 1:3 foi aplicada por imersão dos frutos e a secagem foi realizada em condições ambientais (65\% UR e $25{ }^{\circ} \mathrm{C}$ ) por $30 \mathrm{~min}$. Os frutos foram armazenados a $9 \pm 1{ }^{\circ} \mathrm{C}$ e $90 \pm 5 \%$ de UR durante 15, 30, 45 e 60 dias. Após cada período de armazenamento, foram determinados os parâmetros: a) coloração da casca: valores de croma $\left(\mathrm{C}^{*}\right)$ e ângulo de cor $\left(\mathrm{h}^{\mathrm{o}}\right)$, através de colorímetro Minolta Chroma Meter CR-300; b) taxa respiratória ( $\mathrm{mL} \mathrm{CO}_{2} \mathrm{~kg}^{-}$ ${ }^{1} \mathrm{~h}^{-1}$ ) medida em analisador de gases PBI Dansensor - CheckMate 9900; c) teor de sólidos solúveis totais (SST) expressos em ${ }^{\circ}$ Brix obtido em refratômetro digital; d) acidez total titulável (ATT): neutralização de uma alíquota de $10 \mathrm{~mL}$ de suco, com $\mathrm{NaOH} 0,1 \mathrm{~N}$, sendo os resultados expressos em \% de ácido cítrico anidro; e) relação SST/ATT (ratio); f) teor de vitamina C: neutralização por titulação do ácido ascórbico, em solução de 2,6-dicloro fenol indofenol (DCFI) expressa em mg de ácido ascórbico por $100 \mathrm{~mL}$ de suco (Instituto Adolfo Lutz, 1985); g) \% de perda de massa: percentual entre massa inicial e massa após armazenamento e f) \% de suco: relação percentual entre massa do suco (g) e a massa do fruto.

O delineamento experimental adotado foi inteiramente ao acaso, em esquema fatorial 4 x 5. Os fatores estudados foram: a) concentração de 1-MCP (quatro níveis) e b) tempo de conservação (5 níveis). Foram utilizadas quatro repetições de oito frutos por parcela. Os modelos de regressão linear foram determinados através do programa Sistema de Análise Estatística - SANEST (Zonta \& Machado, 1984).

\subsection{Resultados e Discussão}

De acordo com os quadros de análise de variância (Tabelas 1, 2, 3, 4, 5 e 6), houve interação significativa do tempo de armazenamento com tratamento $(\mathrm{PROB}>\mathrm{F}=$ $<0,010)$ para as variáveis: croma, ângulo de cor, SST, ATT, ratio, vitamina C, TR a 9 ${ }^{\circ} \mathrm{C}$ e \% de suco. Não houve interação significativa para as variáveis perda de massa e TR a $25{ }^{\circ} \mathrm{C}$ (Tabelas 5 e 6), respectivamente. A aplicação de 1-MCP não afetou significativamente a perda de massa dos frutos de 'Murcote', sendo a perda de massa observada devido ao tempo de armazenamento (Figura 6B). 
A regressão solicitada para o tempo dentro do tratamento (Tabelas $2 \mathrm{~A}$ e $\mathrm{B} ; 3 \mathrm{~A}$ e $\mathrm{B} ; 4 \mathrm{~A}$ e B; 5A e 6A) apresentou equações significativas ( $\mathrm{PROB}>\mathrm{F}=0,05)$, descritas nas respectivas figuras, devendo ser adotadas por possuir maior coeficiente de determinação.
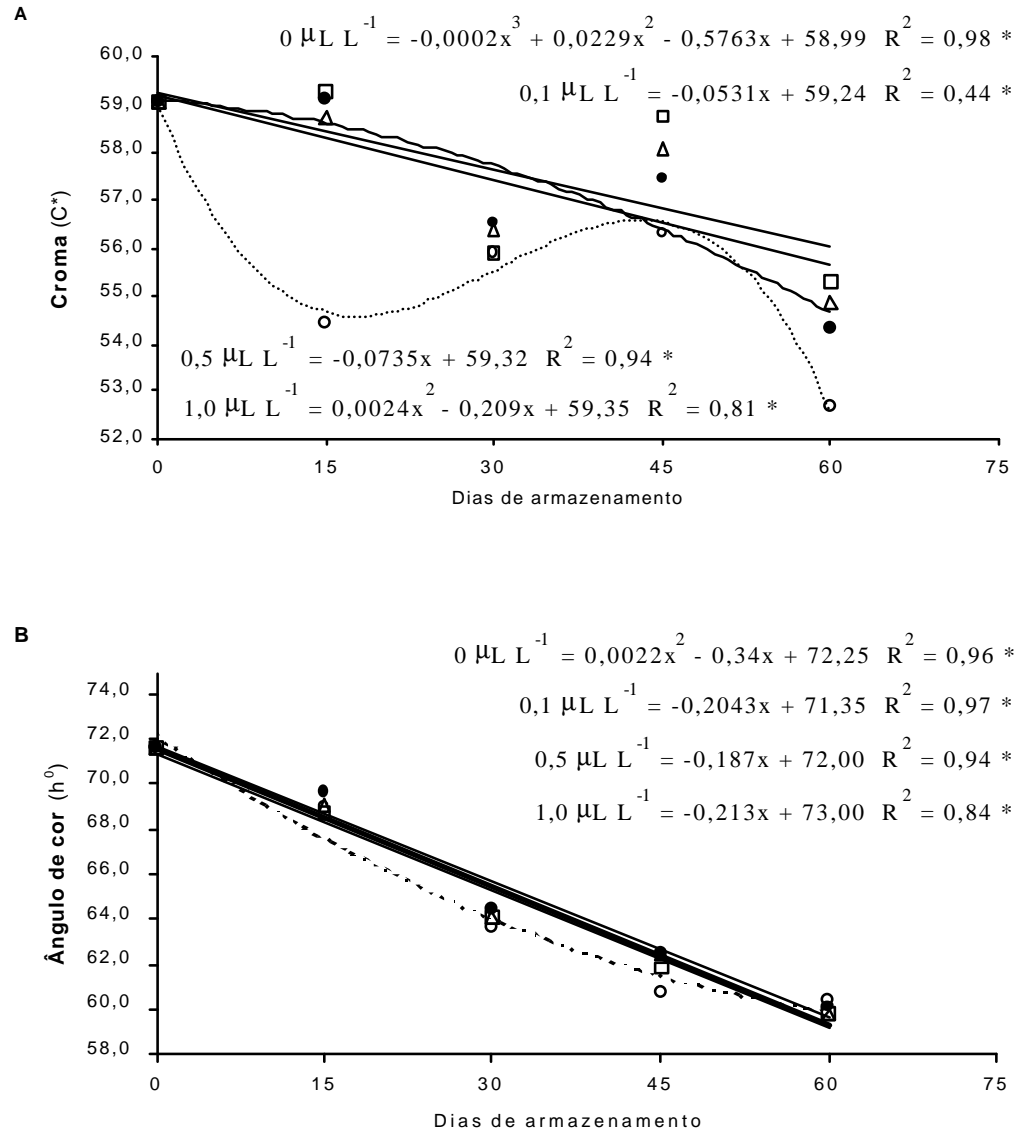

Figura 2 - Modelos de regressão polinomial para as variáveis: A) intensidade de cor (croma) e B) ângulo de cor $\left(\mathrm{h}^{\circ}\right)$ em casca de frutos de tangor 'Murcote' tratado com: 0 (o); 0,1 ( ); $0,5(\Delta)$ e $1,0 \mu \mathrm{L} \mathrm{L}^{-1}(\bullet)$ de 1-MCP, respectivamente

Verificourse, durante o período de armazenamento refrigerado, maior cromaticidade na casca de frutos de 'Murcote' tratados com 1-MCP (Figura 2A), em relação aos frutos não tratados, até 45 dias. Notou-se pequena diferença para $\mathrm{h}^{\mathrm{o}}$ (Figura 2B), entre os frutos durante o seu armazenamento. Esses resultados concordam com os relatos de Blankenship (2003), onde 1-MCP preveniu ou retardou a degradação de clorofilas e vários tipos de mudanças de cor em várias culturas. Goldschmidt (1997) 
relatou que os eventos da maturação relacionam-se à degradação de clorofilas pelo efeito de etileno, mesmo em baixa concentrações.
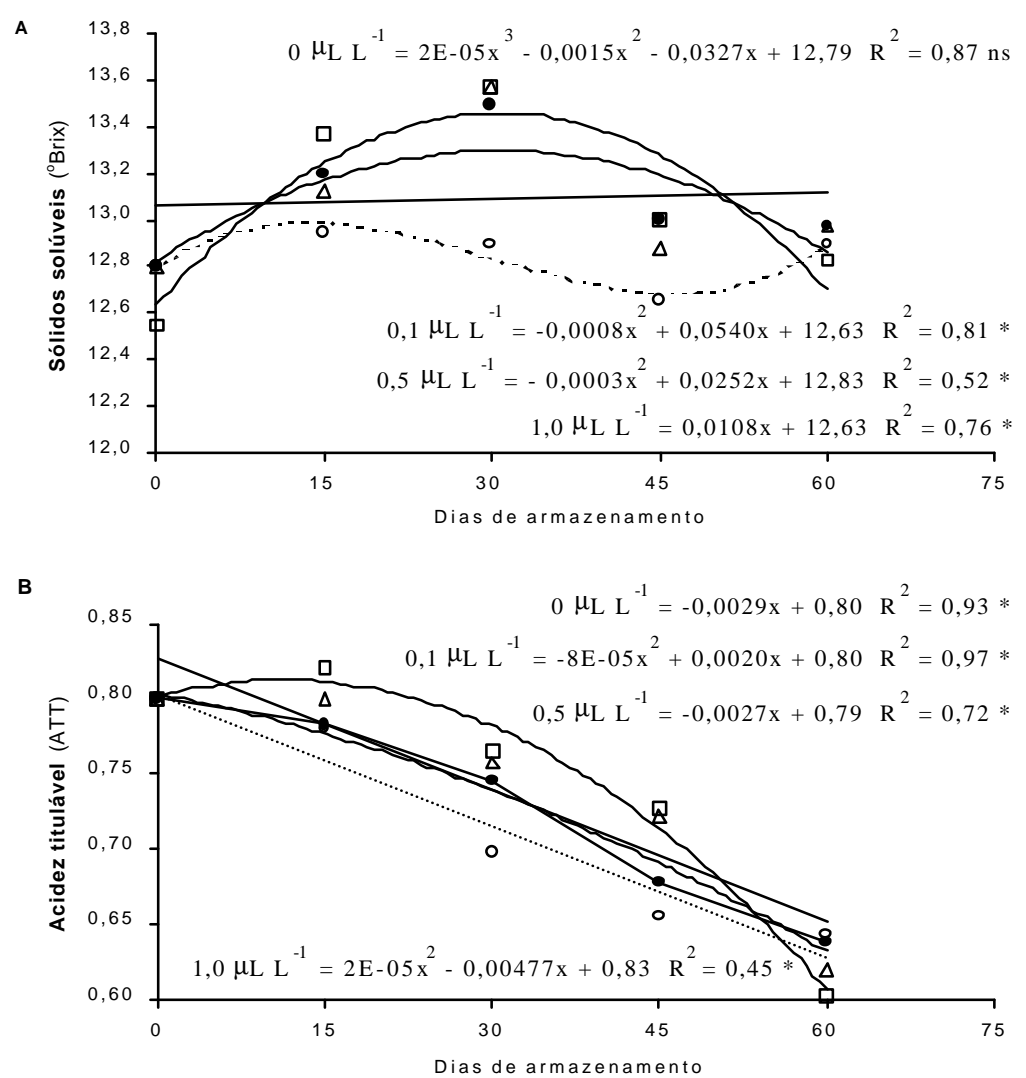

Figura 3 - Modelos de regressão polinomial para as variáveis: A) teor de sólidos solúveis totais ( ${ }^{\circ}$ Brix); B) teor de acidez total titulável (ATT), em suco de tangor 'Murcote' tratado com $0(\mathrm{o}) ; 0,1$ ( ); 0,5 ( $\Delta)$ e $1,0 \mu \mathrm{L} \mathrm{L}^{-1}(\bullet)$ de 1-MCP, respectivamente

A intensidade de cor de casca (croma) permaneceu elevada nos frutos tratados com 1-MCP, enquanto que no controle observou-se uma diminuição nos primeiros 15 dias de armazenamento (Figura 2A). Do ponto de vista comercial, isso é importante, pois realça a intensidade de cor da casca de 'Murcote'.

Aos 30 dias, o ângulo de cor $\left(\mathrm{h}^{\circ}\right)$ na casca de 'Murcote' tratados com 1-MCP não sofreu grandes alterações quando comparado com frutos não tratados. $\mathrm{O}$ resultado 
obtido pode estar relacionado com o estágio de maturação dos frutos, uma vez que o desverdecimento de laranjas foi bloqueado por 1-MCP (Porat et al., 1999).
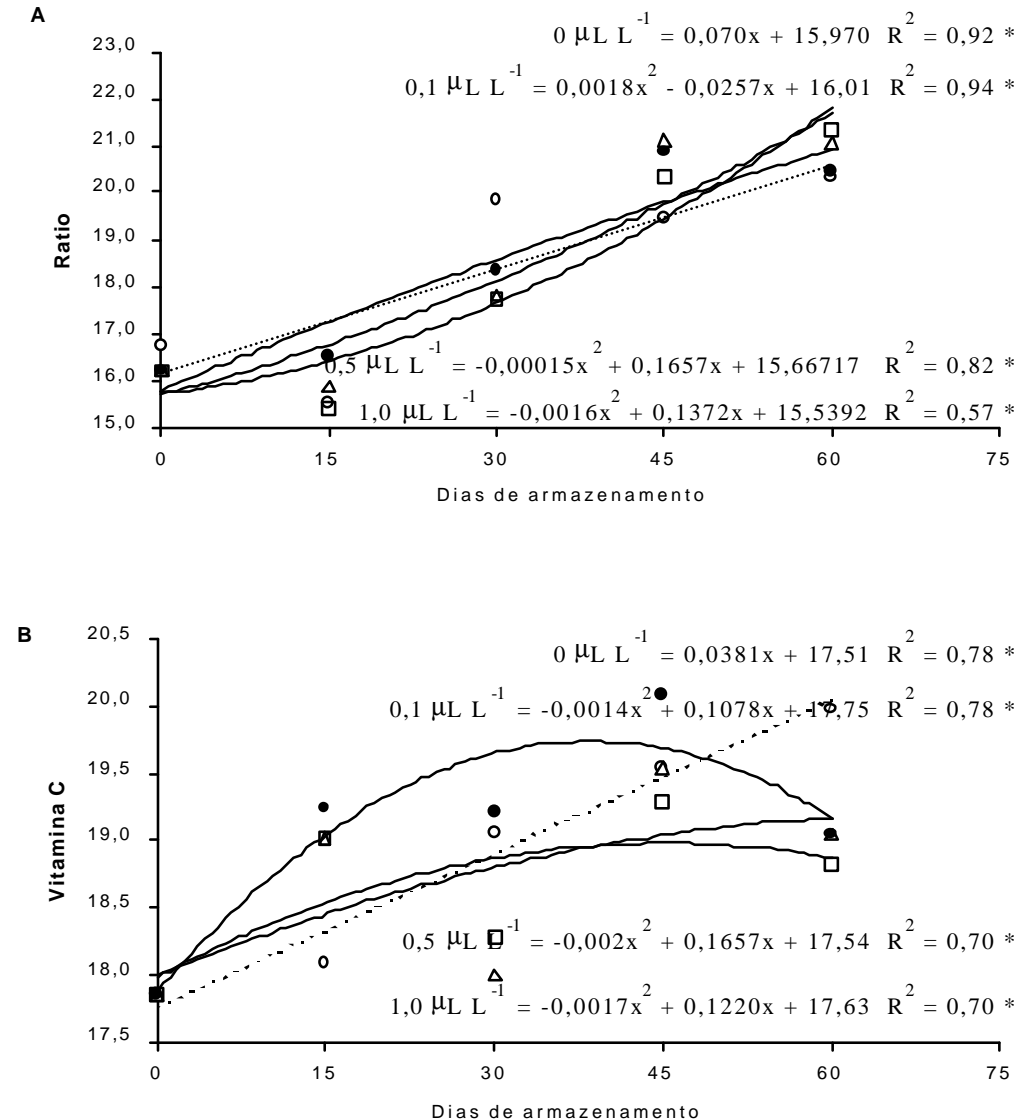

Figura 4 - Modelos de regressão polinomial para as variáveis: A) Ratio (relação SST/ATT) e B) teor de vitamina $\mathrm{C}$, em tangor 'Murcote' tratado com 0 (o); 0,1 ( ); $0,5(\Delta)$ e 1,0 $\mu \mathrm{L}$ $\mathrm{L}^{-1}(\bullet)$ de 1-MCP, respectivamente

O teor de sólidos solúveis totais ( ${ }^{\mathrm{c}}$ Brix) apresentou-se elevado em relação ao controle, com a aplicação do 1-MCP (Figura 3A). A concentração de $0,5 \mu \mathrm{L} \mathrm{L}^{-1}$ de 1 MCP apresentou o maior teor de sólidos solúveis durante o armazenamento refrigerado $\left(+3\right.$ dias a $\left.25^{\circ} \mathrm{C}\right)$.

Altos teores de SST, também foram encontrados em abacaxi (Selvarajah et al., 2001), mamão (Hofman et al., 2001) e maçã (Fan \& Mattheis, 1999) tratados com 1 
MCP. Porat et al. (1999) relataram que não houve alterações no teor de sólidos solúveis em laranjas tratadas com 1-MCP. O teor de ATT (Figura 3B) diminui à razão de 0,040 mg de ácido cítrico anidro a cada 15 dias nos frutos não tratados, sendo de 0,026 mg nos frutos com $1,0 \mu \mathrm{L} \mathrm{L}^{-1}$ de 1-MCP.
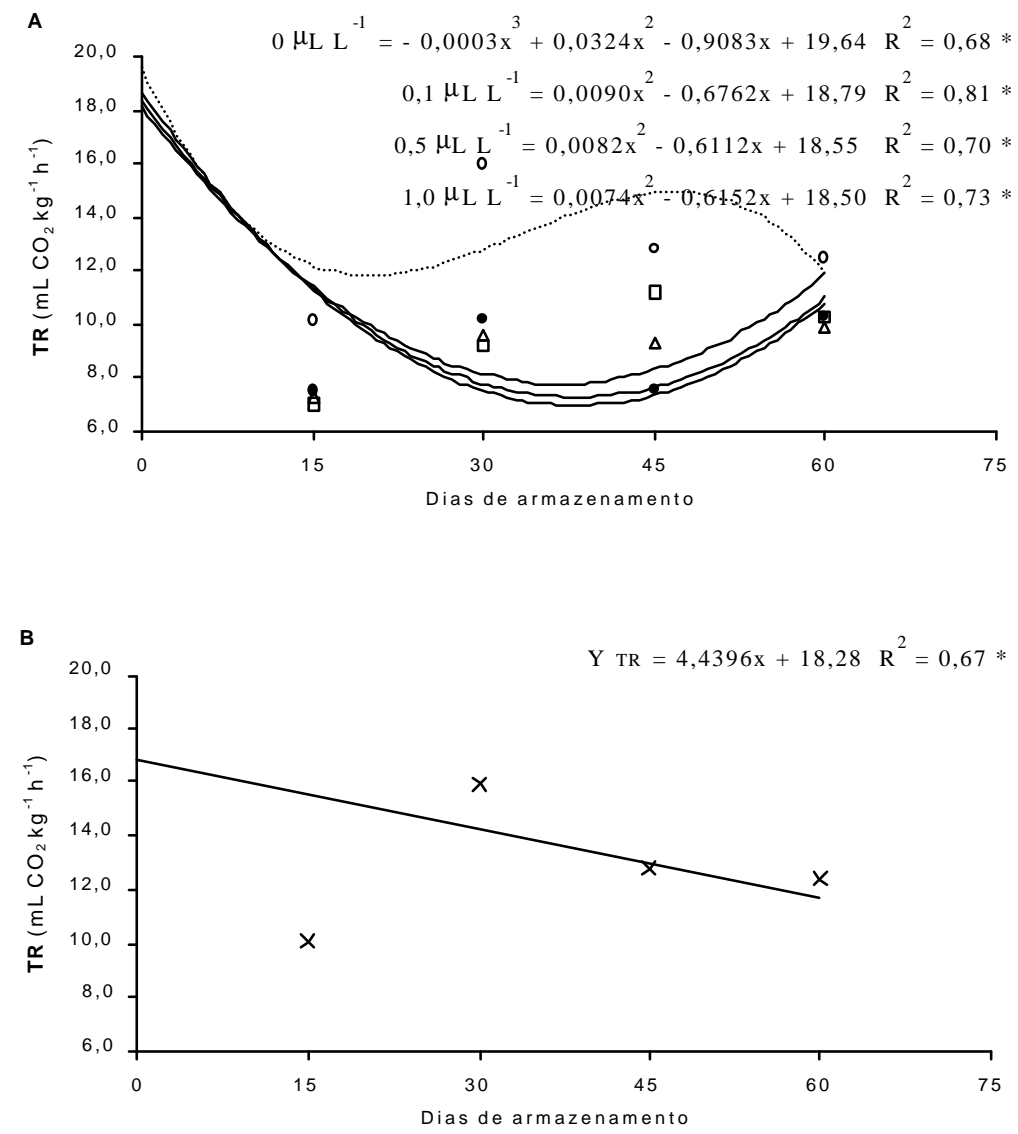

Figura 5 - Modelos de regressão polinomial para as variáveis: A) taxa respiratória $\left(\mathrm{mL} \mathrm{CO}_{2} \mathrm{~kg}^{-1}\right.$ $\mathrm{h}^{-1}$ ) a $9{ }^{\circ} \mathrm{C}$ e B) taxa respiratória a $25{ }^{\circ} \mathrm{C}$ em tangor 'Murcote' tratado com 0 (o); 0,1 ( ); $0,5(\Delta)$ e $1,0 \mu \mathrm{L} \mathrm{L}^{-1}(\bullet)$ de $1-\mathrm{MCP}$, respectiva mente

Vários autores verificaram efeitos semelhantes de redução de perda de acidez com 1-MCP em cenoura (Fan \& Mattheis, 2000b), tomate (Wills \& Ku, 2002) e ameixas (Dong et al., 2002). Porat et al., (1999) relataram que a acidez não foi afetada em 
laranjas 'Shamouti'. A discordância entre os resultados obtidos e os relatados por Porat et al., (1999), estaria no fato de tratar-se de um híbrido e, nesse caso, prevaleceria a condição da tangerina.
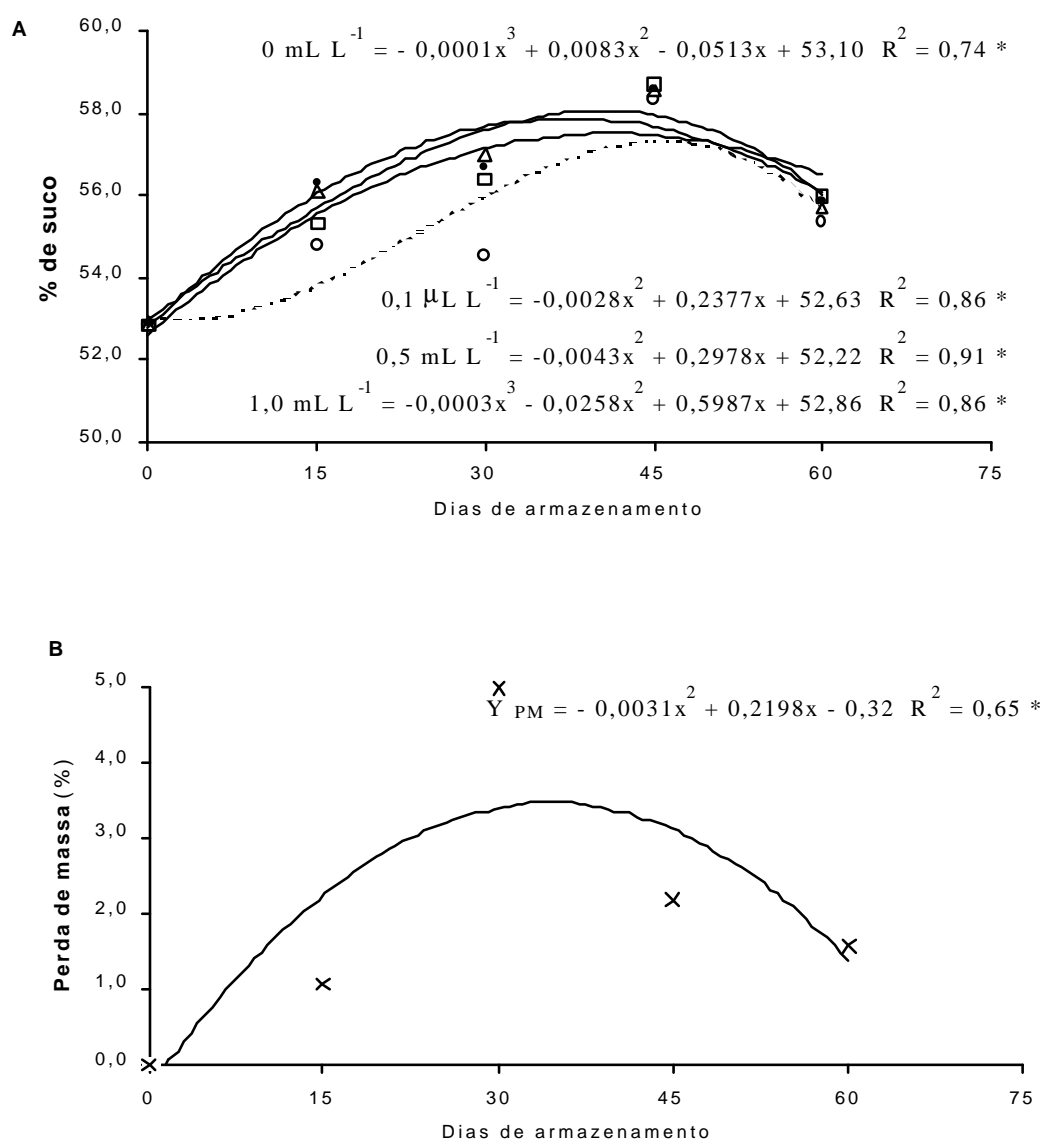

Figura 6 - Modelos de regressão polinomial para as variáveis: A) Porcentagem de suco e B) perda de massa (\%), em tangor 'Murcote' tratado com $0(0) ; 0,1$ ( ); 0,5 ( $\Delta$ ) e 1,0 $\mu \mathrm{L}$ $\mathrm{L}^{-1}(\bullet)$ de 1-MCP, respectivamente

A relação entre o teor de sólidos solúveis totais e acidez total titulável expressa o balanço entre esses componentes no suco, conferindo-lhe o sabor. Esse sabor pode ser mais ou menos ácido em função da região produtora ou das características do cultivar. Segundo o modelo de regressão quadrático (Figura 4A), o ratio estimado aos 45 dias de 
armazenamento para a concentração de $1,0 \mu \mathrm{L} \mathrm{L}^{-1}$ de 1-MCP foi de 18,07. Para frutos não tratados, esse valor foi de 19,12.

A faixa de ratio adequada estaria entre 12,5 no início, e 20,0 no final do processo de maturação em 'Murcote'. Este resultado pode ser entendido através da redução da perda de acidez (Figura 3B) atribuída ao efeito do 1-MCP 1,0 $\mu \mathrm{L} \mathrm{L}^{-1}$, observada nesse período. $\mathrm{O}$ teor de vitamina $\mathrm{C}$ aumentou nos frutos tratados com a concentração de 1,0 $\mu \mathrm{L} \mathrm{L}^{-1}$ até aos 45 dias (Figura $5 \mathrm{~B}$ ), provavelmente devido ao menor estresse provocado nesses frutos.

O 1-MCP reduziu a taxa respiratória em 'Murcote' até aos 45 dias de armazenamento (Figura 5A). Resultados semelhantes foram obtidos em morango (Tian et al., 2000) e brocoli (Fan \& Mattheis, 2000a). A diminuição da TR em 'Murcote' com 1-MCP permitiu aumentar o período de armazenamento refrigerado, devido ao menor consumo de energia (SST), observado na figura 3A.

A maior porcentagem de suco em frutos tratados com 1-MCP, não se deve à menor perda de água por transpiração (Figura 6B), uma vez que a porcentagem de perda de massa observada não foi significativa entre os tratamentos. Porat et al. (1999) também relataram não ser significativa a perda de massa em laranjas.

\subsection{Conclusões}

Os resultados obtidos permitiram concluir que a aplicação de 1 -MCP $0,5 \mu \mathrm{L} \mathrm{L}^{-1}$ :

a) Mantém a qualidade pós-colheita de frutos de tangor 'Murcote' armazenados sob refrigeração a $9 \pm 1{ }^{\circ} \mathrm{C}$ até 45 dias.

b) Diminui a taxa respiratória e reduz a perda de acidez.

c) A relação SST/ATT permanece adequada para consumo em até 45 dias.

d) Retarda o consumo de ácido ascórbico.

e) Disponibiliza maior percentagem de suco. 


\section{EFEITO DO AVG (AMINOETOXIVINILGLICINA) EM PÓS-COLHEITA SOBRE O TANGOR 'MURCOTE'}

\section{Resumo}

A conservação de tangor 'Murcote' (Citrus reticulata Blanco $x$ C. sinensis Osbeck) sob baixa temperatura permite prolongar o seu período de maturação comercial. A utilização de biorreguladores possibilita aumentar a vida útil de frutos cítricos submetidos à refrigeração. $\mathrm{O}$ objetivo deste trabalho foi verificar o efeito da aplicação de aminoetoxivinilglicina (AVG) sobre a manutenção das características físicas e físicoquímicas em tangor 'Murcote' sob refrigeração a $9{ }^{\circ} \mathrm{C}$. Os tratamentos aplicados foram: AVG nas concentrações de 10; 50 e $100 \mathrm{mg} \mathrm{L}^{-1}$, respectivamente, além do controle. Os frutos foram imersos em solução contendo AVG por 1 minuto. Os frutos foram armazenados durante $15,30,45$ e 60 dias à $9 \pm 1{ }^{\circ} \mathrm{C}$ e umidade relativa de $90 \pm 5 \%$. Utilizou-se cera (Sparcitrus) diluída em água na proporção de 1:3 para diminuir a perda de água dos frutos. Avaliou-se a intensidade de cor (croma), ângulo de cor $\left(\mathrm{h}^{\circ}\right)$ na casca, taxa respiratória, teor de sólidos solúveis totais, acidez total titulável, teor de ácido ascórbico e porcentagem de suco em frutos de 'Murcote'. De acordo com os resultados obtidos, a aplicação de AVG: realça a cromaticidade da cor da casca de 'Murcote' em pós-colheita, retarda a diminuição do teor de sólidos solúveis, reduz a taxa respiratória e mantém maior percentagem de suco em frutos de tangor 'Murcote'.

Termos para indexação: Citrus reticulata, AVG, conservação, biorregulador. 


\section{AVG (AMINOETHOXYVINYLGLYCINE), POSTHARVEST TREATMENT UPON 'MURCOTT’ MANDARIN HYBRID}

\section{Summary}

The effectiveness of AVG on delay senescence and to promote reduction of quality losses in 'Murcott' mandarin hybrid was studied in Piracicaba, SP. The storage of 'Murcott' mandarin hybrid (Citrus reticulata Blanco $x$ C. sinensis Osbeck), under low temperatures allows the comercialization period to be extended. The use of bioregulators has helped the extending of fruit shelf life. The objective of his research was to verify the effect of AVG (aminoethoxyvinylglycine) upon the quality of 'Murcott' mandarin hybrid under cold storage. The treatments used were: AVG: $10 \mathrm{mg} \mathrm{L}^{-1}$; AVG: $50 \mathrm{mg} \mathrm{L}^{-1}$, AVG: $100 \mathrm{mg} \mathrm{L}^{-1}$ and control. Fruits were stored during 15, 30, 45 and 60 days at $9 \pm 1$ ${ }^{\circ} \mathrm{C}$ and $90 \pm 5 \% \mathrm{RH}$. The results showed that the aplication of AVG maintained the content of tritiable acid and enhanced the cromaticity in the peel on postharvest. Respiratory rate was lowered by application of AVG. The rate loss of soluble solids decresead with AVG and the fruits showed higher contents of juice.

Key words: Citrus reticulata, AVG, conservation, bioregulator.

\subsection{Introdução}

Os frutos em geral são adquiridos pelo consumidor em função das características externas, como tamanho uniforme e coloração brilhante da casca. A cor vívida é um componente importante na aparência dos frutos, sendo que o croma define a intensidade da cor, assumindo valores próximos a zero em relação às cores neutras (cinza) e em torno de 60 para cores vívidas (McGuire, 1992). O tangor 'Murcote' (Citrus reticulata Blanco $x$ C. sinensis Osbeck), é classificado como fruto não climatérico, por apresentar baixa taxa respiratória e a não produção auto-catalítica de etileno. A manutenção da cor da casca é desejável durante sua vida útil pós-colheita, entretanto, os processos de degradação de clorofila e síntese de carotenóides continuam a ocorrer, mesmo durante o 
seu armazenamento. Baldwin (1994) relatou que mesmo sob condições refrigeradas, estas alterações também continuam a ocorrer.

As condições ambientais para a conservação refrigerada do tangor 'Murcote' são temperatura entre $2-10{ }^{\circ} \mathrm{C}$ e umidade relativa (UR) entre 85 e 95\%. Nessas condições, os frutos podem ser armazenados e mantidos com boa aparência por 4 a 8 semanas, como recomendam Ismail \& Wilhite (1991). Tratamentos com biorreguladores têm sido utilizados em frutos cítricos e outros, com o objetivo de manter sua aparência externa e também as características físico-quimicas desejadas.

\subsection{Material e Métodos}

Frutos de tangor 'Murcote'colhidos em pomar comercial localizado no município de Mogi-Mirim - SP, foram transportados para o Laboratório de Pós-Colheita do Departamento de Produção Vegetal da ESALQ/USP. Foram utilizados frutos sadios e após a seleção, os mesmos foram submetidos à tratamentos com AVG (aminoetoxivinilglicina), por imersão durante 1 minuto, nas concentrações de 0, 10, 50 e $100 \mathrm{mg} \mathrm{L}^{-1}$.

Após esse período aplicourse cera (Sparcitrus) diluída em água na proporção de 1:3 e sendo a secagem em condições ambiente $\left(65 \%\right.$ de umidade relativa e $\left.25{ }^{\circ} \mathrm{C}\right)$, por 30 min. Os frutos foram armazenados a $9 \pm 1{ }^{\circ} \mathrm{C}$ e $90 \pm 5 \%$ de UR durante $15,30,45$ e 60 dias. Após cada período de armazenamento determinaram-se os parâmetros: a) coloração da casca: valores de croma $\left(\mathrm{C}^{*}\right)$ e ângulo de cor $\left(\mathrm{h}^{\mathrm{o}}\right)$, estabelecidos através de colorímetro Minolta Chroma Meter CR-300; b) taxa respiratória ( $\mathrm{mL} \mathrm{CO} \mathrm{Kg}^{-1} \mathrm{~h}^{-1}$ ) medida em analisador de gases (PBI Dansensor - CheckMate 9900); c) teor de sólidos solúveis totais (SST) expresso em ${ }^{\circ}$ Brix obtido em refratômetro digital; d) acidez total titulável (ATT): neutralização de uma alíquota de $10 \mathrm{~mL}$ de suco, com $\mathrm{NaOH} \mathrm{0,1} \mathrm{N}$, sendo os resultados expressos em \% de ácido cítrico anidro; e) relação SST/ATT (ratio); f) teor de vitamina C: neutralização por titulação do ácido ascórbico, em solução de 2,6dicloro fenol indofenol (DCFI) expressa em mg de ácido ascórbico por $100 \mathrm{~mL}$ de suco (Instituto Adolfo Lutz, 1985); g) \% de perda de massa: percentual entre massa inicial e 
massa após armazenamento e f) \% de suco: relação percentual entre massa do suco (g) e a massa do fruto.

O delineamento experimental adotado foi inteiramente ao acaso, em esquema fatorial 4 x 5. Os fatores estudados foram: a) concentração de AVG (quatro níveis) e b) tempo de conservação (5 níveis). Foram utilizadas quatro repetições de oito frutos por parcela. Os dados obtidos foram submetidos à análise de variância (Teste F). Os modelos de regressão linear foram determinados através do programa Sistema de Análise Estatística - SANEST (Zonta \& Machado, 1984).

\subsection{Resultados e Discussão}

De acordo com os quadros de análise de variância (Tabelas 7, 8, 9, 10 e 11), a interação do tempo de armazenamento com tratamento (AVG) apresentaram diferenças significativas ( $\mathrm{PROB}>\mathrm{F}=<0,010$ ) para as variáveis: $\mathrm{C}^{*}$, SST, ratio, vitamina $\mathrm{C}$, TR e \% suco. Não houve interação significativa para as variáveis: ângulo de cor, ATT e perda de massa (Tabelas 7, 8 e 11), respectivamente. A regressão solicitada para o tempo dentro do tratamento (Tabelas 7A; 8A, 9A e B; 10A e B e 11A) apresentou equações significativas $(\mathrm{PROB}>\mathrm{F}=0,05)$, conforme descritas nas respectivas figuras, devendo ser adotadas por possuir maior coeficiente de variação.

Todos os tratamentos com AVG influenciaram na coloração da casca dos frutos de tangor 'Murcote', em relação aos valores obtidos para o croma (Figura 1A). Cores vívidas é um componente importante na aparência dos frutos, sendo que o croma define a intensidade da cor, assumindo valores próximos a zero em relação às cores neutras (cinza) e em torno de 60 para cores vívidas (McGuire, 1992). A inibição da ação do etileno endógeno, com as concentrações utilizadas, não foi suficiente para retardar mudanças na coloração da casca, conforme os resultados de $\mathrm{h}^{\circ}$ apresentados na figura 2B. Segundo Garcia et al. (1986), isso poderia estar relacionado com o início da acumulação de carotenóides, onde aplicações de $\mathrm{GA}_{3}$, também foram ineficientes. Davies et al. (1997) relataram ser rotineiro o uso de ácido giberélico para retardar a senescência da casca em frutos de cítricos. 
Os frutos tratados com AVG apresentaram maior teor de SST em relação ao controle, durante o período de armazenamento refrigerado (Figura 2A). Todas as concentrações com AVG proporcionaram um acúmulo de sólidos solúveis. Verificoutse também a partir do trigésimo dia, declínio no teor de sólidos solúveis, nos frutos tratados com AVG, indicando que este substrato estava sendo consumido. Uma explicação para o resultado encontrado estaria na redução da taxa respiratória (Figura 4A), provavelmente devido à redução na glicólise, uma vez que, não houve consumo diferenciado entre os tratamentos com relação à acidez titulável (Figura 2B) e também para o teor de ácido ascórbico (Figura 3B).
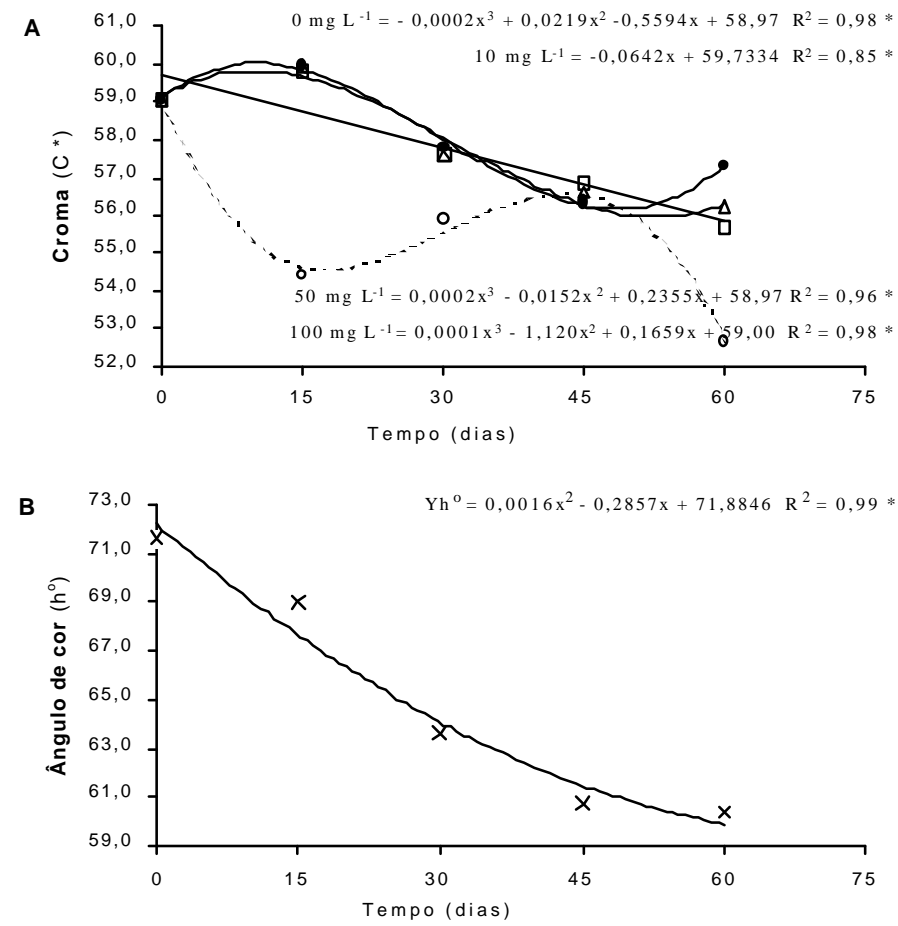

Figura 1 - Modelos de regressão para: A) cor da casca croma $\left(\mathrm{C}^{*}\right)$ e B) ângulo de cor $\left(\mathrm{h}^{\circ}\right) \mathrm{em}$ tangor 'Murcote' após tratamentos com $0 \mathrm{mg} \mathrm{L}^{-1}$ (o); $10 \mathrm{mg} \mathrm{L}^{-1}\left(\right.$ ); $50 \mathrm{mg} \mathrm{L}^{-1}(\Delta) \mathrm{e}$ $100 \mathrm{mg} \mathrm{L}^{-1}(\bullet)$ de AVG e armazenamento a $9^{\circ} \mathrm{C}\left(+3\right.$ dias a $\left.25^{\circ} \mathrm{C}\right)$

Com relação à acidez total titulável, não houve alterações significativas entre os tratamentos com AVG (Figura 2B), estando de acordo com resultados obtidos por Porat et al., (1999) trabalhando com 1-MCP. 

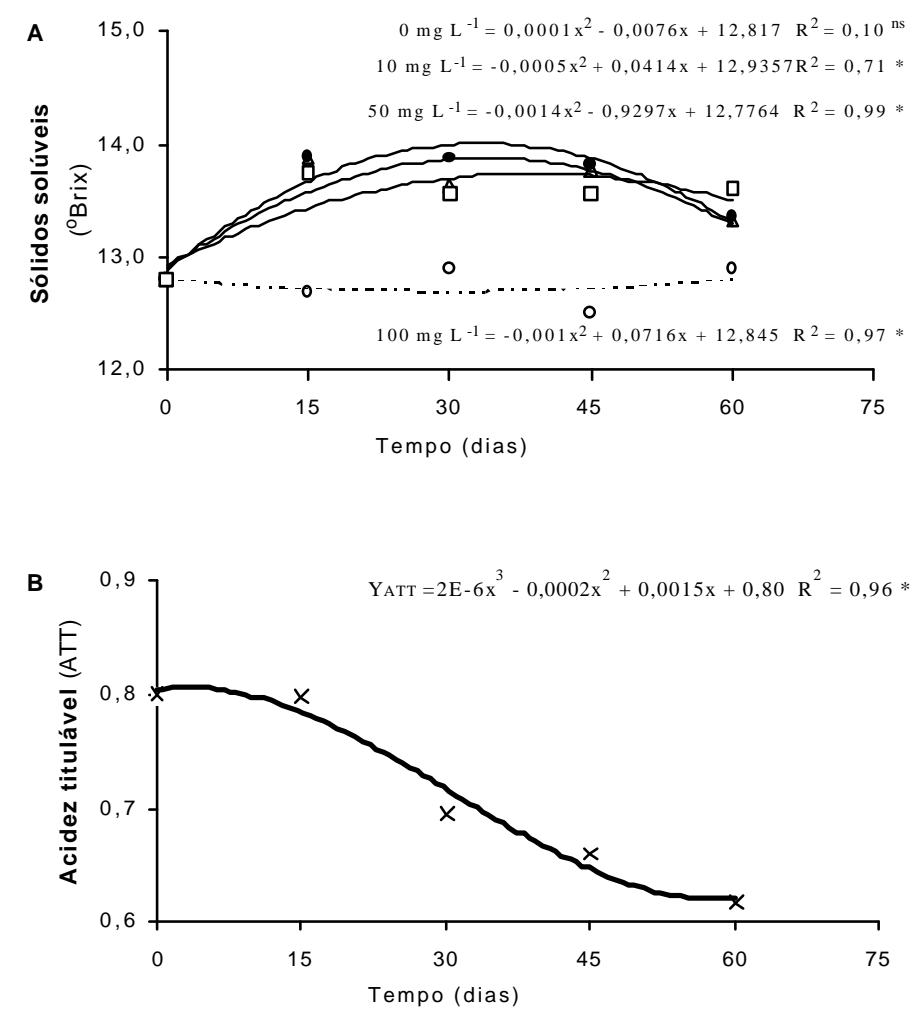

Figura 2 - Modelos de regressão: A) teor de sólidos solúveis totais (SST) e B) acidez total titulável (ATT) em tangor 'Murcote' após tratamentos com $0 \mathrm{mg} \mathrm{L}^{-1}$ (o); $10 \mathrm{mg} \mathrm{L}^{-1}$ ( ); $50 \mathrm{mg} \mathrm{L}^{-1}(\Delta)$ e $100 \mathrm{mg} \mathrm{L}^{-1}(\bullet)$ de $\mathrm{AVG}$ e armazenamento a $9{ }^{\circ} \mathrm{C}\left(+3\right.$ dias a $25^{\circ}$ C)

De maneira geral, resultados variáveis na acidez titulável têm sido relatados, tanto em frutos destacados, quanto para os frutos mantidos na planta com a utilização de biorreguladores (Agusti et al., (1988); Damián \& Monter, 1999; Porat et al., 1999; Selvarajah et al., 2001). As informações descritas acima reforçam a idéia que os biorreguladores disponíveis no mercado, devem ser estudados quanto à época de aplicação e deve-se proceder à verificação da ação dos mesmos nas características físico-químicas dos frutos tratados.

Um balanço adequado da relação entre sólidos solúveis e acidez titulável é necessário para se obter frutos com aroma e sabor de alta qualidade, sendo muito usada 
esta relação para avaliação de frutas cítricas (Ting et al., 1986). A relação entre sólidos solúveis e acidez titulável (Figura 3A), apresentou-se significativamente maior, a partir dos 15 dias de armazenamento para os frutos tratados com AVG, porém, Chitarra (1979) considerou que o limite superior dessa relação deve ficar em torno de 20,0 para um balanço adequado.
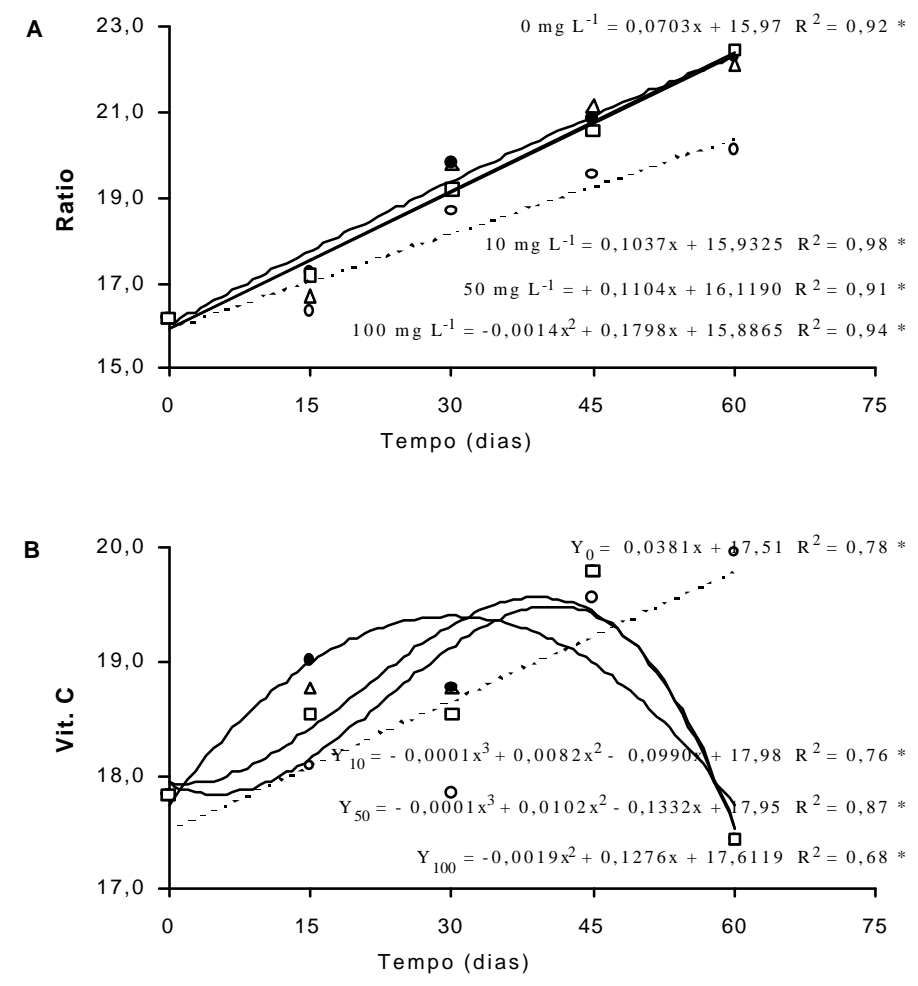

Figura 3 - Modelos de regressão: A) relação SST/ATT ("ratio") e B) teor de vitamina C (mg ácido ascórbico/100 ml de suco) em tangor 'Murcote' após tratamentos com $0 \mathrm{mg} \mathrm{L}^{-1}$ (o); $10 \mathrm{mg} \mathrm{L}^{-1}\left(\right.$ ); $50 \mathrm{mg} \mathrm{L}^{-1}(\Delta)$ e $100 \mathrm{mg} \mathrm{L}^{-1}(\bullet)$ de AVG e armazenamento a $9{ }^{\circ} \mathrm{C}(+$ 3 dias a $25^{\circ} \mathrm{C}$ )

Esse, portanto é um parâmetro a ser considerado para avaliação da qualidade póscolheita de 'Murcote' tratado com AVG, pois, verificou-se que à medida que se aumenta a concentração do produto, diminui o tempo de armazenamento, conforme os modelos de regressão apresentados. Segundo esse critério, os frutos tratados com AVG a 100 mg $\mathrm{L}^{-1}$ estariam aptos para consumo até aos 30 dias de armazenamento, enquanto que os tratados com $10 \mathrm{mg} \mathrm{L}^{-1}$, até 39 dias. Apesar da pequena variação nos resultados obtidos 
para o teor de vitamina $C$, esta mostrou significância para os frutos tratados com AVG aos 30 dias de armazenamento (Figura 3B).

A continuação do processo metabólico, após a colheita, resulta numa mudança gradual da composição do produto, o que eventualmente o levará a senescência (Medina, 1983). A respiração por ser um processo oxidativo ou degradativo, é o principal indicador da taxa metabólica; o seu controle regula o potencial do produto para armazenamento (Wills et al., 1981).
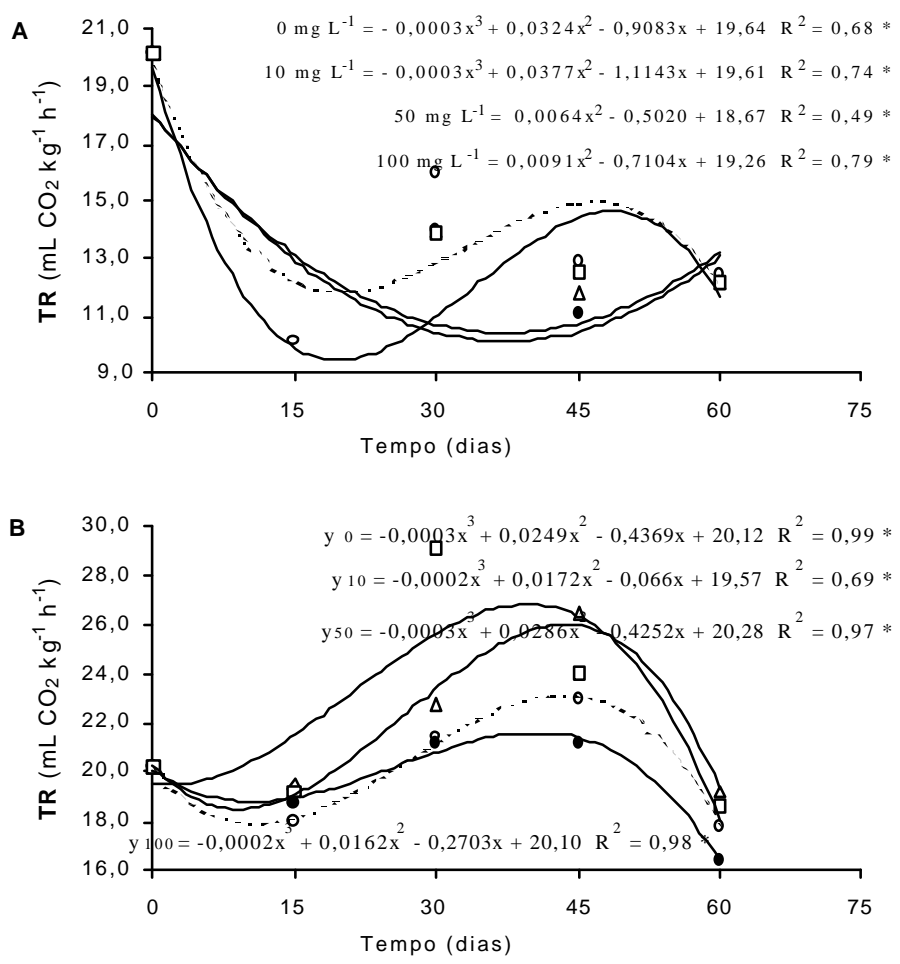

Figura 4 - Modelos de regressão polinomial para a variável taxa respiratória $\left(\mathrm{mL} \mathrm{CO}_{2} \mathrm{~kg}^{-1} \mathrm{~h}^{-1}\right)$ : A) taxa respiratória a $9{ }^{\circ} \mathrm{C}$ e B) taxa respiratória a $25{ }^{\circ} \mathrm{C}$, em tangor 'Murcote' após tratamentos com $0 \mathrm{mg} \mathrm{L}^{-1}\left(\right.$ o); $10 \mathrm{mg} \mathrm{L}^{-1}\left(\right.$ ); $50 \mathrm{mg} \mathrm{L}^{-1}(\Delta)$ e $100 \mathrm{mg} \mathrm{L}^{-1}(\bullet)$ de AVG e armazenamento a $9^{\circ} \mathrm{C}$

Observou-se uma redução significativa na taxa respiratória dos frutos tratados, durante o armazenamento a $9{ }^{\circ} \mathrm{C}$, com AVG (Figura 4A), porém, sem efeito para retardar o declínio do teor de ácido cítrico verificado na figura $2 \mathrm{~B}$ e também do ácido 
ascórbico observado na figura 3B, a partir dos 30 dias. Jacomino et al. (2002) verificaram efeito semelhante na taxa respiratória em mamão. Notoutse uma elevação na taxa respiratória dos frutos tratados com AVG na avaliação de 15 dias (Figura 4B). Isso indica que as concentrações utilizadas foram insuficientes para produzir efeito sobre a mesma.
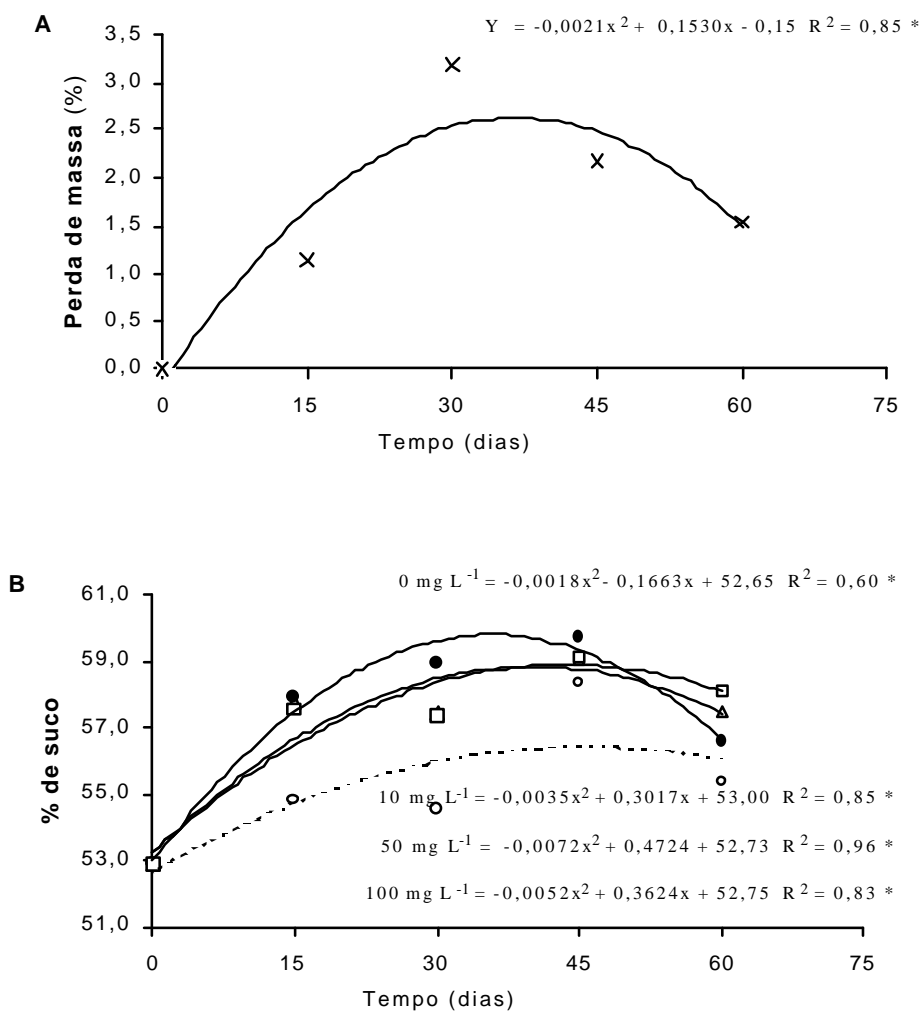

Figura 5 - Modelos de regressão polinomial para: A) perda de massa (\%) e B) quantidade de suco (\%), em tangor 'Murcote' após tratamentos com $0 \mathrm{mg} \mathrm{L}^{-1}$ (o); $10 \mathrm{mg} \mathrm{L}^{-1}$ ( ); $50 \mathrm{mg} \mathrm{L}$ ${ }^{1}(\Delta)$ e $100 \mathrm{mg} \mathrm{L}^{-1}(\bullet)$ de AVG e armazenamento a $9{ }^{\circ} \mathrm{C}$

Observou-se uma elevação na perda de massa, principalmente em função do tempo de armazenamento, já que os tratamentos não afetaram essa variável (Figura 5A). No que se refere à quantidade de suco, notou-se que ocorreu um incremento na porcentagem de suco (Figura 5B). 


\subsection{Conclusões}

De acordo com os resultados obtidos, conclui-se que AVG:

a) Realça a cromaticidade da cor de 'Murcote' em pós-colheita.

b) Retarda a diminuição do teor de sólidos solúveis.

c) Não afeta a acidez titulável.

d) Reduz a taxa respiratória.

e) Aumenta a percentagem de suco. 


\section{MATURAÇÃO E CONSERVAÇÃO DE TANGOR 'MURCOTE' TRATADO COM BIORREGULADORES}

\section{Resumo}

A conservação de tangor 'Murcote' (Citrus reticulata Blanco $x$ C. sinensis Osbeck) sob baixa temperatura permite prolongar o seu período de maturação comercial. A utilização de biorreguladores permite aumentar a vida útil de frutos cítricos submetidos à refrigeração. O objetivo deste trabalho foi verificar o efeito da aplicação de 1-metilciclopropeno, aminoetoxivinilglicina e giberelina, sobre a manutenção das características, físico-químicas em tangor 'Murcote' sob refrigeração a $9{ }^{\circ} \mathrm{C}$. O 1-MCP foi aplicado na concentração $0,5 \mu \mathrm{L} \mathrm{L}^{-1}$ e o AVG com $50 \mathrm{mg} \mathrm{L}^{-1}$ em combinação com GA $20 \mathrm{mg} \mathrm{L}^{-1}$, respectivamente, além de GA $20 \mathrm{mg} \mathrm{L}^{-1}$ e o controle. Os frutos foram expostos ao gás com 1-MCP, por $12 \mathrm{~h}\left(20^{\circ} \mathrm{C}\right)$ em câmaras herméticas. Os frutos tratados com AVG e GA, respectivamente, foram imersos em solução por 1 min. Em seguida foram armazenados durante $15,30,45$ e 60 dias à $9 \pm 1{ }^{\circ} \mathrm{C}$ e umidade relativa de $90 \pm$ $5 \%$. Utilizou-se cera (Sparcitrus) diluída em água na proporção de 1:3 para diminuir a perda de água. Avalioutse a intensidade de cor (croma), ângulo de cor $\left(\mathrm{h}^{\mathrm{o}}\right)$ na casca, taxa respiratória, teor de sólidos solúveis totais, acidez total titulável, teor de ácido ascórbico, Porcentagem de suco e perda de massa em frutos de 'Murcote'. Os resultados apresentados permitiram concluir que frutos tratados com $0,5 \mu \mathrm{L} \mathrm{L}^{-1}$ de 1 -MCP e $50 \mathrm{mg}$ $\mathrm{L}^{-1}$ de $\mathrm{AVG}$, em combinação com GA $20 \mathrm{mg} \mathrm{L}^{-1}$ proporcionaram respectivamente: a) cromaticidade 6,9 e 10,4\% superior, se comparada ao controle; b) redução na variação do ângulo de cor de 2,0\% para GA $20 \mathrm{mg} \mathrm{L}^{-1}$ e de 1,9\% para $1-\mathrm{MCP}+\mathrm{GA}$; c) aumentaram o teor de sólidos solúveis e a percentagem de suco. 
Os tratamentos efetuados não afetaram a acidez titulável, o teor de vitamina $\mathrm{C}$ e a perda de massa.

Termos para indexação: Citrus reticulata, maturação, armazenamento, reguladores vegetais, pós-colheita.

\section{MATURATION AND CONSERVATION OF 'MURCOTT' MANDARIN HYBRID WITH BIOREGULATORS}

\section{Summary}

The storage of 'Murcott' mandarin hybrid (Citrus reticulata Blanco $x$ C. sinensis Osbeck) under low temperature allows the comercialization period to be extended. The use of bioregulators have helped the extending of shelf life fruit. The objective of this research was to verify the effect of 1-MCP (1-methylcyclopropene), AVG (aminoethoxyvinylglycine) and GA (gibberellin) upon the quality of 'Murcott' mandarin hybrid under cold stored. The treatments used were: Check; 1-MCP $0,5 \mu \mathrm{L} \mathrm{L}^{-1}$ plus GA $20 \mathrm{mg} \mathrm{L}^{-1}$; AVG $50 \mathrm{mg} \mathrm{L}^{-1}$ plus GA $20 \mathrm{mg} \mathrm{L}^{-1}$ and GA $20 \mathrm{mg} \mathrm{L}^{-1}$. Fruit were stored during 15, 30, 45 and 60 days at $9 \pm 1^{\circ} \mathrm{C}$ and $90 \pm 5 \% \mathrm{RH}$. The results shows that maturation of peel (chroma) and quality of juice were maintained in 'Murcott' mandarin hybrid, after cold storage (plus 3 days at $25{ }^{\circ} \mathrm{C}$ ) with 1-MCP and AVG combinated GA $20 \mathrm{mg} \mathrm{L}^{-1}$. These treatments did not reduce respiratory rate, loss acidity tritiable and ascorbic acid and loss mass weight but increased juice percentage.

Index words: Citrus reticulata, maturation, shelf life, plant regulators, post-harvest.

\subsection{Introdução}

Os frutos em geral são adquiridos pelo consumidor, através de características externas, como tamanho e coloração brilhante da casca. Uma maior intensidade de coloração $\left(\mathrm{C}^{*}\right)$ em casca de frutos é desejável, uma vez que, realça a sua aparência, um atributo importante durante a comercialização. O croma define a intensidade da cor, 
assumindo valores próximos a zero para cores neutras (cinzas) e ao redor de 60 para cores vívidas e valores de $\mathrm{h}\left({ }^{\circ}\right)$ mais próximos de $90^{\circ}$ representam frutos mais amarelos, à medida que tendem a 0 , tornam-se mais alaranjados e maturos (Mc Guire, 1992). O tangor 'Murcote' (Citrus reticulata Blanco $x$ C. sinensis Osbeck) é classificado como sendo um fruto não climatérico, por apresentar baixa taxa respiratória e produção de etileno. A manutenção da cor da casca é desejável, durante sua vida útil pós-colheita, entretanto, os processos de degradação de clorofila e síntese de carotenóides continuam a ocorrer, mesmo durante o seu armazenamento. Os pigmentos carotenóides são responsáveis pela coloração da casca e ocorrem nos cromoplastos das células do flavedo. Nas frutas cítricas imaturas predomina a cor verde e durante o amadurecimento, ocorre a degradação das clorofilas, começando a aumentar os pigmentos amarelos da casca, mesmo após o completo desaparecimento da clorofila (Chitarra, 1979; Baldwin, 1994).

As condições ambientes para a conservação refrigerada de tangor 'Murcote' são temperatura entre $2-10{ }^{\circ} \mathrm{C}$ e umidade relativa (UR) entre 85 e $95 \%$. Nessas condições, os frutos podem ser armazenados com boa aparência por 4 a 8 semanas, como recomendam Ismail \& Wilhite (1991). Tratamentos com biorreguladores têm sido utilizados em frutos cítricos e outros, com o objetivo de manter a aparência externa e também as características físico-quimicas.

A giberelina é um hormônio relacionado a juvenilidade (Dilley, 1969). Desta forma, a sua aplicação retarda processos ligados à maturação e a senescência, incluindo a degradação da clorofila (Agusti et al., 1988; Schechter et al., 1989). O ácido giberélico é muito usado para retardar mudanças na coloração de casca de lima ácida 'Tahiti' (Barros et al., 1991; Silva \& Donadio, 1997; Spósito et al., 2000). O uso de giberelinas tem-se limitado a aplicações em pré-colheita para laranjas (Goldschmidt et al., 1977; Davies et al, 1997; Damián \& Monter, 1999) e também para tangerinas e híbridos (Garcia et al., 1986; Agusti et al., 1988; El-Otmani \& Coggins, 1991; Garcia et al., 1992; Pozo et al., 2000).

O 1-MCP (1-metilciclopropeno) é um composto gasoso e tem demonstrado ser um eficiente inibidor da ação de etileno, devido ao fato de se ligar ao sítio receptor de etileno, atuando como antagonista. O 1-MCP apresenta grande potencial de uso 
comercial para o controle da maturação de frutas e hortaliças e da senescência em flores (Sisler \& Serek, 1997). Embora os citros apresentem apenas um sistema um de produção de etileno (Vendrell \& Palomer, 1997), isso não significa que não ocorre interferência do etileno sobre a maturação do fruto. Goldschmidt (1997), considerou que o etileno, mesmo em baixas concentrações em frutos não climatéricos, está relacionado a eventos ligados à maturação, como a degradação de clorofilas da casca. Constatou-se que 1MCP aumentou o tempo de conservação de morangos (Ku et al., 1999) e retardou o amadurecimento em frutos climatéricos como banana (Jiang et al., 1999), maçã (Fan \& Mattheis, 1999), abacate (Kluge et al., 2002) e pêssego (Kluge \& Jacomino, 2002). Geralmente, 1-MCP reduz ou atrasa o início da elevação da taxa respiratória, como encontrado em morango (Tian et al., 2000). Entretanto, o 1-MCP não teve efeito na taxa respiratória em nectarinas (Dong et al., 2001) e damasco (Dong et al., 2002). A taxa respiratória em brocoli foi inibida por 1-MCP na faixa de $0-1 \mu \mathrm{L} \mathrm{L}^{-1}$ (Fan \& Mattheis, 2000 a).

O efeito de 1-MCP sobre o teor de acidez total titulável é variável de acordo com a cultura. O 1-MCP atrasou o declínio no teor de ácido ascórbico em abacaxi (Selvarajah et al., 2001), preveniu a queda de acidez em cenouras (Fan \& Mattheis, 2000b), tomate (Wills \& Ku, 2002) e ameixas (Dong et al., 2002). O 1-MCP não afetou o teor de acidez em laranjas 'Shamouti' (Porat et al., 1999). Encontrou-se alto teor de sólidos solúveis em abacaxí (Selvarajah et al., 2001), mamão (Hofman et al., 2001) e maçãs (Fan \& Mattheis, 1999) tratadas com 1-MCP. Entretanto, laranjas, ameixas e mangas não foram afetadas por 1-MCP, no teor de sólidos solúveis (Porat et al., 1999; Hofman et al., 2001; Dong et al., 2002). Tratamentos com 1-MCP em laranjas não afetaram a perda de massa (Porat et al., 1999), enquanto houve um atraso de perda de massa em abacate (Jeong et al., 2002).

O AVG (aminoetoxivinilglicina) inibe a conversão enzimática de SAM (Sadenosilmetionina) para ACC (ácido 1-carboxílico-1-aminociclopropano), sendo o cobalto e outros radicais livres como o ácido ascórbico, inibidores da conversão subseqüente de ACC para etileno (Wenzel et al., 1995). O AVG é largamente utilizado na indústria da maçã, prevenindo a produção interna de etileno, não tendo efeito contra o 
etileno externo. Aplicação de AVG $88 \mathrm{mg} \mathrm{L}^{-1}$ em pré-colheita não afetou a coloração da casca e o teor de sólidos solúveis em maçã 'Delicious' (Byers, 1997; Greene, 1997). Utilizando-se a mistura de GA 100-150 mg L-1 e AVG 100-150 mg L $\mathrm{m}^{-1}$ em pré-colheita, Ju et al., (1999) prolongaram por quatro semanas, a comercialização de pêssegos 'Feicheng' com a inibição da maturação dos frutos na planta. Um atraso no amadurecimento de pêras 'Packham's Triumph' foi obtido com AVG aplicado em précolheita (Munhoz \& Luis, 1998).

O objetivo deste trabalho foi determinar os efeitos dos biorreguladores 1MCP e AVG combinados com ácido giberélico. Sua aplicação em pós-colheita visou retardar a maturação e senescência de tangor 'Murcote'.

\subsection{Material e Métodos}

Frutos de tangor 'Murcote'colhidos em pomar comercial localizado no município de Mogi-Mirim, SP, foram transportados para o Laboratório de Pós-Colheita do Departamento de Produção Vegetal da ESALQ/USP. Foram utilizados frutos sadios apresentando $71,6^{\circ}$ de ângulo de cor $\left(\mathrm{h}^{\circ}\right.$ ) e 59,28 unidades de croma, caracterizando a coloração inicial da casca. $\mathrm{O}$ suco dos frutos apresentavam no início do experimento, um teor de sólidos solúveis totais de $12,8{ }^{\circ}$ Brix e acidez total titulável de 0,83\%. Após a seleção, os frutos foram submetidos aos tratamentos: GA $20 \mathrm{mg} \mathrm{L}^{-1}$; 1-MCP $0,5 \mu \mathrm{L} \mathrm{L}^{-1}$ + GA $20 \mathrm{mg} \mathrm{L}^{-1}$; AVG $50 \mathrm{mg} \mathrm{L}^{-1}$ + GA $20 \mathrm{mg} \mathrm{L}^{-1}$, além do controle. O tratamento com 1-MCP constou da exposição dos frutos ao gás 1-metilciclopropeno (1-MCP) em caixas herméticas, com capacidade para 188,0 litros, utilizando-se o produto comercial $\mathrm{SmartFresh}^{\mathrm{TM}}$, na forma pó molhável, contendo 0,14\% do i.a. de 1-metilciclopropeno. Aos frascos contendo 1-MCP, adicionou-se $20 \mathrm{~mL}$ de água destilada aquecida a $50{ }^{\circ} \mathrm{C}$ e após completa dissolução, os mesmos foram abertos no interior das câmaras, expondo os frutos ao gás durante $12 \mathrm{~h}$ sob temperatura a $20{ }^{\circ} \mathrm{C}$. Os frutos tratados com AVG e GA foram imersos em soluções com as devidas concentrações, por um minuto.

Logo após os tratamentos com 1-MCP e AVG, os frutos foram imersos em outra solução contendo $20 \mathrm{mg} \mathrm{L}^{-1}$ de GA, por um minuto. Após os tratamentos, aplicou-se cera (Sparcitrus) diluída em água na proporção de 1:3 e a secagem foi efetuada em 
condições ambiente $\left(65 \%\right.$ UR e $\left.25{ }^{\circ} \mathrm{C}\right)$ por 30 minutos. Os frutos foram armazenados a 9 $\pm 1{ }^{\circ} \mathrm{C}$ e $90 \pm 5 \%$ de UR durante 15, 30, 45 e 60 dias. Após cada período de armazenamento (+ 3 dias à $25{ }^{\circ} \mathrm{C}$ ), determinaram-se os parâmetros: a) coloração da casca: valores de croma $\left(\mathrm{C}^{*}\right)$ e ângulo de cor $\left(\mathrm{h}^{\mathrm{o}}\right)$, através de colorímetro Minolta Chroma Meter CR-300; b) taxa respiratória $\left(\mathrm{mL} \mathrm{CO}_{2} \mathrm{~kg}^{-1} \mathrm{~h}^{-1}\right)$ me dida em analisador de gases $\left(\mathrm{CO}_{2}\right.$ e $\left.\mathrm{O}_{2}\right)$; c) teor de sólidos solúveis totais (SST) expressos em ${ }^{\circ}$ Brix obtido em refratômetro digital; d) acidez total titulável (ATT): neutralização de uma alíquota de 10 $\mathrm{mL}$ de suco, com $\mathrm{NaOH} 0,1 \mathrm{~N}$, sendo os resultados expressos em $\%$ de ácido cítrico anidro; e) relação SST/ATT (ratio); f) teor de vitamina C: neutralização por titulação do ácido ascórbico, em solução de 2,6-dicloro fenol indofenol (DCFI) expressa em mg de ácido ascórbico por $100 \mathrm{~mL}$ de suco (Instituto Adolfo Lutz, 1985); g) \% de perda de massa: percentual entre massa inicial e massa após armazenamento e f) \% de suco: relação percentual entre massa do suco $(\mathrm{g})$ e a massa do fruto.

O delineamento experimental adotado foi inteiramente ao acaso, em parcelas subdivididas no tempo. Os fatores analisados foram: tratamentos e tempo de conservação (5 níveis). Utilizaram-se quatro repetições de oito frutos por parcela. Determinaram-se os modelos de regressão através do programa Sistema de Análise Estatística - SANEST (Zonta \& Machado, 1984).

\subsection{Resultados e Discussão}

De acordo com os quadros de análise da variância (Tabelas 12, 13, 15 e 16), a interação do tempo de armazenamento com tratamento, apresentou diferenças significativas (PROB $>\mathrm{F}=<0,010$ ) para as variáveis: $\mathrm{C}^{*}, \mathrm{~h}^{\circ}, \mathrm{SST}$, TR a $9{ }^{\circ} \mathrm{C}$ e $\%$ suco. Não houve interação significativa para as variáveis: ATT, ratio, vit. C e perda de massa (Tabelas 13, 14 e 16), respectivamente. A regressões solicitadas para o tempo dentro do tratamento (Tabelas 12A e B; 13A, 15A e B 16A) qpresentaram equações significativas $(\mathrm{PROB}>\mathrm{F}=0,05)$, conforme descritas nas respectivas figuras, devendo ser adotadas por possuir maior coeficiente de determinação.

Após 30 dias de armazenamento $\left(+3\right.$ dias a $25^{\circ} \mathrm{C}$ ), frutos tratados com 1-MCP $0,5 \mu \mathrm{L} \mathrm{L}^{-1}$ e AVG $50 \mathrm{mg} \mathrm{L}^{-1}$, em combinação com GA3 $20 \mathrm{mg} \mathrm{L}^{-1}$, apresentaram 
respectivamente, uma cromaticidade 6,9 e 10,4\% maior, em comparação com os frutos não tratados. Aos 45 dias, somente frutos com $A V G+\mathrm{GA}_{3}$ apresentaram uma coloração de casca mais vívida (Figura 1A). Vários autores reportaram que a resposta máxima na redução da coloração em tangerinas pode ser obtida com aplicação de $\mathrm{GA}_{3} 10-25 \mathrm{mg} \mathrm{L}^{-1}$ no início da coloração da casca (Garcia et al., 1986; Agusti et al., 1988; El-Otmani et al., 1991; Pozo et al., 2000). Provavelmente, mesmo em baixa concentração, o etileno atuou em processos ligados à maturação (Goldschmidt, 1977).
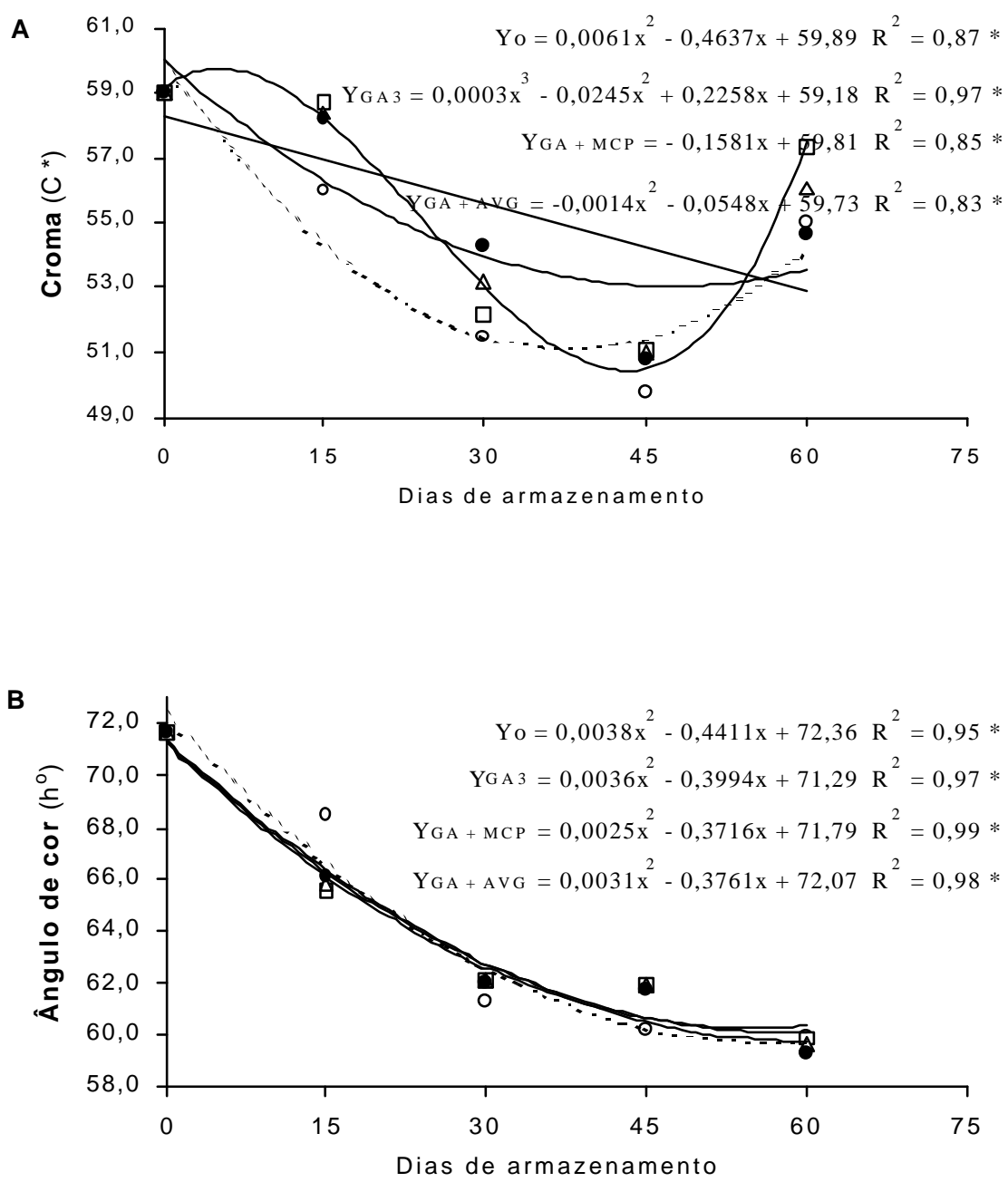

Figura 1 - Modelos de regressão para as variáveis: A) intensidade de cor (C*) e B) ângulo de cor $\left(\mathrm{h}^{\mathrm{o}}\right)$ em casca de tangor 'Murcote' tratado com reguladores vegetais: $\mathrm{GA}_{3} 20 \mathrm{mg} \mathrm{L}^{-1}$ ( ) $; 1-\mathrm{MCP}+\mathrm{GA}_{3}(\ddot{\mathrm{A}}), \mathrm{AVG}+\mathrm{GA}_{3}(\bullet)$, além do controle (o) 
Verificoutse um acúmulo no teor de sólidos solúveis (Figura 2A), nos frutos

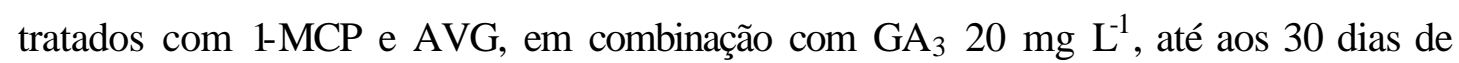
armazenamento $\left(+3\right.$ dias a $25{ }^{\circ} \mathrm{C}$ ) em relação aos frutos não tratados. Após esse período ocorreu um decréscimo no teor de sólidos solúveis desses frutos, até o final do armazenamento.
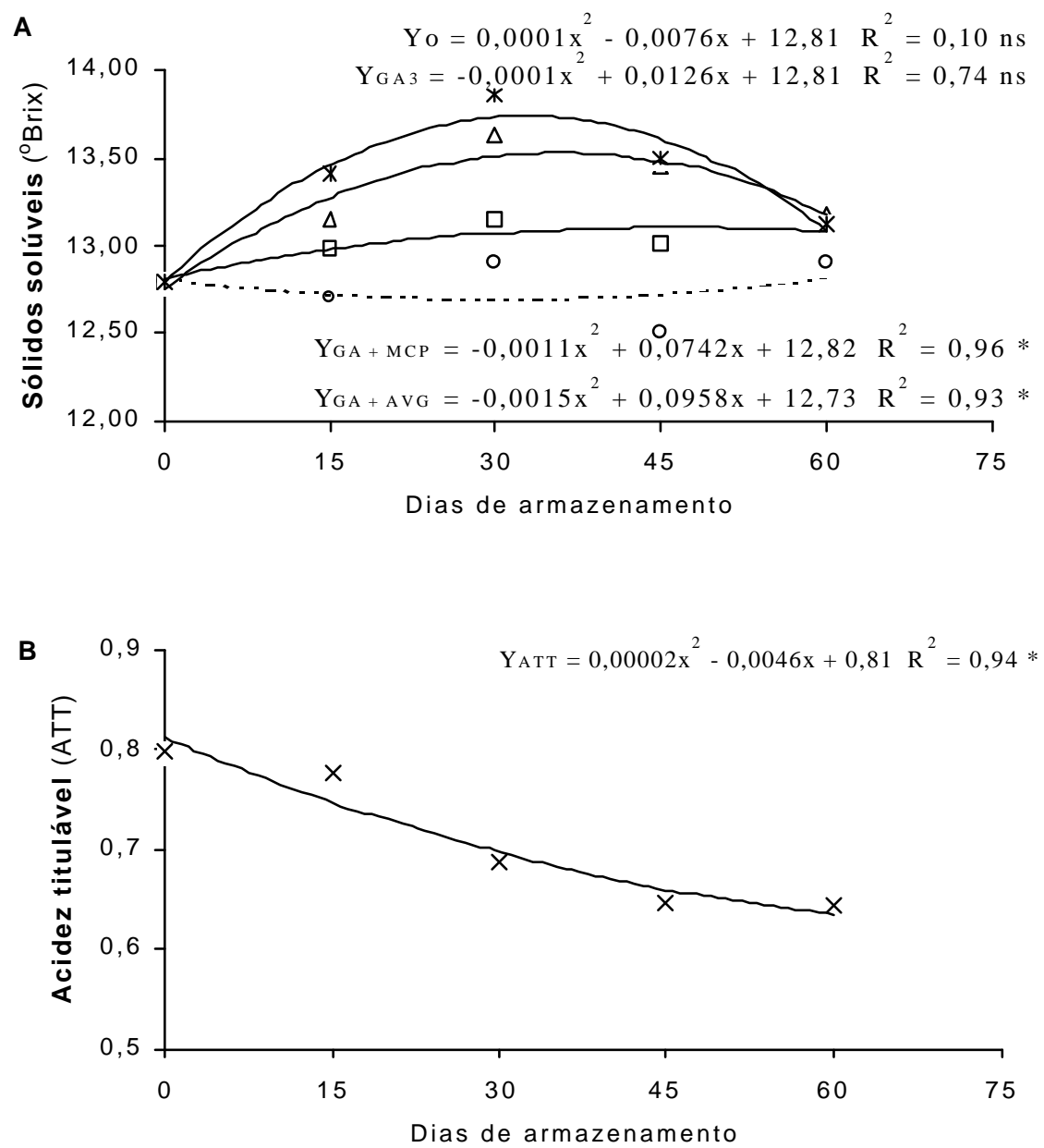

Figura 2 - Modelos de regressão para as variáveis: A) teor de sólidos solúveis ( ${ }^{\circ}$ Brix) e B) acidez total titulável em suco de tangor 'Murcote' tratado com reguladores vegetais: $\mathrm{GA}_{3} 20$ $\mathrm{mgL}^{-1}(\mathrm{)}) ; 1-\mathrm{MCP}+\mathrm{GA}_{3}(\ddot{\mathrm{A}}), \mathrm{AVG}+\mathrm{GA}_{3}(\bullet)$, além do controle (o) 
Outros autores, também encontraram altos teores de sólidos solúveis em abacaxi (Selvarajah et al., 2001), mamão (Hofman et al., 2001) e maçãs (Fan \& Mattheis, 1999) tratadas com 1-MCP, entretanto, laranjas não foram afetadas (Porat et al., 1999).

$\mathrm{O}$ teor de sólidos solúveis nos frutos tratados com $\mathrm{GA}_{3} 20 \mathrm{mg} \mathrm{L}^{-1}$ não foi significativo, concordando com Iglesias et al. (2001), onde sugeriram que a mudança da coloração da casca em mandarina Satsuma 'Okitsu', está correlacionada positivamente com o teor de açúcares e que o $\mathrm{GA}_{3}$ age como repressor da estimulação sacarose-etileno.

A
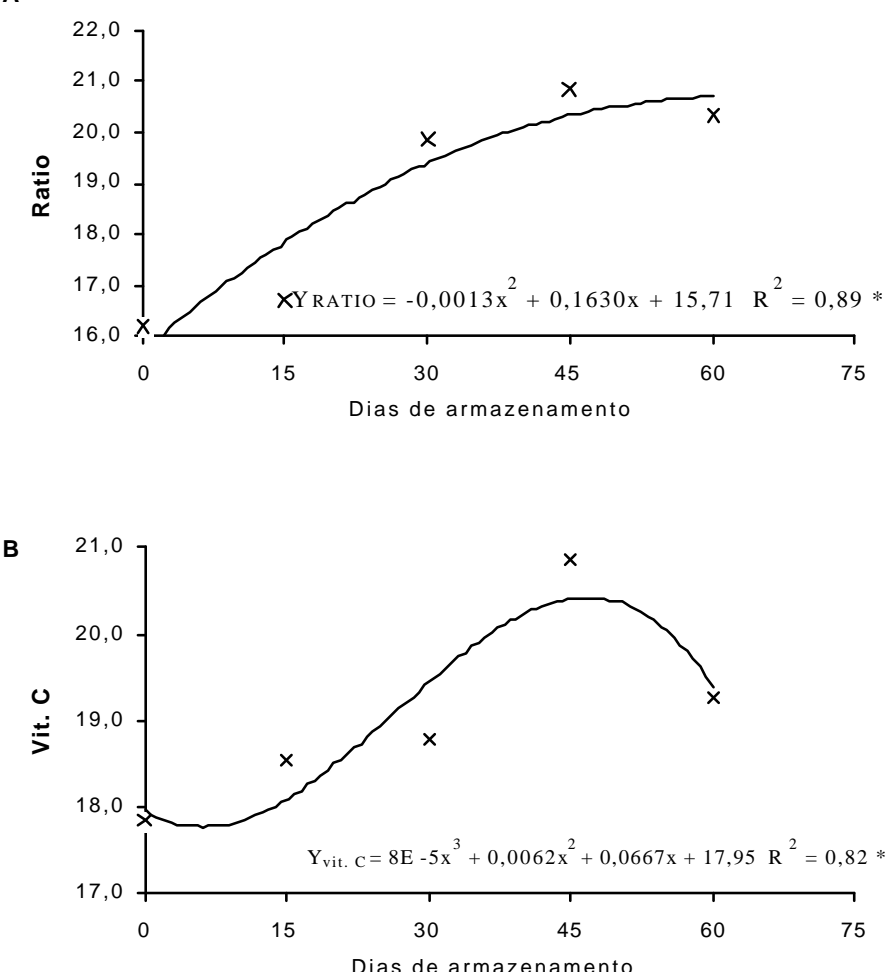

Figura 3 - Modelos de regressão para as variáveis: A) Ratio e B) teor de vitamina C, em suco e tangor 'Murcote' tratado com eguladores vegetais: $\mathrm{GA}_{3} 20 \mathrm{mg} \mathrm{L}^{1}$ ( ); $1 \mathrm{MCP}+$ $\mathrm{GA}_{3}(\mathrm{~A}), \mathrm{AVG}+\mathrm{GA}_{3}(\bullet)$, além do controle (o)

Notaram-se que os tratamentos efetuados não alteraram a acidez titulável, de forma significativa (Figura 2B). Vários autores relataram que $\mathrm{GA}_{3}$ não causou efeitos 
sobre a acidez titulável quando aplicado em pré-colheita (El-Otmani \& Coggins, 1991; Pozo et al., 2000). Porat et al. (1999), também não observaram alterações na acidez titulável de laranjas 'Shamouti'.
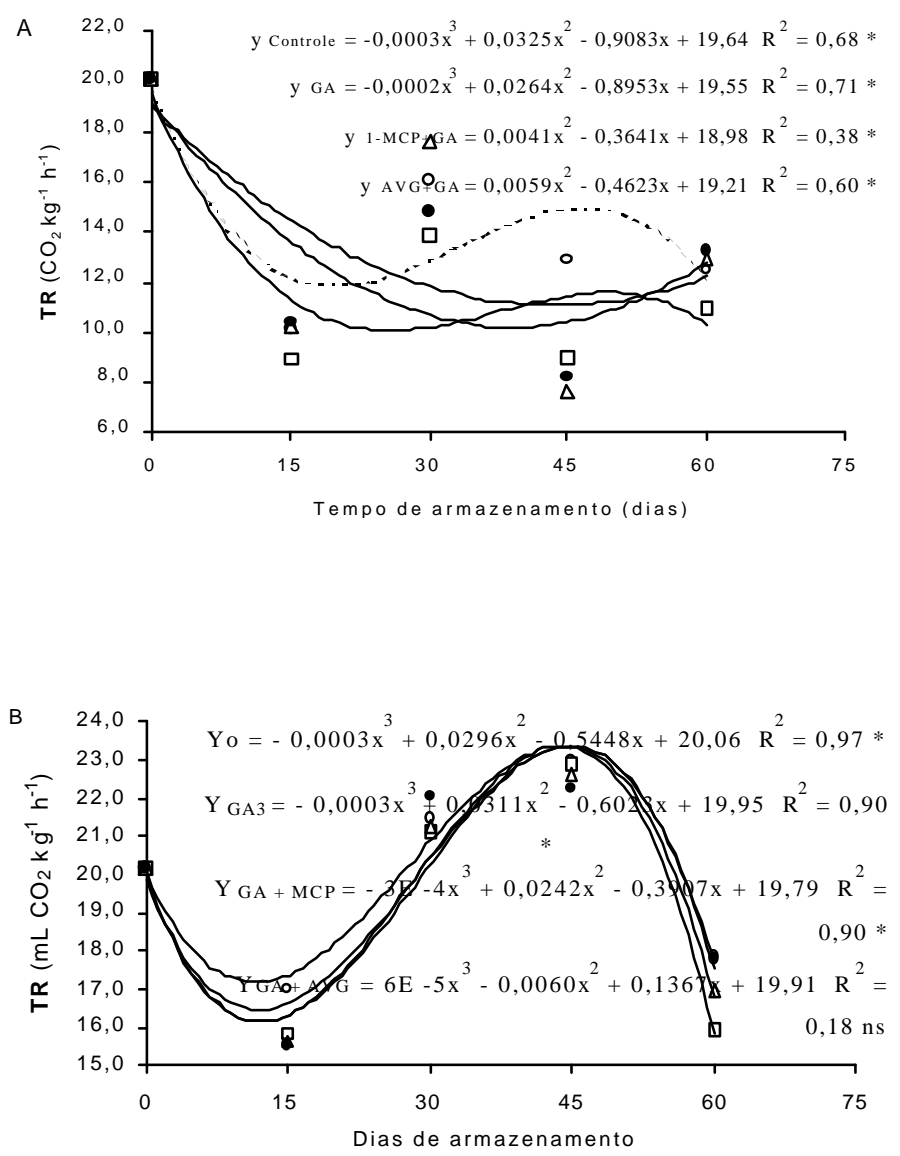

Figura 4 - Modelos de regressão para taxa re spiratória $\left(\mathrm{mL} \mathrm{CO}_{2} \mathrm{~kg}^{-1} \mathrm{~h}^{-1}\right)$, em tangor 'Murcote' (a $9{ }^{\circ} \mathrm{C}$ e a $25{ }^{\circ} \mathrm{C}$ ) tratado com reguladores vegetais: $\mathrm{GA}_{3} 20 \mathrm{mg} \mathrm{L}^{-1}\left(\right.$ ); $1-\mathrm{MCP}+\mathrm{GA}_{3}$ $(\mathrm{A}), \mathrm{AVG}+\mathrm{GA}_{3}(\bullet)$, além do controle (o)

A razão (ratio) entre o teor de sólidos solúveis e a acidez titulável aumentou, durante o período de armazenamento (Figura 3A). Isso ocorreu devido provavelmente à diminuição do teor de acidez titulável no decorrer do tempo. Não houve interação significativa entre tratamentos e o tempo de armazenamento para o teor de vitamina $\mathrm{C}$ (Figura 3B). 
O modelo de regressão ajustado para o teor de vitamina $\mathrm{C}$, evidencia a tendência de acúmulo dessa substância no decorrer do tempo. Segundo Wenzel et al. (1995), o ácido ascórbico atua como inibidor da conversão de ACC para etileno, portanto, uma elevação no teor do mesmo, poderá atrasar o processo de senescência em frutos de tangor 'Murcote'.
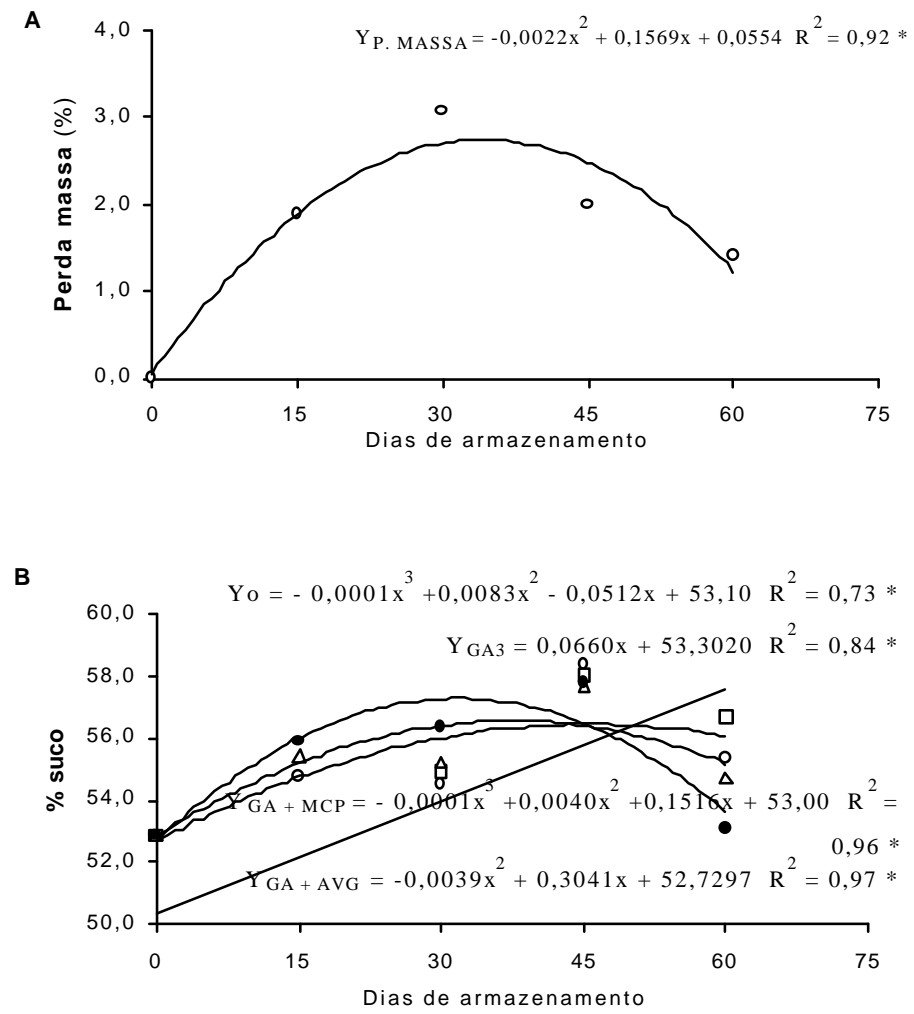

Figura 5 - Modelos de regressão para as variáveis: A) perda de massa (\%) e B) porcentagem de suco em tangor 'Murcote' tratado com reguladores vegetais: $\mathrm{GA}_{3} 20 \mathrm{mg} \mathrm{L}^{-1}($ ); 1$\mathrm{MCP}+\mathrm{GA}_{3}(\ddot{\mathrm{A}}), \mathrm{AVG}+\mathrm{GA}_{3}(\bullet)$, além do controle (o)

A taxa respiratória dos frutos de 'Murcote' após o armazenamento refrigerado (+3 dias a $25{ }^{\circ} \mathrm{C}$ ) não apresentou grandes diferenças entre os tratamentos (Figura 4B). Dong et al. (2001) e Dong et al. (2002) obtiveram resultados semelhantes em nectarinas e damascos tratados com 1-MCP, entretanto, Fan \& Mattheis, (2000a) afirmaram ter inibido a taxa respiratória em brócoli. Goldschmidt et al. (1997) observaram que a taxa 
respiratória em frutos de laranjas 'Shamouti' não foi alterada por aplicação de $\mathrm{GA}_{3} 25$ mg L L ${ }^{-1}$, entretanto Damián \& Monter (1999) reportaram a ocorrência de uma menor taxa respiratória em frutos de 'Valência Tardia', tratados com giberelina a $5 \mathrm{mg} \mathrm{L}^{-1}$ em précolheita.

Não houve diferenças significativas de perda de massa entre os tratamentos efetuados, sendo que o aumento verificado na perda de massa é devido ao tempo de armazenamento (Figura 5A). El-Otmani \& Coggins (1991) não verificaram perda de massa em tangerinas 'Clementina' e laranjas 'Washington' com aplicação de GA3 em pulverização pré-colheita. Porat et al. (1999) obtiveram resultados semelhantes em laranja 'Shamouti'. A variação na perda de massa em 'Murcote' situour-se dentro do limite de 5\%, permitido para comercialização de frutos in natura.

Observou-se uma diminuição na porcentagem de suco em frutos tratados com $\mathrm{GA}_{3} 20 \mathrm{mg} \mathrm{L}^{-1}$ (Figura 5B). Davies et al. (1997) verificaram aumento na porcentagem de suco em laranjas 'Valência' e 'Pineapple'.

\subsection{Conclusões}

Os resultados acima discutidos permitem concluir que:

a) A intensidade de cor da casca é afetada por 1-MCP e AVG aplicados em combinação com $\mathrm{GA}_{3} 20 \mathrm{mg} \mathrm{L}^{-1}$.

b) As combinações de 1-MCP e AVG com GA3 utilizadas, proporcionam maiores níveis de sólidos solúveis e porcentagem de suco, nos primeiros trinta dias de armazenamento refrigerado.

c) Aplicações com $\mathrm{GA}_{3}$ ou 1-MCP e AVG em combinação com $\mathrm{GA}_{3} 20 \mathrm{mg} \mathrm{L} \mathrm{L}^{-1}$, não afetam a acidez titulável, vitamina $\mathrm{C}$, perda de massa e a taxa respiratória de frutos de 'Murcote'. 


\section{CONSERVAÇÃO PÓS-COLHEITA DA LIMA ÁCIDA 'TAHITI' TRATADA COM 1-METILCICLOPROPENO}

\section{Resumo}

A lima ácida 'Tahiti' tem ocupado cada vez mais posição de destaque na citricultura brasileira, pela maior demanda dos mercados, interno e de exportação de frutas de qualidade superior. $\mathrm{O}$ seu armazenamento refrigerado permite prolongar o período de conservação e comercialização, entretanto, a perda da coloração verde da casca e, de suas características físico-químicas impedem este prolongamento. Com o objetivo de aumentar o tempo de vida útil pós-colheita de lima ácida 'Tahiti', aplicou-se o 1-metilciclopropeno nas concentrações de: 0; 0,1;0,5 e 1,0 $\mu \mathrm{L} \mathrm{L}^{-1}$. Os frutos foram armazenados durante 80 dias a $9 \pm 1{ }^{\circ} \mathrm{C}$ e $90 \pm 5 \%$ de UR e avaliados em períodos de 20 dias. A aplicação de 1-MCP nas concentrações de 0,5 e $1,0 \mu \mathrm{L} \mathrm{L}^{-1}$ prolongou a vida útil pós-colheita de lima ácida 'Tahiti', por 40 dias. Retardou mudanças na intensidade e tonalidade de cor, mantendo um ratio adequado para a comercialização. Não afetou a taxa respiratória, teor de vitamina $\mathrm{C}$, perda de massa e porcentagem de suco dos frutos.

Termos para indexação: Citrus latifolia, 1-metilciclopropeno, armazenamento.

\section{Summary}

Due to the increased demand in internal and foreign markets for higher quality fruits, 'Tahiti' lime has more and more occupied na outstanding position in Brazilian citriculture. Its cold storage allows to extend the storage and marketing periods, however, the loss of pell green color and its physical-chemical features affect this lentthening. The 1-methylcyclopropene at $0 ; 0,1 ; 0,5$ and $1,0 \mu \mathrm{L} \mathrm{L}^{-1}$ was applied trying 
to increase the shelf-life of 'Tahiti' lime. The fruits were stored during 80 days at $9+1{ }^{\circ} \mathrm{C}$ with $90 \pm 5 \%$ of relative humidity, and assessments were made at each 20 days. The 1MCP application at 0,5 and $1,0 \mu \mathrm{L} \mathrm{L}^{-1}$ increased the shelf life for 40 days, delayed changes in color intensity and tonality, keeping na adequate ratio for marketing. Such treatments did not affect the respiratory rate, the ascorbic acid concentration, the weight loss and the percentage of juice in the fruits.

Index terms: Citrus latifolia, 1-methylcyclopropene, storage.

\subsection{Introdução}

A lima ácida 'Tahiti' é adquirida pelo consumidor, principalmente em função das características externas, como o tamanho uniforme e a coloração verde escura da casca. A lima 'Tahiti' (Citrus latifolia, Tanaka) é classificada como sendo um fruto não climatérico, por apresentar baixa taxa respiratória e baixa produção de etileno. Para a sua comercialização, o desejável é a predominância da cor verde, durante a vida útil póscolheita. Os pigmentos carotenóides são responsáveis pela coloração da casca e ocorrem nos cromoplastos das células do flavedo. Nas frutas cítricas imaturas predomina a cor verde e durante a sua maturação, ocorre a degradação das clorofilas, começando a predominar os pigmentos amarelos da casca. Estes continuam a aumentar, mesmo após o completo desaparecimento da clorofila (Chitarra, 1979; Baldwin, 1994). Além da coloração da casca, também é importante a textura ou firmeza da casca dos frutos.

A conservação da lima 'Tahiti', sob baixa temperatura, prolonga seu período de conservação. Entretanto, a perda da coloração da casca é fator determinante na decisão de compra pelo consumidor. O croma define a intensidade da cor, assumindo valores próximos a zero para cores neutras (cinzas) e ao redor de 60 para cores vívidas. Portanto, maiores valores de croma representam maior intensidade da cor amarela. $\mathrm{O}$ ângulo de 
cor $\left(\mathrm{h}^{\mathrm{o}}\right)$ define a tonalidade da cor. Em lima ácida 'Tahiti', o $\mathrm{h}^{\mathrm{h}}$ mais próximo de $180\left({ }^{\circ}\right)$ representa frutos mais verdes e à medida que tende a $90\left(^{\circ}\right)$, os frutos tornam-se mais amarelos e maturos (McGuire, 1992).

Cada cultivar apresenta um limite de armazenamento que, quando atingido, leva a fruta a senescência e deterioração. As condições ambientais para a conservação refrigerada de lima 'Tahiti' são com temperaturas entre $10-12{ }^{\circ} \mathrm{C}$ e umidade relativa (UR) entre 85 e 95\%. Nessas condições, os frutos podem ser armazenados com boa aparência. Temperaturas abaixo de $8{ }^{\circ} \mathrm{C}$, por longos períodos induzem o aparecimento de injúrias causadas pelo frio (Chitarra \& Chitarra, 1990; Kluge et al., 2001). Tratamentos com biorreguladores têm sido utilizados em frutos cítricos e outros, com o objetivo de prolongar sua aparência externa desejável e manter suas características físicas, químicas e físico-quimicas.

O 1-MCP (1-metilciclopropeno) é um composto gasoso que tem demonstrado ser um eficiente inibidor da ação de etileno. Ele se liga ao sítio receptor de etileno, atuando como antagonista. Apresenta grande potencial no uso comercial para o controle da maturação e senescência de frutas e hortaliças, e de flores (Sisler \& Serek, 1997). Embora os citros apresentem apenas um sistema de produção de etileno (endógeno), diferente dos frutos climatéricos, onde existe também a produção autocatalítica de etileno (Vendrell \& Palomer, 1997), isso não significa que não ocorre interferência do etileno sobre a maturação do fruto. Goldschmidt (1997) considerou que o etileno, mesmo em baixas concentrações em frutos não climatéricos, está relacionado aos processos ligados à maturação, como a degradação de clorofilas da casca. Constatou-se que 1-MCP aumentou o tempo de conservação de morangos (Ku et al., 1999) e retardou o amadurecimento em frutos climatéricos como banana (Jiang et al., 1999), maçã (Fan \& Mattheis, 1999), abacate (Kluge et al., 2002b) e pêssego (Kluge \& Jacomino, 2002). Geralmente o 1-MCP reduz ou atrasa o início da elevação da taxa respiratória, como observado em morango (Tian et al., 2000). Entretanto o 1-MCP não teve efeito na taxa respiratória em nectarinas (Dong et al., 2001) e damasco (Dong et al., 2002). A taxa 
respiratória em brocoli foi inibida por 1-MCP na faixa de $0-1,0 \mu \mathrm{L} \mathrm{L}^{-1}$ (Fan \& Mattheis, 2000 a).

O efeito de 1-MCP sobre o nível de acidez total titulável é variável, de acordo com a cultura. Este biorregulador atrasou o declínio no teor de ácido ascórbico em abacaxi (Selvarajah et al., 2001), preveniu a queda de acidez em cenouras (Fan \& Mattheis, 2000b), tomate (Wills \& Ku, 2002) e ameixas (Dong et al., 2002). O 1-MCP não afetou o teor de acidez em laranjas 'Shamouti' (Porat et al., 1999). Encontrou-se alto teor de sólidos solúveis em abacaxí (Selvarajah et al., 2001), mamão (Hofman et al., 2001) e maçãs (Fan \& Mattheis, 1999) tratadas com 1-MCP. Entretanto, laranjas, ameixas e mangas não foram afetadas por 1-MCP, no teor de sólidos solúveis (Porat et al., 1999; Hofman et al., 2001; Dong et al., 2002). Tratamentos com 1-MCP em laranjas não afetaram a perda de massa (Porat et al., 1999), enquanto houve um atraso de perda de massa em abacate (Jeong et al., 2002).

O objetivo deste trabalho foi determinar o efeito do 1-MCP em lima 'Tahiti' visando retardar sua senescência após a colheita e prolongar o seu período de conservação.

\subsection{Material e Métodos}

A colheita da lima 'Tahiti' foi realizada em pomar localizado na fazenda Areião, município de Piracicaba, SP. Os frutos foram transportados para o Laboratório de PósColheita do Departamento de Produção Vegetal da ESALQ/USP. Foram utilizados frutos sadios, colhidos pela manhã e caracterizados segundo as normas de classificação da lima 'Tahiti' e inseridos na classe C1 (CQH/Ceagesp, 2001). Apresentavam inicialmente, uma tonalidade média de $119,7^{\circ}$, para o ângulo de cor $\left(\mathrm{h}^{\circ}\right.$ ) e 25,79 unidades para a intensidade de cor (croma). O teor de sólidos solúveis totais e da acidez total titulável inicial foi de $8,76{ }^{\circ}$ Brix e 6,69 (mg de ácido cítrico anidro/ $100 \mathrm{ml}$ de suco), respectivamente. Os frutos foram submetidos aos tratamentos, pela sua exposição ao gás 1-metilciclopropeno (1-MCP) nas concentrações de $0 ; 0,1 ; 0,5$ e $1,0 \mu \mathrm{L} \mathrm{L}^{-1}$. A aplicação de 1-MCP foi realizada em caixas herméticas, com capacidade para 188,0 
litros, utilizando-se o produto comercial SmartFresh ${ }^{\mathrm{TM}}$, na forma pó molhável, contendo 0,14\% de i.a. de 1-metilciclopropeno. Aos frascos contendo 1MCP, foram adicionados $20 \mathrm{~mL}$ de água destilada aquecida a $50{ }^{\circ} \mathrm{C}$. Após completa dissolução, os frascos foram abertos no interior das câmaras, expondo os frutos ao gás durante $12 \mathrm{~h}$ sob temperatura de $20{ }^{\circ} \mathrm{C}$.

Após esse período, a cera (Sparcitrus) diluída em água, na proporção de 1:3 foi aplicada por imersão dos frutos e a secagem foi realizada em condições ambientais $(65 \%$ UR e $25{ }^{\circ} \mathrm{C}$ ) por $30 \mathrm{~min}$. Os frutos foram armazenados a $9 \pm 1{ }^{\circ} \mathrm{C}$ e $90 \pm 5 \%$ de UR durante 15, 30, 45 e 60 dias. Após cada período de armazenamento, foram determinados os parâmetros: a) coloração da casca: valores de croma $\left(\mathrm{C}^{*}\right)$ e ângulo de cor $\left(\mathrm{h}^{\circ}\right)$, através de colorímetro Minolta Chroma Meter CR-300; b) taxa respiratória $\left(\mathrm{mL} \mathrm{CO}_{2} \mathrm{~kg}^{-}\right.$ ${ }^{1} \mathrm{~h}^{-1}$ ) medida em analisador de gases PBI Dansensor - CheckMate 9900; c) teor de sólidos solúveis totais (SST) expressos em ${ }^{\circ}$ Brix obtido em refratômetro digital; d) acidez total titulável (ATT): neutralização de uma alíquota de $10 \mathrm{~mL}$ de suco, com $\mathrm{NaOH} 0,1 \mathrm{~N}$, sendo os resultados expressos em \% de ácido cítrico anidro; e) relação SST/ATT (ratio); f) teor de vitamina C: neutralização por titulação do ácido ascórbico, em solução de 2,6-dicloro fenol indofenol (DCFI) expressa em mg de ácido ascórbico por $100 \mathrm{~mL}$ de suco (Instituto Adolfo Lutz, 1985); g) \% de perda de massa: percentual entre massa inicial e massa após armazenamento e f) \% de suco: relação percentual entre massa do suco $(\mathrm{g})$ e a massa do fruto.

O delineamento experimental adotado foi inteiramente ao acaso, em esquema fatorial 4 x 5. Os fatores estudados foram: a) concentração de 1-MCP (quatro níveis) e b) tempo de conservação (5 níveis). Foram utilizadas quatro repetições de oito frutos por parcela. Os modelos de regressão linear foram determinados através do programa Sistema de Análise Estatística - SANEST (Zonta \& Machado, 1984).

\subsection{Resultados e Discussão}

De acordo com os quadros de análise da variância (Tabelas 17, 18, 19, 20 e 21) houve significância para a interação do tempo de armazenamento com tratamento 
(PROB $>\mathrm{F}=<0,010$ ) para as variáveis: $\mathrm{C}^{*}, \mathrm{~h}^{\circ}$, SST, ATT, ratio, TR a $25{ }^{\circ} \mathrm{C}$ e PM. Não houve interação significativa para as variáveis: vit. C e \% de suco (Tabelas 19 e 21), respectivamente. As regressões solicitadas para o tempo dentro do tratamento (Tabelas 17A e B; 18A e B, 19A, 20A e B e 21A) apresentaram equações significativas $(\mathrm{PROB}>\mathrm{F}=0,05)$, conforme descritas nas respectivas figuras, devendo ser adotadas por possuir maior coeficiente de determinação.
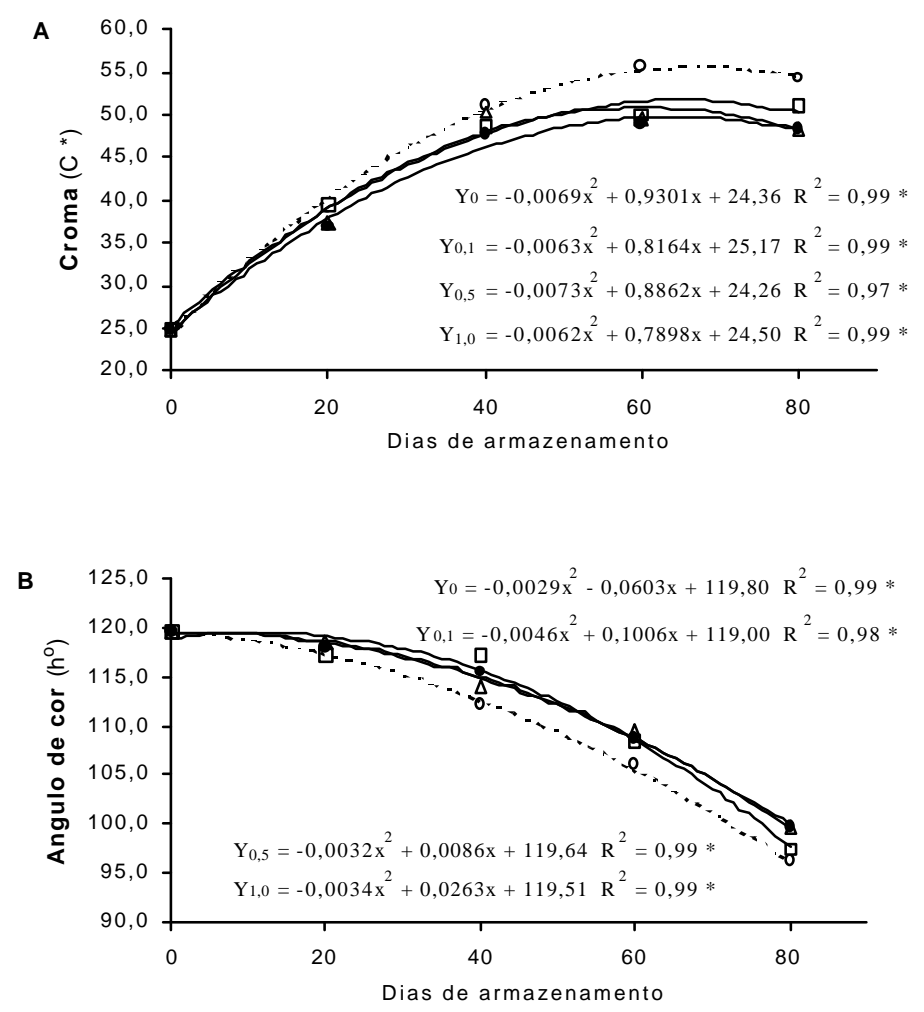

Figura 1 - Modelos de regressão para as variáveis: A) croma $\left(\mathrm{C}^{*}\right)$ e B) ângulo de cor $\left(\mathrm{h}^{\mathrm{o}}\right) \mathrm{em}$ casca de lima ácida 'Tahiti' tratada com $0 \mu \mathrm{L} \mathrm{L}^{-1}(\mathrm{o}), 0,1 \mu \mathrm{L} \mathrm{L}^{-1}\left(\right.$ ), $0,5 \mu \mathrm{L} \mathrm{L}^{-1}(\Delta) \mathrm{e}$ $1,0 \mu \mathrm{L} \mathrm{L}^{-1}(\bullet)$ de 1-MCP, respectivamente

A intensidade de cor $\left(\mathrm{C}^{*}\right)$ na casca da lima 'Tahiti' armazenada sob refrigeração (+ 3 dias a $25{ }^{\circ} \mathrm{C}$ ), evoluiu de forma semelhante, para todos os tratamentos efetuados, até 
aos 20 dias (Figura 1A) situando os frutos na classe C2 conforme a Tabela 1. A partir deste ponto, os frutos que receberam 1-MCP apresentaram menor cromaticidade, em relação aos frutos não tratados.

Do ponto de vista agronômico, verificoutse alteração na classificação dos frutos não tratados aos 40 dias. Isso indica que houve retenção significativa na evolução da cromaticidade dos frutos tratados. A maior retenção na intensidade de cor observada, na casca de lima 'Tahiti', ocorreu na concentração de 1,0 $\mu \mathrm{L} \mathrm{L}^{-1}$ de 1-MCP, aos 60 dias de armazenamento. Essa diferença foi $11,17 \%$ maior, quando comparada ao controle. Os frutos tratados com 1-MCP apresentaram uma classificação C3 aos 60 dias, enquanto os frutos não tratados exibiram uma classe C5 (conforme Tabela 1).
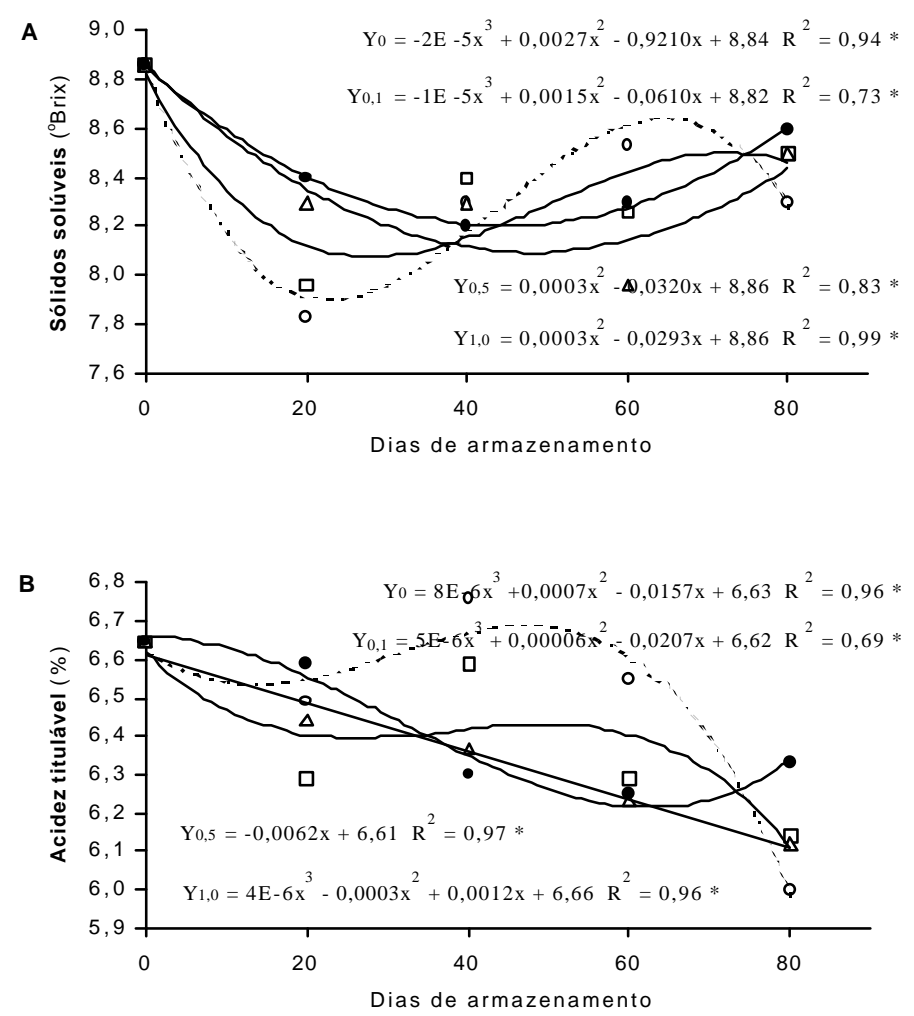
Figura 2 - Modelos de regressão para as variáveis: A) sólidos solúveis (Brix) e B) acidez titulável (\%) em suco de lima ácida 'Tahiti' tratada com $0 \mu \mathrm{L} \mathrm{L}^{-1}(\mathrm{o}), 0,1 \mu \mathrm{L} \mathrm{L}^{-1}$ $\left(\right.$ ) $, 0,5 \mu \mathrm{L} \mathrm{L}^{-1}(\Delta)$ e $1,0 \mu \mathrm{L} \mathrm{L}^{-1}(\bullet)$ de $1-\mathrm{MCP}$, respectivamente

O mesmo se observou para a tonalidade de cor de casca $\left(\mathrm{h}^{\mathrm{o}}\right)$, demonstrado através dos maiores valores obtidos para o ângulo de cor (Figura 1B). Atrasar a mudança de cor de casca em lima 'Tahiti' durante a sua comercialização é fundamental, uma vez que o preço é baseado em sua classificação. Verificourse que o período adequado, para a conservação e comercialização de lima 'Tahiti', tratada com 1-MCP à 0,5 e 1,0 $\mu \mathrm{L} \mathrm{L}^{-1}$, situou-se na faixa de 40 dias, baseando-se tanto na cromaticidade $\left(\mathrm{C}^{*}\right)$, quanto no ângulo de cor, enquanto que para os frutos não tratados, esse período foi de aproximadamente 20 dias.

Diversos autores constataram que 1-MCP aumentou o tempo de conservação, como em morangos ( $\mathrm{Ku}$ et al., 1999) e retardou o amadurecimento em frutos climatéricos como banana (Jiang et al., 1999), maçã (Fan \& Mattheis, 1999), abacate (Kluge et al., 2002b) e pêssego (Kluge \& Jacomino, 2002).

Os sólidos solúveis totais ( ${ }^{\circ}$ Brix) são compostos solúveis em água, importantes na determinação da qualidade da fruta. Também fazem parte dos sólidos solúveis totais, ácidos, vitaminas, aminoácidos e algumas pectinas. Os frutos tratados com 0,5 e 1,0 $\mu \mathrm{L}$ $\mathrm{L}^{-1}$ de 1-MCP mantiveram o teor de sólidos solúveis totais (SST), até aos 40 dias do armazenamento. Os teores de SST normalmente aumentam no transcorrer do processo de maturação da fruta, seja por biossíntese ou pela degradação de polissacarídeos. De acordo com os modelos de regressão solicitados (Figuras 1A e 1B), observou-se que durante o período de maior retenção da cor verde dos frutos de 'Tahiti', as concentrações de 0,5 e 1,0 $\mu \mathrm{L} \mathrm{L}^{-1}$, também apresentaram maior teor de sólidos solúveis (Figura 2A). Encontrou-se também, alto teor de sólidos solúveis em abacaxí (Selvarajah et al., 2001), mamão (Hofman et al., 2001) e maçãs (Fan \& Mattheis, 1999) tratadas com 1-MCP. Entretanto, laranjas, ameixas e mangas não foram afetadas por 1-MCP, no teor de sólidos solúveis (Porat et al., 1999; Hofman et al., 2001; Dong et al., 2002). 
A acidez titulável diminuiu com o tempo de armazenamento (Figura 2B). O efeito de 1-MCP sobre o teor de acidez total titulável mostrou-se variável. Essa variação, também ocorreu para outros cultivares (Blankenship \& Dole, 2003). A lima 'Tahiti' tratada com 1,0 $\mu \mathrm{L} \mathrm{L}^{-1}$ apresentou um decréscimo gradual no teor de acidez titulável total nos primeiros 20 dias de armazenamento, enquanto a lima não tratada manteve sua acidez titulável próxima da inicial.

Porat et al. (1999) relataram que não houve efeito do 1MCP no teor de acidez em laranjas 'Shamouti'. Entretanto, este biorregulador atrasou o declínio no teor de ácido ascórbico em abacaxi (Selvarajah et al., 2001), preveniu a queda de acidez em cenouras (Fan \& Mattheis, 2000b), tomate (Wills \& Ku, 2002) e ameixas (Dong et al., 2002).

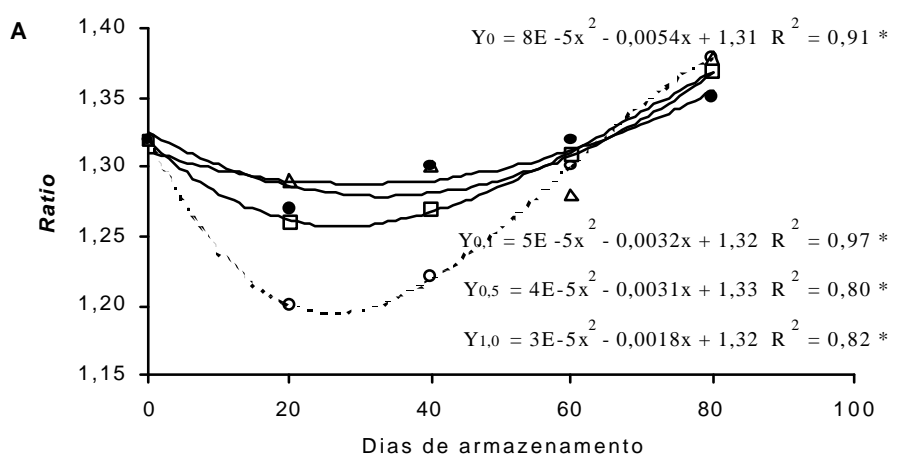

Figura 3 - Modelos de regressão para as variáveis: A) ratio e B) teor de vitamina C, em suco de lima ácida 'Tahiti' tratada com $0 \mu \mathrm{L} \mathrm{L}^{-1}(\mathrm{o}), 0,1 \mu \mathrm{L} \mathrm{L}^{-1}\left(\right.$ ), $0,5 \mu \mathrm{L} \mathrm{L}^{-1}(\Delta)$ e $1,0 \mu \mathrm{L}$ $\mathrm{L}^{-1}(\bullet)$ de 1-MCP, respectivamente

Através da relação entre sólidos solúveis e acidez titulável (ratio), uma menor

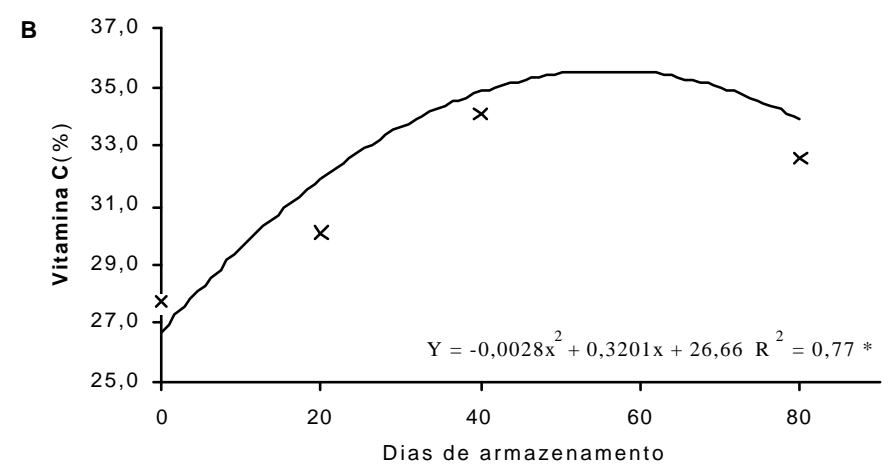


amplitude de variação, para os frutos tratados com 1-MCP em relação ao controle (Figura 3A) foi verificada. A concentração de 0,5 e 1,0 $\mu \mathrm{L} \mathrm{L}^{-1}$ de 1-MCP atuou de forma positiva, apresentando pequena variação do ratio durante 60 dias de armazenamento. $\mathrm{O}$ ratio, no fruto não tratado diferiu significativamente do fruto tratado com 1-MCP, nos primeiros 20 dias, devido à diminuição da quantidade de sólidos solúveis (Figura 2A).

Os tratamentos com 1-MCP, não tiveram efeito significativo no teor de vitamina C. De acordo com o modelo de regressão (Figura 3B), o incremento no teor de vitamina C ocorreu em função do tempo, desde o início do armazenamento até aos 40 dias.
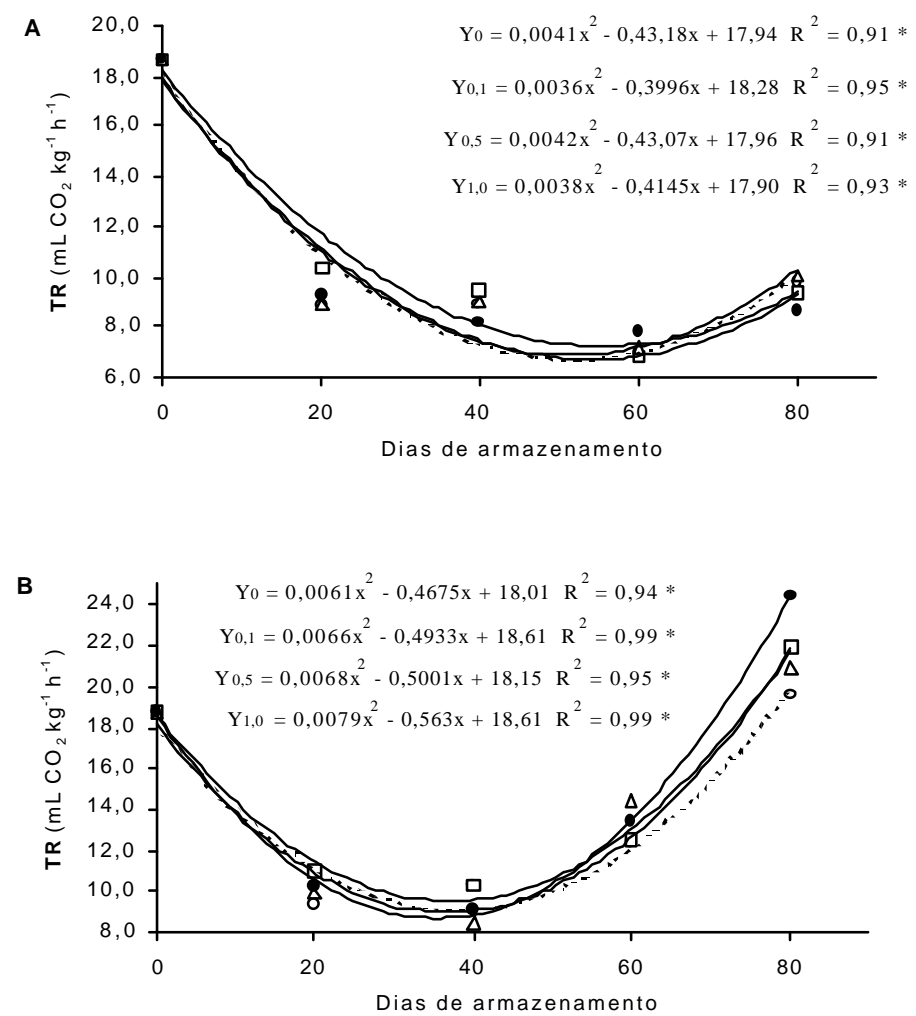

Figura 4 - Modelos de regressão para as variáveis: A) taxa respiratória $\left(\mathrm{mL} \mathrm{CO}_{2} \mathrm{~kg}^{-1} \mathrm{~h}^{-1}\right)$ sob refrigeração e B) taxa respiratória após 3 dias a $25{ }^{\circ} \mathrm{C}$, em lima ácida 'Tahiti' tratada com $0 \mu \mathrm{L} \mathrm{L}^{-1}(\mathrm{o}), 0,1 \mu \mathrm{L} \mathrm{L}^{-1}\left(\right.$ ), $0,5 \mu \mathrm{L} \mathrm{L}^{-1}(\Delta)$ e $1,0 \mu \mathrm{L} \mathrm{L}^{-1}(\bullet)$ de 1-MCP, respectivamente 
$\mathrm{O}$ armazenamento refrigerado tem sido o método mais utilizado para a preservação de frutos após a colheita. Nesse sistema, a diminuição na taxa respiratória visa retardar o processo de senescência. A taxa respiratória (TR) da lima 'Tahiti' foi analisada em duas etapas (Figuras 4A e 4B), sendo a primeira, logo após a saída dos frutos da câmara fria e a outra, após um período de 3 dias a $25{ }^{\circ} \mathrm{C}$. Em ambas etapas, notou-se que a lima 'Tahiti' apresentou o mesmo padrão respiratório, até aos 40 dias.

Após esse período, a TR dos frutos armazenados a $9{ }^{\circ} \mathrm{C}$ continuou abaixo de 8,0 $\mathrm{mL} \mathrm{CO} \mathrm{kg}^{-1} \mathrm{~h}^{-1}$ prolongando-se até aos 60 dias, enquanto que os frutos após 3 dias a 25 ${ }^{\circ} \mathrm{C}$, apresentaram uma elevação da TR a partir dos 40 dias.
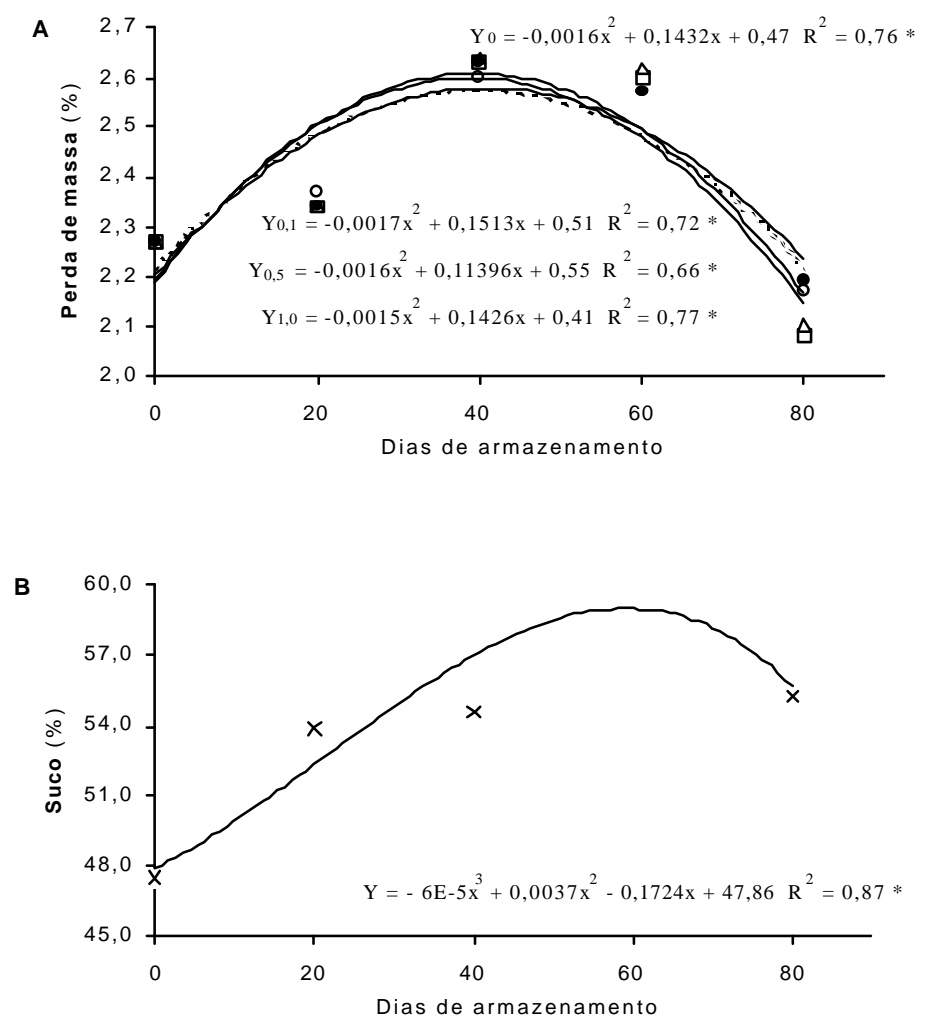

Figura 5 - Modelos de regressão para as variáveis: a) perda de massa (\%) e B) porcentagem de suco em lima ácida 'Tahiti' tratada com $0 \mu \mathrm{L} \mathrm{L}^{-1}(\mathrm{o}), 0,1 \mu \mathrm{L} \mathrm{L}^{-1}\left(\right.$ ), $0,5 \mu \mathrm{L} \mathrm{L}^{-1}(\Delta) \mathrm{e}$ $1,0 \mu \mathrm{L} \mathrm{L}^{-1}(\bullet)$ de 1-MCP, respectivamente 
Isso sugere então, que a diminuição da TR contribuiu para a conservação da lima 'Tahiti' e que após 40 dias de armazenamento e exposição de 3 dias a $25{ }^{\circ} \mathrm{C}$, inicia-se o processo de senescência com mais intensidade, para todos os tratamentos efetuados.

Apesar de significativa, a interação do tempo com o tratamento, notou-se que esta interação foi devida ao tempo de armazenamento, já que não houve significância para o fator tratamento. Entretanto, a perda de massa observada ficou abaixo do limite permitido de 5\% (Figura 5A), para a sua comercialização. Este resultado está de acordo com os encontrados em laranjas 'Shamouti' (Porat et al., 1999). Também não houve variação significativa na quantidade porcentual de suco, para os tratamentos efetuados (Figura 5B).O incremento observado, na porcentagem de suco, de acordo com o modelo de regressão solicitado foi em função do tempo de armazenamento.

\subsection{Conclusões}

De acordo com os resultados obtidos, destacam-se entre os tratamentos efetuados, as concentrações com 0,5 e $1,0 \mu \mathrm{L} \mathrm{L}^{-1}$ de 1-MCP, por prolongarem a vida útil da lima ácida 'Tahiti' em mais de 40 dias de armazenamento refrigerado.

Os frutos tratados apresentam as seguintes características:

a) Menor intensidade de cor de casca.

b) Atraso na mudança de tonalidade de cor.

c) Menor amplitude de variação no ratio. 


\section{EFEITO DE AMINOETOXIVINILGLICINA (AVG) NA CONSERVAÇÃO PÓS-COLHEITA DE LIMA ÁCIDA 'TAHITI'}

\section{Resumo}

A lima ácida 'Tahiti' tem ocupado cada vez mais posição de destaque na citricultura brasileira, pela maior demanda do mercado interno e de exportação, de frutas de qualidade superior. $\mathrm{O}$ seu armazenamento refrigerado permite prolongar o período de conservação e comercialização, entretanto, a perda da coloração verde da casca e, de suas características físico-químicas diminui a qualidade do fruto. O objetivo do presente trabalho foi avaliar a ação do AVG sobre a vida útil pós-colheita da lima ácida 'Tahiti'. Aplicou-se o aminoetoxivinilglicina (AVG) nas concentrações de: 0; 10; 50 e $100 \mathrm{ng} \mathrm{L}$

${ }^{1}$. Os frutos foram armazenados durante 80 dias a $9 \pm 1{ }^{\circ} \mathrm{C}$ e $90 \pm 5 \%$ de UR e avaliados em intervalos de 20 dias. A aplicação de AVG nas concentrações testadas, não retardou as mudanças de coloração na casca de lima 'Tahiti'. A concentração de $100 \mathrm{mg} \mathrm{L}^{-1}$ prolongou a vida útil pós-colheita de lima ácida 'Tahiti', por 40 dias, retardando a degradação de sólidos solúveis e acidez titulável. O tratamento não afetou o teor de vitamina $\mathrm{C}$, a porcentagem de suco e a taxa respiratória dos frutos de lima ácida 'Tahiti'.

Termos para indexação: Citrus latifolia, inibidor de etileno, armazenamento.

\section{Summary}

Due to the increased demand in internal and foreign markets for higher quality fruits, 'Tahiti' lime has more and more occupied an outstanding position in Brazilian citriculture. Its cold storage allows to extend the storage and marketing periods, however, the loss of pell green color and its physical-chemical features affect this lenthening. The AVG at $0 ; 10 ; 50$ and $100 \mathrm{mg} \mathrm{L}^{-1}$ was applied trying to increase the 
shelf-life of 'Tahiti' lime. The fruits were stored during 80 days at $9+1{ }^{\circ} \mathrm{C}$ with $90+5 \%$ of relative humidity, and assessments were made at each 20 days. The AVG application at $100 \mathrm{mg} \mathrm{L}^{-1}$ increased the soluble sólids and tritiable acids for 40 days, keeping an adequate ratio for marketing. Did not delay changes in color intensity and tonality. Such treatments did not affect the respiratory rate, the ascorbic acid concentration, and the percentage of juice in the fruits.

Index terms: Citrus latifolia, ethylene inhibitor, conservation.

\subsection{Introdução}

A lima ácida 'Tahiti' é adquirida pelo consumidor, principalmente em função das características externas, como o tamanho uniforme e a coloração verde escura da casca. A lima 'Tahiti' (Citrus latifolia, Tanaka) é classificada como sendo um fruto não climatérico, por apresentar baixa taxa respiratória e não produzir etileno auto-catalítico. Durante a sua comercialização, o desejável é a predominância da coloração verde da casca. Os pigmentos carotenóides são responsáveis pela coloração da casca e ocorrem nos cromoplastos das células do flavedo. Nas frutas cítricas imaturas predomina a cor verde e durante a sua maturação, ocorre a degradação das clorofilas, começando a predominar os pigmentos amarelos da casca. Estes continuam a aumentar, mesmo após o completo desaparecimento da clorofila (Chitarra, 1979; Baldwin, 1994). Além da coloração da casca, também é importante a textura ou firmeza da casca dos frutos.

A conservação da lima 'Tahiti', sob baixa temperatura, prolonga seu período de conservação. Entretanto, a perda da coloração da casca é fator determinante na decisão de compra pelo consumidor. O croma define a intensidade da cor, assumindo valores próximos a zero para cores neutras (cinzas) e ao redor de 60 para cores vívidas. Portanto, maiores valores de croma representam maior intensidade da cor amarela. O ângulo de cor $\left(\mathrm{h}^{\mathrm{o}}\right)$ define a tonalidade da cor. Em lima ácida 'Tahiti', o 19 mais próximo de $180\left(^{\circ}\right)$ 
representa frutos mais verdes e à medida que tende a $90\left(^{\circ}\right)$, os frutos tornam-se mais amarelos e maturos (McGuire, 1992).

Todo cultivar apresenta um limite de armazenamento que, quando atingido, leva a fruta a senescência e degradação. As condições ambientais recomendadas para a conservação refrigerada de lima 'Tahiti' são com temperaturas entre $10-12{ }^{\circ} \mathrm{C}$ e umidade relativa (UR) entre 85 e 95\%. Temperaturas abaixo de $8{ }^{\circ} \mathrm{C}$, por longos períodos induzem o aparecimento de injúrias causadas pelo frio (Chitarra \& Chitarra, 1990). Tratamentos com biorreguladores têm sido utilizados em frutos cítricos e outros, com o objetivo de conservar a sua aparência externa desejável e manter suas características físico-quimicas.

O AVG (aminoetoxivinilglicina) inibe a conversão enzimática de SAM (S-adenosilmetionina) para ACC (ácido 1-carboxílico-1-aminociclopropano), assim como o cobalto e o ácido ascórbico são inibidores da conversão subseqüente do ACC para etileno (Wenzel et al., 1995). O AVG é largamente utilizado na indústria da maçã, prevenindo a produção interna de etileno, não tendo efeito contra o etileno externo. Trabalhos recentes relataram a utilização de AVG em pós-colheita para maçã (Kang \& Byun, 2002; Brackmann et al., 2001), pêssego (Bregoli et al., 2001; Garner et al., 2001), pera (Munhoz \& Luis, 1998) e uva (Hu et al., 1999). Aplicação de AVG na concentração de $88 \mathrm{mg} \mathrm{L}^{-1}$, em pré-colheita não afetou a coloração da casca e o teor de sólidos solúveis em maçã 'Delicious' (Byers, 1997; Greene, 1997). Também não se observou mudança significativa no nível de SST e ATT de pêssegos 'Snow King' tratados por imersão com $50 \mathrm{mg} \mathrm{L}^{-1}$ de AVG (Garner et al., 2001). Utilizando-se a mistura de GA 100-150 mg L ${ }^{-1}$ e AVG 100-150 mg L ${ }^{-1}$ em pré-colheita, Ju et al., (1999) prolongaram por quatro semanas, a comercialização de pêssegos 'Feicheng' com a inibição da maturação dos frutos na planta. Um atraso no amadurecimento de pêras 'Packham's Triumph' foi obtido com AVG aplicado em pré-colheita (Munhoz \& Luis, 1998). O teor de sólidos solúveis totais não foi afetado após armazenamento, em frutos de melão tratados com AVG (Shellie, 1999) 
O objetivo deste trabalho foi determinar o efeito do aminoetoxivinilglicina em lima ácida 'Tahiti' visando retardar sua senescência após a colheita e prolongar o seu período de conservação.

\subsection{Material e Métodos}

A colheita da lima 'Tahiti' foi realizada em pomar localizado na fazenda Areião, município de Piracicaba, SP. Os frutos foram transportados para o Laboratório de PósColheita do Departamento de Produção Vegetal da ESALQ/USP. Foram utilizados frutos sadios, colhidos pela manhã e caracterizados segundo as normas de classificação da lima 'Tahiti' e inseridos na classe C1 (CQH/Ceagesp, 2001). Apresentavam inicialmente, uma tonalidade média de $119,7^{\circ}$, para o ângulo de cor $\left(\mathrm{h}^{\circ}\right.$ ) e 25,79 unidades para a intensidade de cor (croma). O teor de sólidos solúveis totais e da acidez total titulável inicial foi de 8,76 ${ }^{\circ}$ Brix e 6,69 (mg de ácido cítrico anidro/ $100 \mathrm{ml}$ de suco), respectivamente. Os frutos foram imersos em soluções contendo as devidas concentrações de AVG, durante um minuto.

Após esse período, a cera (Sparcitrus) diluída em água, na proporção de 1:3 foi aplicada por imersão dos frutos e a secagem foi realizada em condições ambientais $(65 \%$ UR e $25{ }^{\circ} \mathrm{C}$ ) por $30 \mathrm{~min}$. Os frutos foram armazenados a $9 \pm 1{ }^{\circ} \mathrm{C}$ e $90 \pm 5 \%$ de UR durante 15, 30, 45 e 60 dias. Após cada período de armazenamento, foram determinados os parâmetros: a) coloração da casca: valores de croma $\left(\mathrm{C}^{*}\right)$ e ângulo de cor $\left(\mathrm{h}^{\mathrm{o}}\right)$, através de colorímetro Minolta Chroma Meter CR-300; b) taxa respiratória ( $\mathrm{mL} \mathrm{CO}_{2} \mathrm{~kg}^{-}$ ${ }^{1} \mathrm{~h}^{-1}$ ) medida em analisador de gases PBI Dansensor - CheckMate 9900; c) teor de sólidos solúveis totais (SST) expressos em ${ }^{\circ}$ Brix obtido em refratômetro digital; d) acidez total titulável (ATT): neutralização de uma alíquota de $10 \mathrm{~mL}$ de suco, com $\mathrm{NaOH} 0,1 \mathrm{~N}$, sendo os resultados expressos em \% de ácido cítrico anidro; e) relação SST/ATT (ratio); f) teor de vitamina C: neutralização por titulação do ácido ascórbico, em solução de 2,6-dicloro fenol indofenol (DCFI) expressa em mg de ácido ascórbico por $100 \mathrm{~mL}$ de suco (Instituto Adolfo Lutz, 1985); g) \% de perda de massa: percentual 
entre massa inicial e massa após armazenamento e f) \% de suco: relação percentual entre massa do suco $(\mathrm{g})$ e a massa do fruto.

O delineamento experimental adotado foi inteiramente ao acaso, em esquema fatorial 4 x 5. Os fatores estudados foram: a) concentração de AVG (quatro níveis) e b) tempo de conservação (5 níveis). Foram utilizadas três repetições de oito frutos por parcela. Os modelos de regressão linear foram determinados através do programa Sistema de Análise Estatística - SANEST (Zonta \& Machado, 1984).

\subsection{Resultados e Discussão}

De acordo com os quadros de análise da variância (Tabelas 22, 23, 24 e 25), a interação do tempo de armazenamento com tratamento, apresentoutse significativa (PROB $>\mathrm{F}=<0,010)$ para as variáveis: $\mathrm{C}^{*}, \mathrm{~h}^{\circ}, \mathrm{SST}$, ATT, ratio e TR. Observourse na Figura 1A, que a pigmentação (croma) da casca mostrou diferença significativa, a partir dos 20 dias, notando-se a maior amplitude, aos 60 dias, em relação aos frutos não tratados.

Todos os frutos tratados com AVG mantiveram uma coloração de casca menos intensa, situando-os na classe $\mathrm{C} 3$, enquanto os frutos não tratados foram classificados como C3 (CQH/Ceagesp, 2001b), sendo também válida essa classificação de acordo com a Tabela 1.

A inibição da ação do etileno endógeno, nas concentrações de AVG utilizadas, não foi suficiente para retardar mudanças na coloração da casca, durante $\mathrm{o}$ armazenamento, conforme os resultados obtidos para $\mathrm{h}^{\circ}$, apresentados na figura $1 \mathrm{~B}$. 

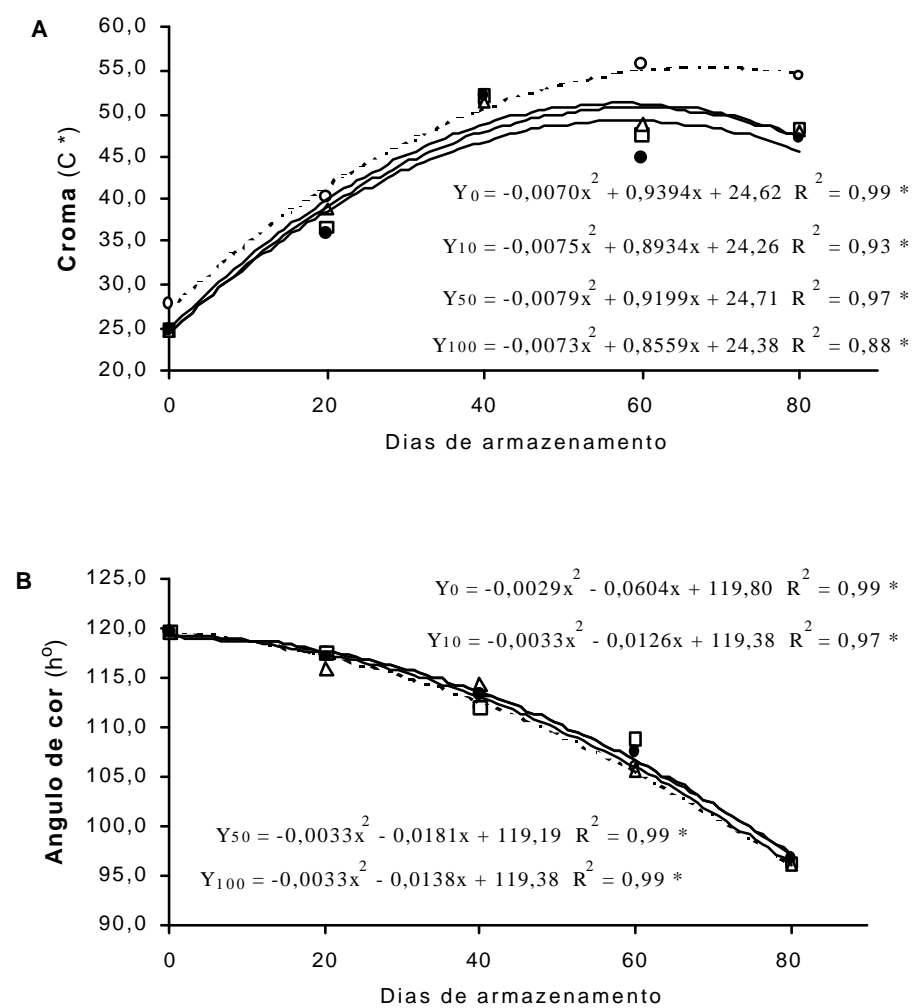

Figura 1 - Modelos de regressão para: A) Croma $\left(C^{*}\right)$ e B) ângulo de cor $\left(h^{\circ}\right)$ em lima 'Tahiti', após tratamentos com $0 \mathrm{mg} \mathrm{L}^{-1}(\mathrm{o}) ; 10 \mathrm{mg} \mathrm{L}^{-1}\left(\right.$ ); $50 \mathrm{mg} \mathrm{L}^{-1}(\Delta)$ e $100 \mathrm{mg} \mathrm{L}^{-1}(\bullet)$ de AVG e armazenamento a $9{ }^{\circ} \mathrm{C}\left(+3\right.$ dias a $\left.25^{\circ} \mathrm{C}\right)$

Aplicação de AVG na concentração de $88 \mathrm{mg} \mathrm{L}^{-1}$, em pré-colheita não afetou a coloração da casca e o teor de sólidos solúveis em maçã 'Delicious' (Byers, 1997; Greene, 1997). Utilizando-se a mistura de GA - 150 mg L-1 e AVG 100-150 mg L-1 em pré-colheita, Ju et al. (1999) prolongaram por quatro semanas, a comercialização de pêssegos 'Feicheng' com a inibição da maturação dos frutos na planta.

Os frutos tratados com AVG apresentaram teor de SST maior em relação ao controle, até aos 40 dias do armazenamento refrigerado. Todas as concentrações com AVG proporcionaram um acúmulo de sólidos solúveis (Figura 2A). Verificou-se um declínio no nível de sólidos solúveis, nos frutos não tratados, nos primeiros 20 dias. 

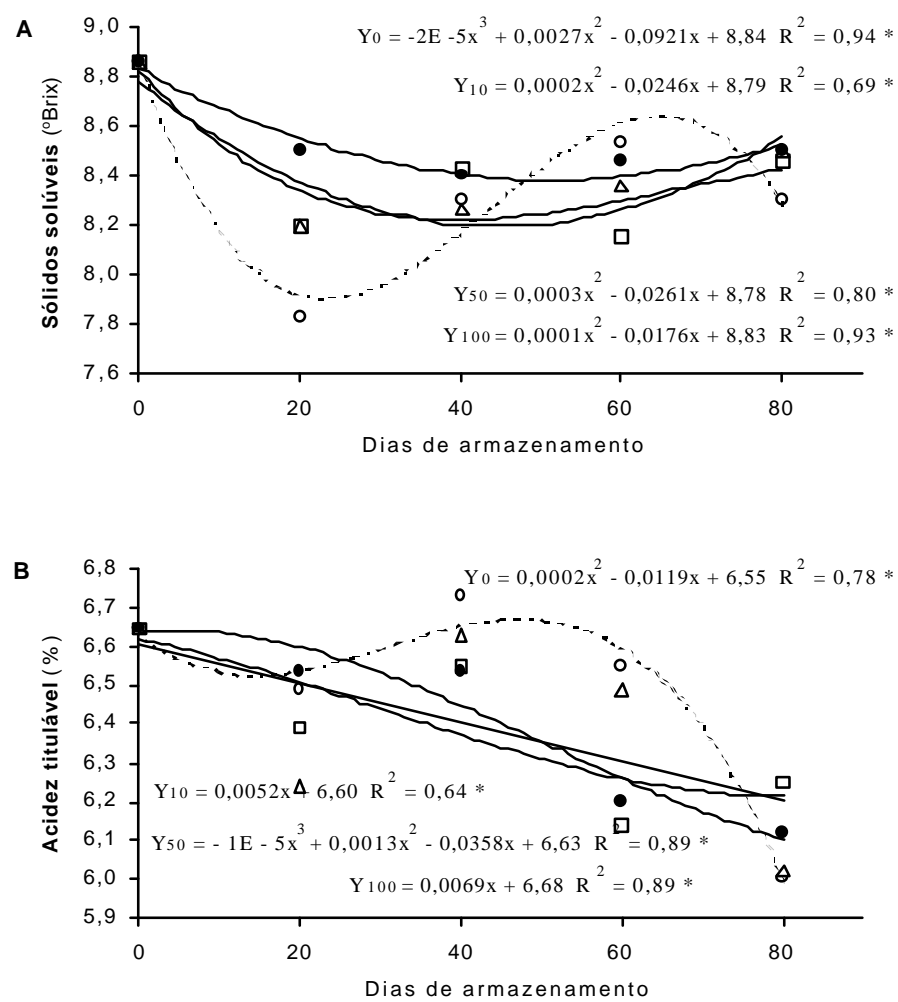

Figura 2 - Modelos de regressão: A) teor de sólidos solúveis totais ( ${ }^{\circ}$ Brix) e B) acidez total titulável (ATT) em lima 'Tahiti' após tratamentos com $0 \mathrm{mg} \mathrm{L}^{-1}$ (o); $10 \mathrm{mg} \mathrm{L}^{-1}$ ( ); 50 $\mathrm{mgL}^{-1}(\Delta)$ e $100 \mathrm{mg} \mathrm{L}^{-1}(\bullet)$ de AVG e armazenamento a $9^{\circ} \mathrm{C}\left(+3\right.$ dias a $\left.25^{\circ} \mathrm{C}\right)$

A aplicação de AVG com $100 \mathrm{mg} \mathrm{L}^{-1}$ apresentou o maior nível de sólidos solúveis, até aos 60 dias de armazenamento. Entretanto, não se observou mudança significativa no nível de SST e ATT de pêssegos 'Snow King' tratados por imersão com $50 \mathrm{mg} \mathrm{L}^{-1}$ de AVG (Garner et al., 2001). Um atraso no amadurecimento de pêras 'Packham's Triumph' foi obtido com AVG aplicado em pré-colheita (Munhoz \& Luis, 
1998), sendo que o teor de sólidos solúveis totais não foi afetado após armazenamento, em frutos de melão tratados com AVG (Shellie, 1999).
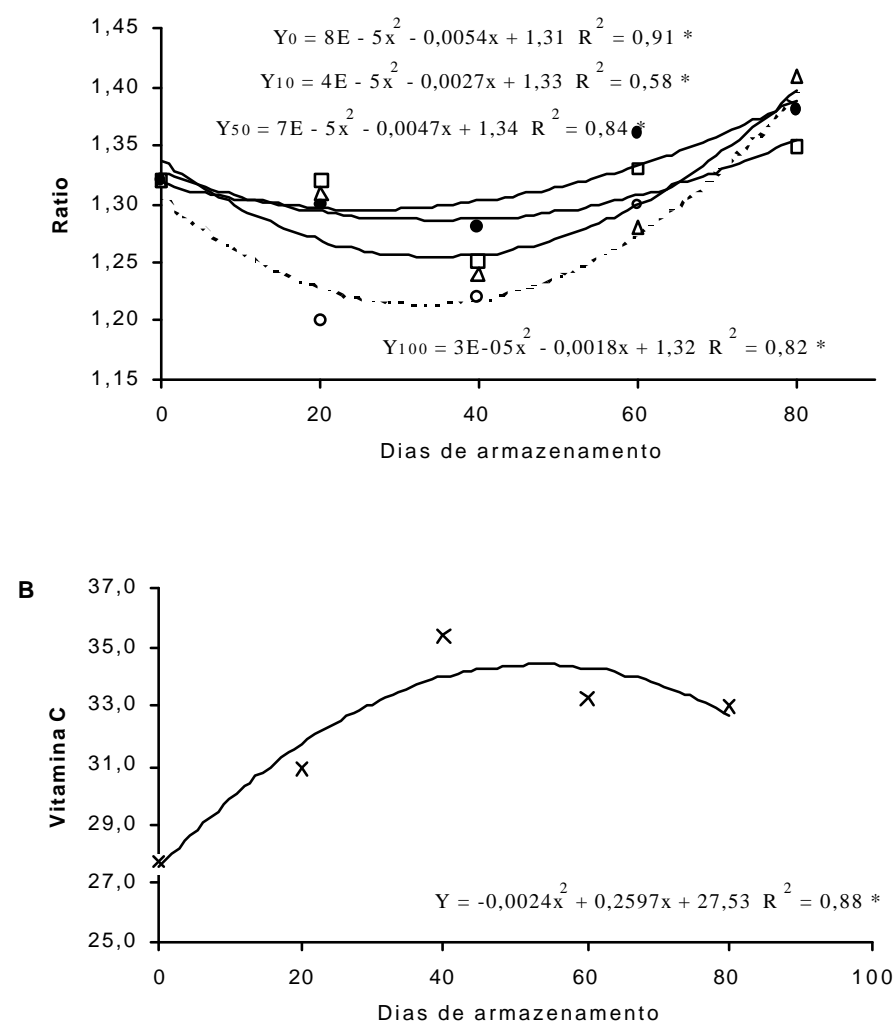

Figura 3 - Modelos de regressão: A) Ratio (relação SST/ATT) e B) teor de vitamina C (expresso em $\mathrm{mg}$ ácido ascórbico/100 $\mathrm{ml}$ de suco) em lima 'Tahiti', após tratamentos com $0 \mathrm{mg}$ $\mathrm{L}^{-1}(\mathrm{o}) ; 10 \mathrm{mg} \mathrm{L}^{-1}$ ( ); $50 \mathrm{mg} \mathrm{L}^{-1}(\Delta)$ e $100 \mathrm{mg} \mathrm{L}^{-1}(\bullet)$ de AVG e armazenamento a 9 ${ }^{\circ} \mathrm{C}\left(+3\right.$ dias a $\left.25^{\circ} \mathrm{C}\right)$

Com relação à acidez total titulável, houve alterações significativas para os tratamentos com AVG (Figura 2B). Os frutos tratados com $100 \mathrm{mg} \mathrm{L}^{-1}$ de AVG apresentaram um nível maior de ATT, até aos 40 dias, com relação aos não tratados. Kang \& Byun (2002) conseguiram manter elevado, o nível de acidez titulável por 60 dias com $150 \mathrm{mg} \mathrm{L}^{-1}$ de AVG em maçã 'Tsugaru'. 

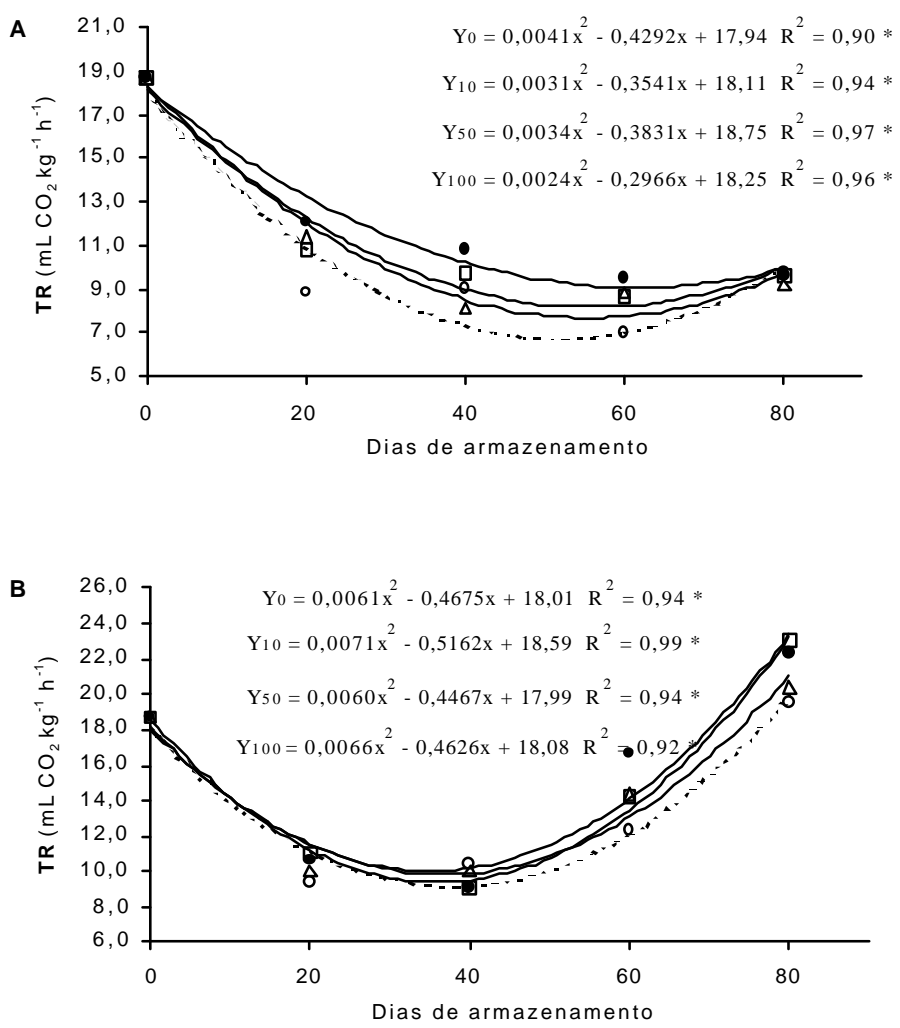

Figura 4 - Modelos de regressão para a variável taxa respiratória $\left(\mathrm{mL} \mathrm{CO}_{2} \mathrm{~kg}^{-1} \mathrm{~h}^{-1}\right)$ : A) TR a $9{ }^{\circ} \mathrm{C}$ e B) TR a $25{ }^{\circ} \mathrm{C}$, em lima 'Tahiti' após tratamentos com $0 \mathrm{mg} \mathrm{L}^{-1}$ (o); $10 \mathrm{mg} \mathrm{L}^{-1}$ ( ); $50 \mathrm{mg} \mathrm{L}^{-1}(\Delta)$ e $100 \mathrm{mg} \mathrm{L}^{-1}(\bullet)$ de AVG

Um balanço adequado da relação (ratio) entre sólidos solúveis e acidez titulável é necessário, para se obter frutos com alta qualidade. O ratio é muito usado para avaliar frutas cítricas (Ting et al., 1986). Durante o período de 60 dias, a relação SST/ATT dos frutos tratados com AVG, apresentou diferenças significativas em relação ao controle (Figura 3A). 

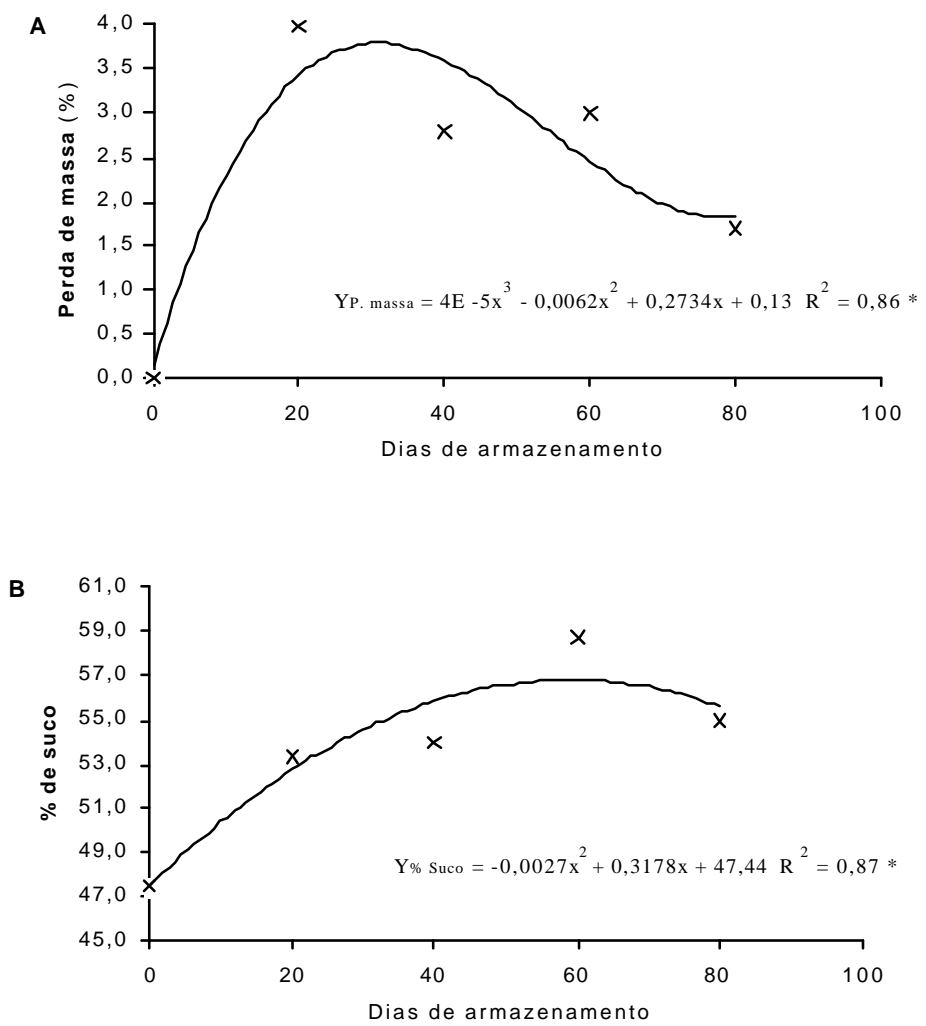

Figura 5 - Modelos de regressão: A) perda de massa (\%) e B) quantidade de suco (\%), em lima 'Tahiti', após tratamentos com $0 \mathrm{mg} \mathrm{L}^{-1}(\mathrm{o}) ; 10 \mathrm{mg} \mathrm{L}^{-1}\left(\right.$ ); $50 \mathrm{mg} \mathrm{L}^{-1}(\Delta)$ e $100 \mathrm{mg} \mathrm{L}$ ${ }^{1}(\bullet)$ de AVG e armazenamento a $9{ }^{\circ} \mathrm{C}\left(+3\right.$ dias a $\left.25^{\circ} \mathrm{C}\right)$

A aplicação de AVG não afetou o teor de vitamina C. Notourse que o nível de vitamina $\mathrm{C}$ aumentou até aos 40 dias, permanecendo estável até aos 60 dias (Figura 3B).

A respiração por ser um processo oxidativo ou degradativo, é o principal indicador da taxa metabólica e o seu controle, regula o potencial do produto para armazenamento (Wills et al., 1981).

Uma diminuição significativa na taxa respiratória, entre os frutos tratados e não tratados foi observada a partir de 20 dias, sob refrigeração (Figura 4A), entretanto, o AVG não afetou a taxa respiratória em maçãs (Kang \& Byun, 2002). Isso 
provavelmente, explicaria a elevação no teor da acidez titulável observada nos frutos não tratados (Figura 2B).

Não houve efeito significativo para os tratamentos com relação às variáveis, perda de massa e quantidade de suco. Os tratamentos efetuados não afetaram a perda de massa e também a quantidade de suco (Figura 5A e B). O modelo de regressão para o tempo de armazenamento indica que a maior quantidade de suco ocorreu no período de 40 dias (Figura 5B).

\subsection{Conclusões}

De acordo com os resultados obtidos, conclui-se que:

a) A concentração de $100 \mathrm{mg} \mathrm{L}^{-1}$ de $\mathrm{AVG}$, diminui o consumo de sólidos solúveis e a acidez titulável, durante 40 dias de armazenamento.

b) O AVG não afeta a taxa respiratória dos frutos após 3 dias a $25{ }^{\circ} \mathrm{C}$ e o teor de vitamina $\mathrm{C}$. 


\section{EFEITO DO GA3 E SUA COMBINAÇÃO COM 1-MCP E AVG, NA QUALIDADE PÓS-COLHEITA DA LIMA ÁCIDA 'TAHITI'}

\section{Resumo}

A pesquisa pós-colheita tem evoluído, principalmente com relação à lima ácida 'Tahiti', devido ao aumento na produção e na demanda, aos estímulos oferecidos às exportações e à necessidade de abastecimento regular do mercado. A diferença de preço obtida entre as diferentes classes pode variar em até $46 \%$, em média. A refrigeração tem sido utilizada para conservação dos frutos após a colheita. A aplicação de biorreguladores em pós-colheita tem demonstrado bom potencial para aumentar a longevidade dos frutos, retardando os processos envolvidos na maturação e senescência. O objetivo deste trabalho foi verificar o efeito do $\mathrm{GA}_{3}$ e de sua combinação com 1-MCP e com o AVG, na manutenção da coloração da casca e também das características físicoquímicas da lima ácida 'Tahiti'. Os tratamentos efetuados foram: $\mathrm{GA}_{3} 20 \mathrm{mg} \mathrm{L} \mathrm{L}^{-1}$; 1-

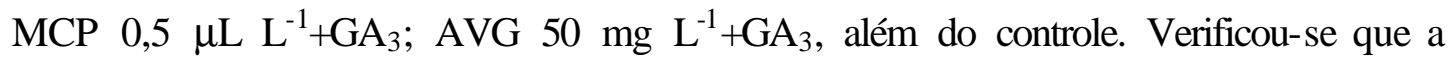
aplicação de 1-MCP+GA 3 proporcionou uma melhor classificação quanto à cor de casca, manteve o nível de vitamina $\mathrm{C}$, não afetou a taxa respiratória e a quantidade de suco.

Termos para indexação: Citrus latifolia, biorregulador, armazenamento.

\section{Summary}

Post harvest research in 'Tahiti' lime has evolved, mainly, due to factors as: increased production and demand, incentive to exportation and the need of regular 
market offer. The difference in price among the different classes can vary even $46 \%$, in average. Cold has been used in fruit post harvest conservation, however, in some cases, the application of bioregulators can be useful in delaying maturation and senescence processes. Identifying the effect of $\mathrm{GA}_{3}$ and its combinations with 1-MCP and AVG, respectively, for the maintenance of 'Tahiti' lime peel color and physic-chemical characteristics, was the aim of this research. The following treatments were accomplished: $\mathrm{GA}_{3}$ at $20 \mathrm{mg} \mathrm{L}^{-1}$; $1-\mathrm{MCP}+\mathrm{GA}_{3}\left(0.5 \mu \mathrm{L} \mathrm{L}^{-1}+20 \mathrm{mg} \mathrm{L}^{-1}\right) ; \mathrm{AVG}+\mathrm{GA}_{3}$ $\left(50 \mathrm{mg} \mathrm{L^{-1 }}+20 \mathrm{mg} \mathrm{L}^{-1}\right.$ ) and the control. The application of 1-MCP $+\mathrm{GA}_{3}$ provided a better pattern for peel color, the level of $\mathrm{C}$ vitamin was kept high and there was no effect on the respiratory rate and on the juice content.

Index terms: Citrus latifolia, ethylene inhibitor, conservation.

\subsection{Introdução}

Os frutos em geral são adquiridos pelo consumidor, através de características externas, como tamanho e coloração brilhante da casca. Uma maior intensidade de coloração $\left(C^{*}\right)$ em casca de frutos é desejável, uma vez que, realça a sua aparência, um atributo importante durante a comercialização. O croma define a intensidade da cor, assumindo valores próximos a zero para cores neutras (cinzas) e ao redor de 60 para cores vívidas e valores de $\mathrm{h}{ }^{\circ}$ ) mais próximos de $180^{\circ}$ representam frutos mais verdes, à medida que tendem a $90^{\circ}$, tornam-se mais amarelos e maduros (Mc Guire, 1992). A lima 'Tahiti' (Citrus latifolia Tanaka) é classificada como sendo um fruto não climatérico por apresentar baixa taxa respiratória e ausência da produção autocatalítica de etileno. A manutenção da cor da casca é desejável, durante sua vida útil pós-colheita, entretanto, os processos de degradação de clorofila e síntese de carotenóides continuam a ocorrer, mesmo durante o seu armazenamento. Os pigmentos carotenóides são responsáveis pela coloração da casca e ocorrem nos cromoplastos das células do flavedo. Na lima 'Tahiti' predomina a cor verde e durante o seu amadurecimento, ocorre a degradação das clorofilas, e o aumento dos pigmentos amarelos da casca, mesmo após o completo desaparecimento da clorofila (Chitarra, 1979; Baldwin, 1994). 
As condições ambientes para a conservação refrigerada da lima 'Tahiti' são temperatura entre $10-12{ }^{\circ} \mathrm{C}$ e umidade relativa (UR) entre 85 e 95\%. Nessas condições, os frutos podem ser armazenados por 4 a 8 semanas, como recomendam Ismail \& Wilhite (1991). Tratamentos com biorreguladores têm sido utilizados, com o objetivo de manter a aparência externa e também suas características físico-quimicas.

A giberelina é um hormônio relacionado a juvenilidade (Dilley, 1969). Desta forma, a sua aplicação retarda processos ligados à maturação e a senescência, incluindo a degradação da clorofila (Agusti et al., 1988; Schechter et al., 1989). O ácido giberélico é muito usado para retardar mudanças na coloração de casca de lima ácida 'Tahiti' (Barros et al., 1991; Silva \& Donadio, 1997; Spósito et al., 2000). O uso de giberelinas tem-se limitado a aplicações em pré-colheita para laranjas (Goldschmidt et al., 1977; Davies et al, 1997; Damián \& Monter, 1999) e também para tangerinas e híbridos (Garcia et al., 1986; Agusti et al., 1988; El-Otmani \& Coggins, 1991; Garcia et al., 1992; Pozo et al., 2000).

O 1-MCP (1-metilciclopropeno) é um composto gasoso e tem demonstrado ser um eficiente inibidor da ação de etileno, devido ao fato de se ligar ao sítio receptor de etileno, atuando como antagonista. O 1-MCP apresenta grande potencial de uso comercial, para o controle da maturação de frutas e hortaliças e da senescência em flores (Sisler \& Serek, 1997). Embora os citros apresentem apenas um sistema um de produção de etileno (Vendrell \& Palomer, 1997), isso não significa que não ocorre interferência do etileno sobre a maturação do fruto. Goldschmidt (1997), considerou que o etileno, mesmo em baixas concentrações em frutos não climatéricos, relaciona-se a eventos ligados à maturação, como a degradação de clorofilas da casca. Constatourse que 1MCP aumentou o tempo de conservação de morangos (Ku et al., 1999) e retardou o amadurecimento em frutos climatéricos como banana (Jiang et al., 1999), maçã (Fan \& Mattheis, 1999), abacate (Kluge et al., 2002) e pêssego (Kluge \& Jacomino, 2002). Geralmente, 1-MCP reduz ou atrasa o início da elevação da taxa respiratória, como encontrado em morango (Tian et al., 2000). Entretanto, o 1-MCP não teve efeito na taxa respiratória em nectarinas (Dong et al., 2001) e damasco (Dong et al., 2002). A taxa 
respiratória em brocoli foi inibida por 1-MCP na faixa de $0-1 \mu \mathrm{L} \mathrm{L}^{-1}$ (Fan \& Mattheis, 2000 a).

O efeito de 1-MCP sobre o teor de acidez total titulável é variável de acordo com a cultura. O 1-MCP atrasou o declínio no teor de ácido ascórbico em abacaxi (Selvarajah et al., 2001), preveniu a queda de acidez em cenouras (Fan \& Mattheis, 2000b), tomate (Wills \& Ku, 2002) e ameixas (Dong et al., 2002). O 1-MCP não afetou o teor de acidez em laranjas 'Shamouti' (Porat et al., 1999). Encontrou-se alto teor de sólidos solúveis em abacaxí (Selvarajah et al., 2001), mamão (Hofman et al., 2001) e maçãs (Fan \& Mattheis, 1999) tratadas com 1-MCP. Entretanto, laranjas, ameixas e mangas não foram afetadas por 1-MCP, no teor de sólidos solúveis (Porat et al., 1999; Hofman et al., 2001; Dong et al., 2002). Tratamentos com 1-MCP em laranjas não afetaram a perda de massa (Porat et al., 1999), enquanto houve um atraso de perda de massa em abacate (Jeong et al., 2002).

O AVG (aminoetoxivinilglicina) inibe a conversão enzimática de SAM (Sadenosilmetionina) para ACC (ácido 1-carboxílico-1-aminociclopropano), sendo o cobalto e outros radicais livres, como o ácido ascórbico, inibidores da conversão subseqüente de ACC para etileno (Wenzel et al., 1995). O AVG é largamente utilizado na indústria da maçã, prevenindo a produção interna de etileno, não tendo efeito contra o etileno externo. Aplicação de AVG $88 \mathrm{mg} \mathrm{L}^{-1}$ em pré-colheita não afetou a coloração da casca e o teor de sólidos solúveis em maçã 'Delicious' (Byers, 1997; Greene, 1997). Utilizando-se a mistura de GA 100-150 mg L-1 e AVG 100-150 mg L-1 em pré-colheita, Ju et al., (1999) prolongaram por quatro semanas, a comercialização de pêssegos 'Feicheng' com a inibição da maturação dos frutos na planta. Um atraso no amadurecimento de pêras 'Packham's Triumph' foi obtido com AVG aplicado em précolheita (Munhoz \& Luis, 1998).

O objetivo deste trabalho foi determinar os efeitos dos biorreguladores 1MCP e AVG combinados com ácido giberélico, na pós-colheita da lima ácida 'Tahiti'. Sua aplicação em pós-colheita visou retardar a maturação e senescência da lima 'Tahiti'. 


\subsection{Material e Métodos}

Frutos de lima 'Tahiti'colhidos em pomar localizado na fazenda Areião, município de Piracicaba, SP, foram transportados para o Laboratório de Pós-Colheita do Departamento de Produção Vegetal da ESALQ/USP. Os frutos de lima 'Tahiti' apresentavam inicialmente, uma tonalidade média de $119,7^{\circ}$, caracterizando o ângulo de cor $\left(\mathrm{h}^{\circ}\right)$ e 25,79 unidades para a intensidade de cor (Croma). O teor de sólidos solúveis totais e da acidez total titulável inicial foi de 8,76 ${ }^{\circ}$ Brix e 6,69 (mg de ácido cítrico anidro/ $100 \mathrm{ml}$ de suco), respectivamente, sendo classificados como $\mathrm{C} 1$ (CQH/Ceagesp, 2001b). Constatourse um teor de 27,71 mg de ácido ascórbico por $100 \mathrm{ml}$ de suco. A quantidade de suco apresentada foi de 47,46\%. A taxa respiratória dos frutos de lima ácida 'Tahiti', inicial foi de $18,74 \mathrm{~mL} \mathrm{CO} \mathrm{kg}^{-1} \mathrm{~h}^{-1}$. Após a caracterização, os frutos foram submetidos aos tratamentos: $\mathrm{GA}_{3} 20 \mathrm{mg} \mathrm{L}^{-1}$; 1-MCP $0,5 \mu \mathrm{L} \mathrm{L}^{-1}+\mathrm{GA}_{3} 20 \mathrm{mg} \mathrm{L}^{-1}$, AVG $50 \mathrm{mg} \mathrm{L}^{-1}+\mathrm{GA}_{3} 20 \mathrm{mg} \mathrm{L}^{-1}$, além do controle.

O tratamento com 1-MCP constou da exposição dos frutos ao gás 1metilciclopropeno (1-MCP) em caixas herméticas, com capacidade para 188,0 litros, utilizando-se o produto comercial SmartFresh ${ }^{\mathrm{TM}}$, na forma pó molhável, contendo $0,14 \%$ do i.a. de 1-metilciclopropeno. Aos frascos contendo 1-MCP, adicionou-se $20 \mathrm{~mL}$ de água destilada aquecida a $50{ }^{\circ} \mathrm{C}$ e após completa dissolução, os mesmos foram abertos no interior das câmaras, expondo os frutos ao gás durante $12 \mathrm{~h}$ sob temperatura a $20{ }^{\circ} \mathrm{C}$. Os frutos tratados com AVG e GA foram imersos em soluções com as devidas concentrações, por um minuto.

Logo após os tratamentos com 1-MCP e AVG, os frutos foram imersos em outra solução contendo $20 \mathrm{mg} \mathrm{L}^{-1}$ de GA, por um minuto. Após os tratamentos, aplicou-se cera (Sparcitrus) diluída em água na proporção de 1:3 e a secagem foi efetuada em condições ambiente $\left(65 \%\right.$ UR e $\left.25{ }^{\circ} \mathrm{C}\right)$ por 30 minutos. Os frutos foram armazenados a 9 $\pm 1{ }^{\circ} \mathrm{C}$ e $90 \pm 5 \%$ de UR durante $20,40,60$ e 80 dias. Após cada período de armazenamento (+ 3 dias a $25^{\circ} \mathrm{C}$ ), determinaram-se os parâmetros: a) coloração da casca: valores de croma $\left(\mathrm{C}^{*}\right)$ e ângulo de cor $\left(\mathrm{h}^{\mathrm{o}}\right)$, através de colorímetro Minolta Chroma Meter CR-300; b) taxa respiratória $\left(\mathrm{mL} \mathrm{CO}_{2} \mathrm{~kg}^{-1} \mathrm{~h}^{-1}\right)$ medida em analisador de gases $\left(\mathrm{CO}_{2}\right.$ e $\left.\mathrm{O}_{2}\right)$; c) teor de sólidos solúveis totais (SST) expressos em ${ }^{\circ}$ Brix obtido em 
refratômetro digital; d) acidez total titulável (ATT): neutralização de uma alíquota de 10 $\mathrm{mL}$ de suco, com $\mathrm{NaOH} 0,1 \mathrm{~N}$, sendo os resultados expressos em \% de ácido cítrico anidro; e) relação SST/ATT (ratio); f) teor de vitamina C: neutralização por titulação do ácido ascórbico, em solução de 2,6-dicloro fenol indofenol (DCFI) expressa em mg de ácido ascórbico por $100 \mathrm{~mL}$ de suco (Instituto Adolfo Lutz, 1985); g) \% de perda de massa: percentual entre massa inicial e massa após armazenamento e f) \% de suco: relação percentual entre massa do suco (g) e a massa do fruto.

O delineamento experimental adotado foi inteiramente ao acaso, em parcelas subdivididas no tempo. Os fatores analisados foram: tratamentos e tempo de conservação (5 níveis). Utilizaram-se três repetições de oito frutos por parcela. Determinaram-se os modelos de regressão através do programa Sistema de Análise Estatística - SANEST (Zonta \& Machado, 1984).

\subsection{Resultados e Discussão}

De acordo com os quadros de análise da variação (Tabelas 27, 28, 29, 30 e 31), a interação do tempo de armazenamento com tratamento, apresentou diferenças significativas ( $\mathrm{PROB}>\mathrm{F}=<0,010$ ) para as variáveis: $\mathrm{C}^{*}, \mathrm{~h}^{\circ}$, SST, ATT, ratio, vit. C, TR e PM. Não houve interação significativa para a variável quantidade de suco (\%) (Tabela 31). As regressões solicitadas para o tempo dentro do tratamento (Tabelas 27A e $\mathrm{B} ; 28 \mathrm{~A}$ e B, 29A e B; 30A e B e 31A) apresentaram equações significativas ( $\mathrm{PROB}>\mathrm{F}=$ $0,05)$, conforme descritas nas respectivas figuras, devendo ser adotadas por possuir maior coeficiente de determinação.

Alterações significativas ocorreram na coloração da casca de lima ácida 'Tahiti', tanto para a intensidade $\left(\mathrm{C}^{*}\right)$, quanto para a tonalidade de cor, a partir de 20 dias de armazenamento (Figuras 1A e B). A maior retenção de cromaticidade nos frutos, foi verificada nas combinações de $\mathrm{GA}_{3}$ com 1-MCP e AVG. De acordo com a tabela de classificação (Tabela 1), as combinações de $\mathrm{GA}_{3}$ com 1-MCP e AVG situaram-se na classe C2, enquanto o controle foi classificado como C3. Diferenças significativas para esses frutos persistiram durante todo o armazenamento, sendo mantido a cromaticidade 
na classe C2. Os frutos não tratados foram classificados como C4 aos 40 dias e aos 60 dias atingiram a classificação C5.

Com relação ao ângulo de cor $\left(\mathrm{h}^{\mathrm{o}}\right)$, notou-se que todos os tratamentos efetuados proporcionaram uma classificação C2, para os frutos de lima ácida 'Tahiti' (Figura 1B) nos primeiros 20 dias de armazenamento refrigerado. Diferença significativa foi observada aos 40 dias, sendo os frutos tratados classificados como C3, enquanto os frutos não tratados foram classificados como C4. Aos 60 dias, os frutos tratados, ainda permaneciam como C3, enquanto os frutos do controle já estavam na classe C5 (Figura 7).
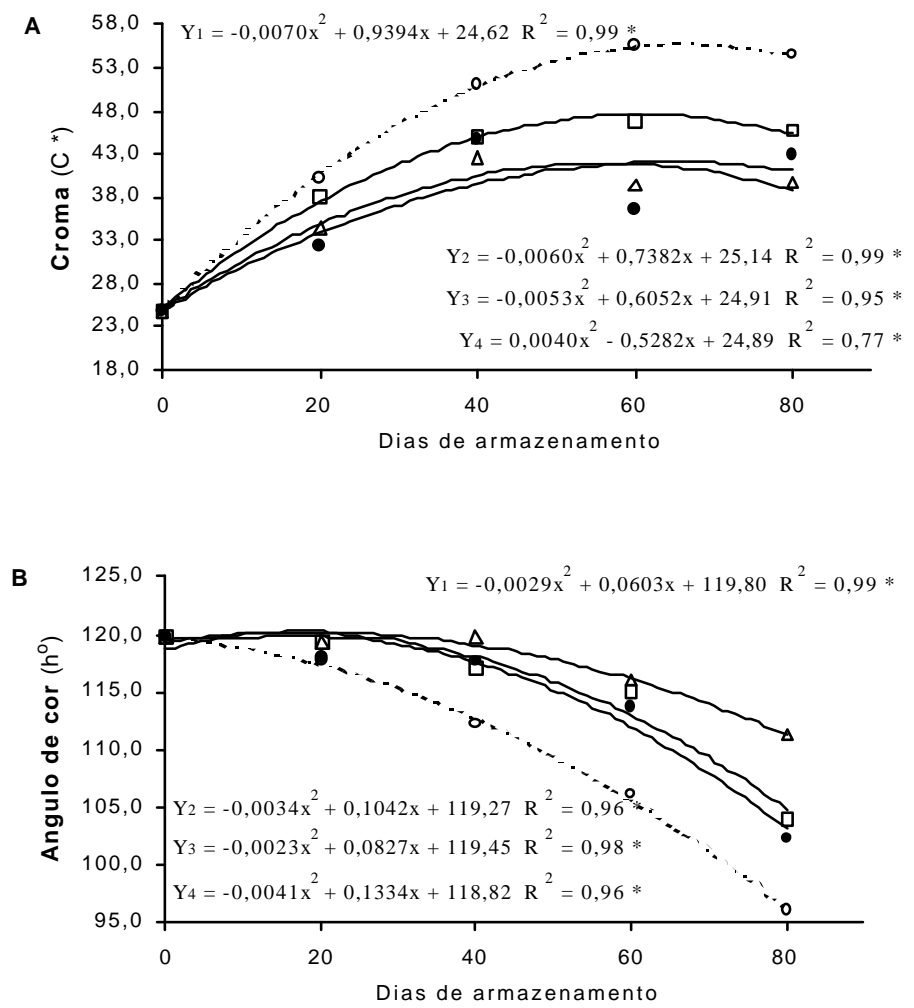

Figura 1 - Modelos de regressão para as variáveis: A) intensidade de cor (C*) e B) ângulo de cor $\left(\mathrm{h}^{\mathrm{o}}\right)$ em casca de lima ácida 'Tahiti' tratada com reguladores vegetais: Controle (o); $\mathrm{GA}_{3} 20 \mathrm{mg} \mathrm{L}^{-1}\left(\right.$ ); $1-\mathrm{MCP}+\mathrm{GA}_{3}(\ddot{\mathrm{A}}) \mathrm{e} \mathrm{AVG}+\mathrm{GA}_{3}(\bullet)$ 
Verificourse até aos 40 dias de armazenamento, que os frutos tratados apresentaram um consumo menor de sólidos solúveis totais (Figura 2A), em relação ao controle. Alto teor de sólidos solúveis, também foi detectado em abacaxí (Selvarajah et al., 2001), mamão (Hofman et al., 2001) e maçãs (Fan \& Mattheis, 1999) tratadas com 1-MCP. Entretanto, laranjas, ameixas e mangas não foram afetadas por 1MCP, no teor de sólidos solúveis (Porat et al., 1999; Hofman et al., 2001; Dong et al., 2002).
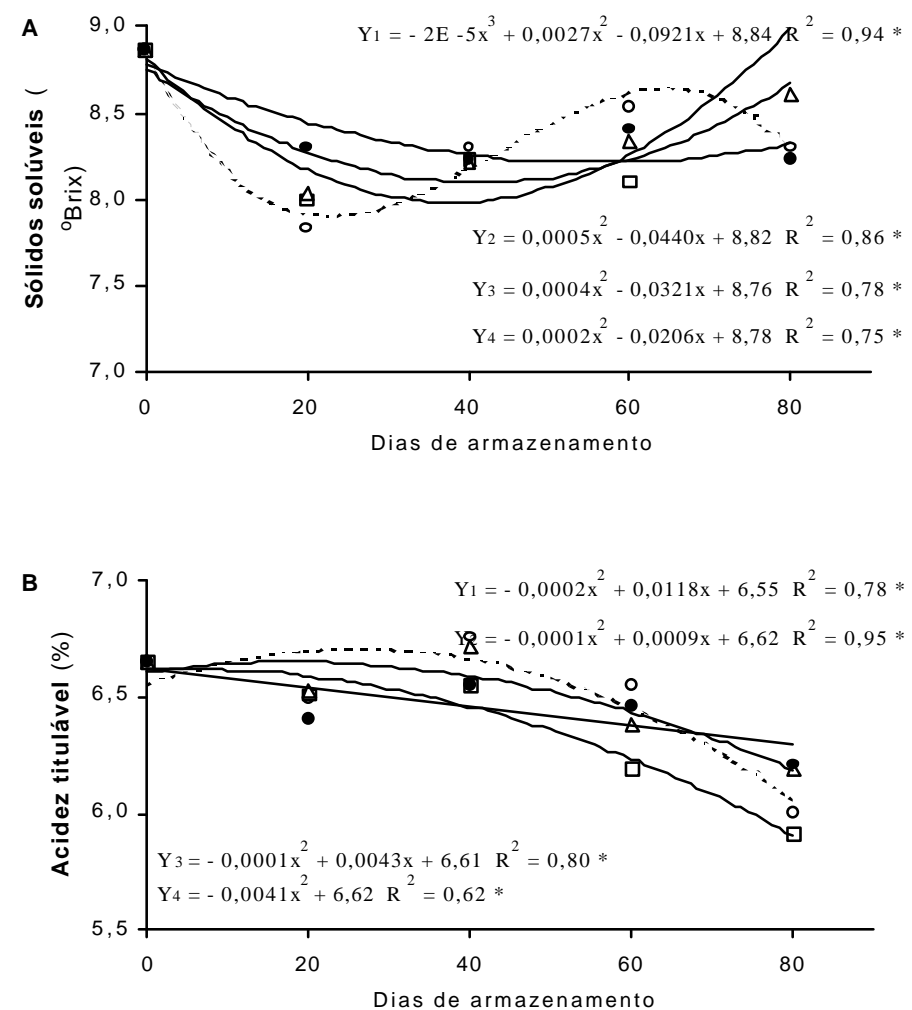

Figura 2 - Modelos de regressão para as variáveis: A) teor de sólidos solúveis ( ${ }^{\mathrm{B}}$ Brix) e B) acidez total titulável em suco de lima ácida 'Tahiti' tratada com reguladores vegetais: Controle (o); $\mathrm{GA}_{3} 20 \mathrm{mg} \mathrm{L}^{-1}\left(\right.$ ); $1-\mathrm{MCP}+\mathrm{GA}_{3}(\ddot{\mathrm{A}}) \mathrm{e} \mathrm{AVG}+\mathrm{GA}_{3}(\bullet)$

Com relação à acidez titulável (Figura 2B), observou-se menor porcentagem no nível de ácido cítrico nos frutos tratados. Os frutos tratados com $\mathrm{GA}_{3}$ apresentaram maior consumo de ácidos se comparados ao controle. Vários autores relataram que $\mathrm{GA}_{3}$ 
não causou efeitos sobre a acidez titulável quando aplicado em pré-colheita (El-Otmani \& Coggins, 1991; Pozo et al., 2000). Porat et al. (1999), também não observaram alterações na acidez titulável de laranjas 'Shamouti'.

Não houve alteração significativa para o ratio dos frutos tratados com AVG+ $\mathrm{GA}_{3}$, durante o armazenamento refrigerado (Figura 3A). Diferença significativa ocorreu a partir dos 40 dias, em frutos tratados somente com $\mathrm{GA}_{3}$.
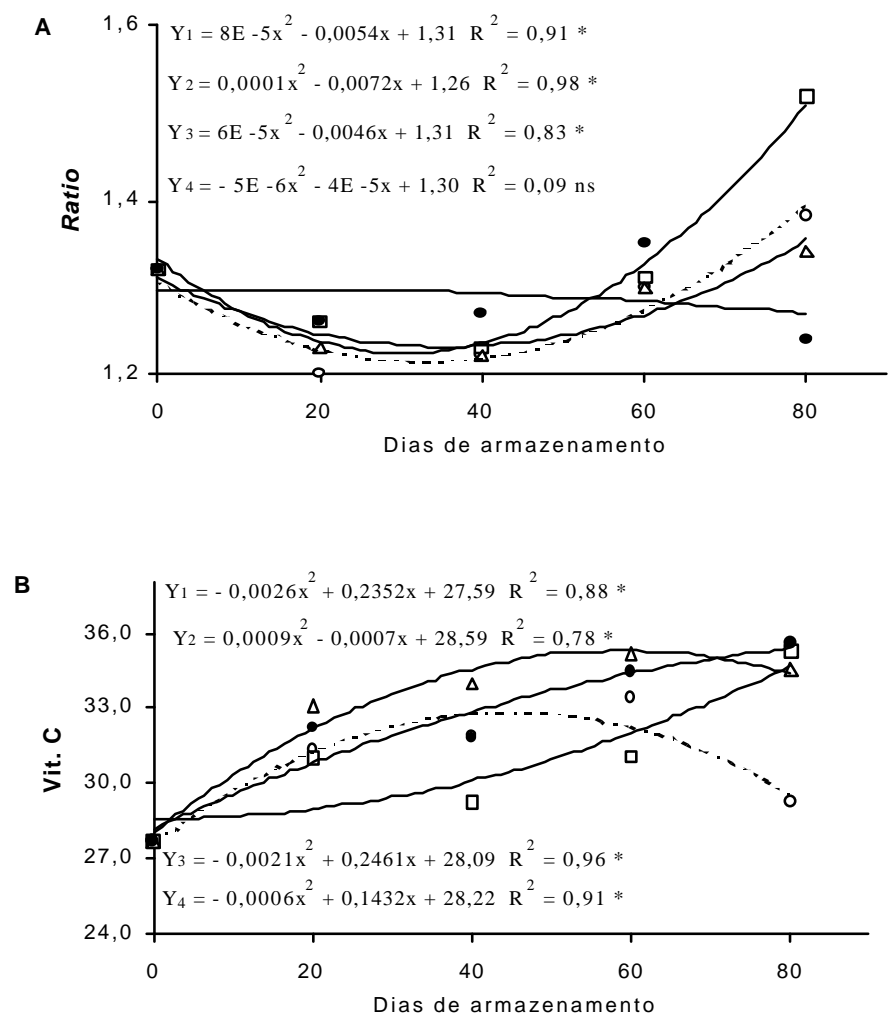

Figura 3 - Modelos de regressão para as variáveis: A) Ratio e B) teor de vitamina C, em suco de lima ácida 'Tahiti' tratada com reguladores vegetais: Controle (o); GA 20 mg L ( ); $1-\mathrm{MCP}+\mathrm{GA}_{3}(\ddot{\mathrm{A}})$ e $\mathrm{AVG}+\mathrm{GA}_{3}(\bullet)$

O nível de vitamina $\mathrm{C}$ permaneceu elevado nos frutos tratados com 1-MCP+GA3 até aos 60 dias, quando comparado com os frutos controle (Figura 29B). Os frutos tratados com $\mathrm{GA}_{3}$ apresentaram menor nível de vitamina $\mathrm{C}$ até aos 60 dias, comparando- 
se ao controle. Segundo Wenzel et al. (1995), o ácido ascórbico atua como inibidor da conversão de ACC para etileno, portanto, uma elevação no teor do mesmo, poderá atrasar o processo de senescência do fruto. Essa informação confirma os resultados obtidos nos frutos tratados com 1-MCP+GA3.

Houve diminuição na taxa respiratória para todos os tratamentos efetuados em frutos de lima ácida 'Tahiti' (Figura 4A) armazenados sob refrigeração.
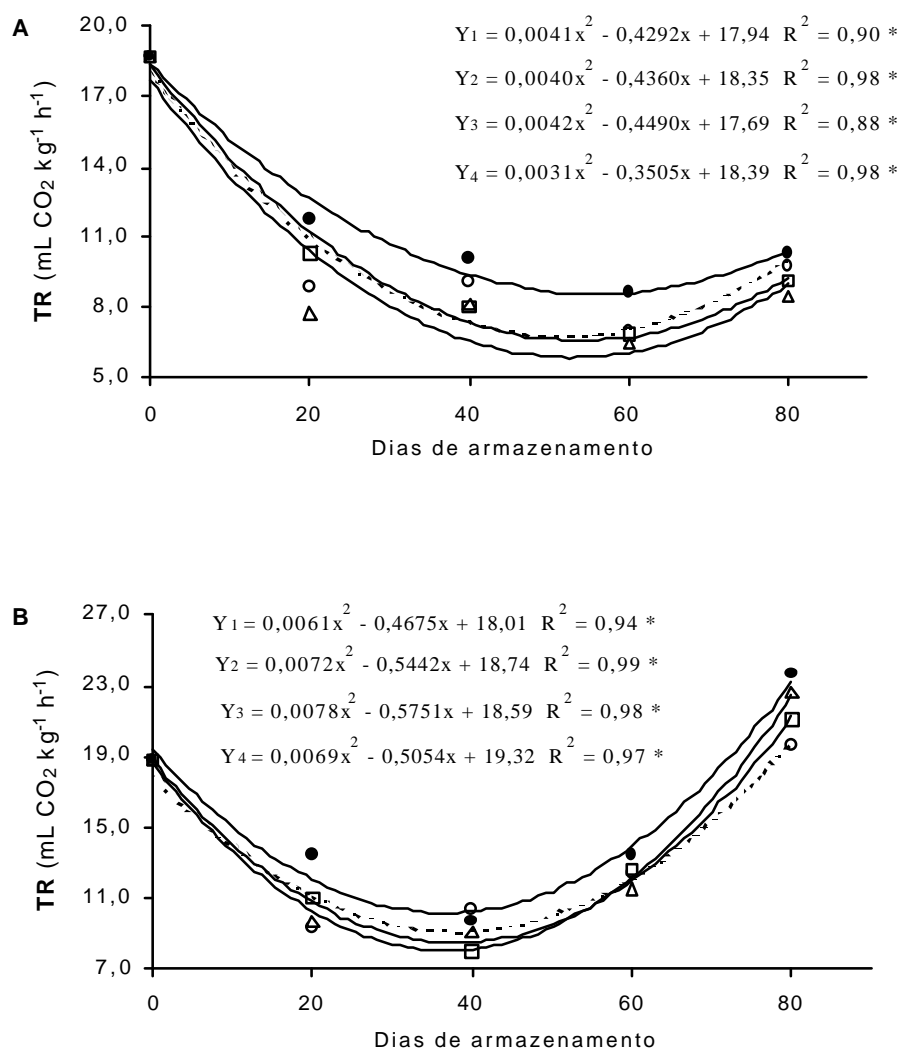

Figura 4 - Modelos de regressão para taxa respiratória $\left(\mathrm{mL} \mathrm{CO}_{2} \mathrm{~kg}^{-1} \mathrm{~h}^{-1}\right)$, em lima ácida 'Tahiti' (a $9{ }^{\circ} \mathrm{C}$ e a $25^{\circ} \mathrm{C}$ ) tratada com reguladores vegetais: Controle (o); $\mathrm{GA}_{3} 20 \mathrm{mg} \mathrm{L}^{-1}$ ( ); $1-\mathrm{MCP}+\mathrm{GA}_{3}(\ddot{\mathrm{A}})$ e $\mathrm{AVG}+\mathrm{GA}_{3}(\bullet)$

A partir dos 60 dias observou-se uma elevação na TR dos mesmos. Os frutos que receberam $\mathrm{AVG}+\mathrm{GA}_{3}$ exibiram uma TR significativamente maior em relação aos frutos controle. Entre 20 e 40 dias, os frutos tratados com $1-\mathrm{MCP}+\mathrm{GA}_{3}$ exibiram menor TR. 
Dong et al. (2001) e Dong et al. (2002) obtiveram resultados semelhantes em nectarinas e damasco tratado com 1-MCP, entretanto, Fan \& Mattheis (2000 a), afirmaram ter inibido a taxa respiratória em brócoli. Goldschmidt et al. (1997) observaram que a taxa respiratória em frutos de laranjas 'Shamouti' não foi alterada por aplicação de $\mathrm{GA}_{3} 25$ mg L L ${ }^{-1}$, entretanto Damián \& Monter (1999) reportaram a ocorrência de uma menor taxa respiratória em frutos de 'Valência Tardia', tratados com giberelina a $5 \mathrm{mg} \mathrm{L}^{-1}$ em précolheita.
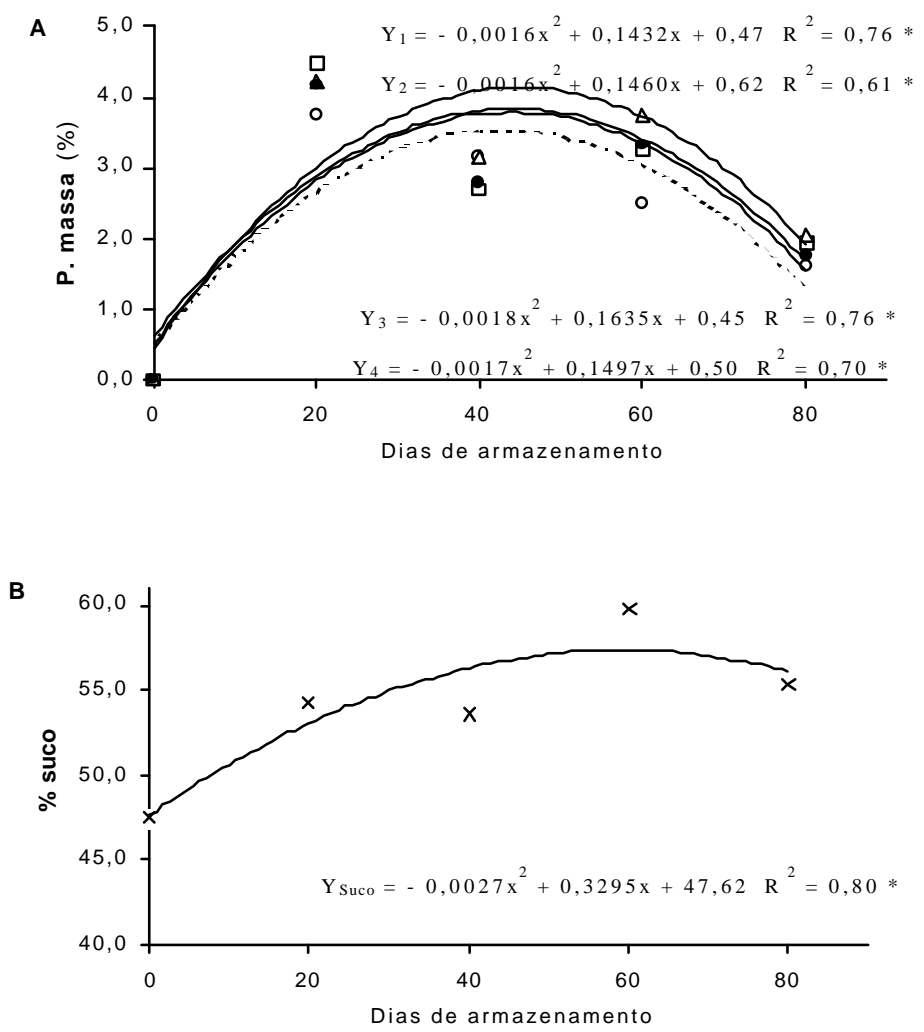

Figura 5 - Modelos de regressão para as variáveis: A) perda de massa (\%) e B) porcentagem de suco em lima ácida 'Tahiti' tratada com reguladores vegetais: Controle (o); $\mathrm{GA}_{3} 20$ $\mathrm{mgL}^{-1}\left(\right.$ ); $1-\mathrm{MCP}+\mathrm{GA}_{3}(\ddot{\mathrm{A}}) \mathrm{e} \mathrm{AVG}+\mathrm{GA}_{3}(\bullet)$

Após o período de 3 dias a $25{ }^{\circ} \mathrm{C}$, a elevação na TR se inicia a partir dos 40 dias do armazenamento (Figura 4B). Essa comparação sugere, que o armazenamento 
refrigerado a $9{ }^{\circ} \mathrm{C}$ apresenta um potencial de conservação para a lima ácida 'Tahiti' entre 40 e 60 dias.

Aos 40 e 60 dias, a perda de massa nos frutos tratados com $1 \mathrm{MCP}+\mathrm{GA}_{3}$ foi maior, se comparada ao controle (Figura 5A), porém sem exceder o nível de 5\% estabelecido como limite para a sua comercialização. Não houve variações significativas para a variável \% de suco, sendo o incremento observado (Figura 5B) devido ao tempo de armazenamento.

\subsection{Conclusões}

De acordo com os resultados apresentados, sugere-se que 1-MCP+GA 3 :

a) Proporciona melhor classificação quanto à coloração de casca em até 60 dias de armazenamento.

b) Mantém elevado o nível de vitamina $\mathrm{C}$.

c) Não afeta a taxa respiratória e a quantidade de suco da lima ácida 'Tahiti'. 


\section{CONCLUSÕES GERAIS}

\subsection{Tangor 'Murcote'}

- Os biorreguladores devem ser aplicados em 'Murcote' no início de sua maturação fisiológica para a obtenção de melhores resultados, em termos de manutenção da coloração da casca.

- As combinações utilizadas nesse trabalho apresentaram pontos positivos quanto à diminuição do estresse provocado durante a sua conservação refrigerada, diminuindo o consumo de sólidos solúveis, sem afetar os níveis de ácidos e a taxa respiratória.

\subsection{Lima ácida 'Tahiti'}

- O biorregulador 1-MCP apresentou um potencial para retardar as mudanças de coloração na casca da lima 'Tahiti'.

- O regulador vegetal AVG não impediu a evolução da coloração na casca da lima ácida 'Tahiti'. Isso sugere que a ação do etileno exógeno deve ser bloqueada, conforme notado com a aplicação do 1-MCP.

\subsection{Combinações de biorreguladores em pós-colheita}

- O uso de combinações de biorreguladores pode ajudar a conservar as características externas e internas da lima ácida 'Tahiti'. 
- Os frutos de lima ácida 'Tahiti' permanecem em classes mais valorizadas no mercado, por um maior período de tempo, quando tratados com biorreguladores combinados. 


\section{REFERÊNCIAS BIBLIOGRÁFICAS}

ABELES, F.B.; MORGAN, P.W.; SALTVEIT JR., M.E. Ethylene in plant biology. 2. ed. New York: Academic Press, 1992. 414p.

ADAMS, D.O.; YANG, S.F. Ethylene biosynthesis: Identification of 1aminocyclopropane-1-carboxilic acid as an intermediate in the conversion of methionine to ethylene. Proceedings of the National Academic of Sciences of the U.S.A., v.76, p.170-174, 1979.

AGUSTI, M.; ALMELA,V.; GUARDIOLA, J.L. Aplicación de ácido giberelico para el control de alteraciones de la corteza de las mandarinas asociadas a la maduracion. Investigaciones Agrarias de Produtos Para Proteción Vegetales, v.3, n.2, p.125137, 1988.

AWAD, M. Fisiologia pós -colheita de frutos. São Paulo: Nobel, 1993. 114p.

BALDWIN, E.A. Citrus fruit. In: SEYMOUR, G.B.; TAYLOR, J.E.; TUCKER, G.A. (Ed.). Biochemistry of fruit ripening. London: Chapman \& Hall, 1994. p.255-271.

BARROS, S.A.; RODRIGUES, J.D.; RODRIGUES, S.D.; PEDRAS, J.F. Efeito do ácido giberélico e do uniconazole na fisiologia pós-colheita do limão 'Tahiti' Citrus latifólia Tanaka). Revista Brasileira de Fruticultura, v.13, p.223-226, 1991. 
BLANKENSHIP, S.M.; DOLE, J.M. 1-Methylcyclopropene: a review. Postharvest Biology and Technology, v.00, p.1-25, 2003.

BLANKENSHIP, S.M.; SISLER, E.C. Diazocyclopentadiene (DACP), a light sensitive reagent for the ethylene receptor in plants. Plant Growth Regulators, v.12, n.1-2, p.125-132, 1993.

BLEINROTH, E.W.; SIGRIST, J.M.M.; ARDITO, E.F.G.; CASTRO, J.V.; SPAGNOL, W.A.; NEVES FILHO, L.C. Tecnologia de pós-colheita de frutas tropicais. Campinas: ITAL, 1992. 203p.

BYERS, R.E. Effects of aminoethoxyvinilglycine (AVG) on posharvest fruit drop and maturity of 'Delicious' apples. Journal of Tree Fruit Production, v.2, p.53-75, 1997.

CASTRO, P.R.C.; VIEIRA, E.L. Aplicações de reguladores vegetais na agricultura tropical. Guaíba: Agropecuária, 2001. 132p.

COMPANHIA DE ENTREPOSTOS E ARMAZÉNS GERAIS DE SÃO PAULO Programa brasileiro para a melhoria dos padrões comerciais e de embalagens de hortigranjeiros: classificação das tangerinas. São Paulo: Centro de Qualidade em Horticultura, 2000a. 1v.

COMPANHIA DE ENTREPOSTOS E ARMAZÉNS GERAIS DE SÃO PAULO Programa brasileiro para a melhoria dos padrões comerciais e de embalagens de hortigranjeiros: classificação das tangerinas. São Paulo: Centro de Qualidade em Horticultura, 2000b. 1v. 
CRISTOFFERSEN, R.E.; LATIES, G.G. Ethylene regulation of gene expression in carrots. Proceedings of the National Academic of Sciences of the U.S.A., v.79, p.4060-4063, 1982.

CHITARRA, M.I.; CHITARRA, A.B. Pós-colheita de frutos: fisiologia e manuseio. Lavras: ESAL; FAEPE, 1990. 320p.

CHITARRA, M.I.F. Características físicas, físico-químicas e químicas de alguns frutos cítricos cultivados em Minas Gerais. Ensaio com laranjas (Citrus sinensis (L.) Osbeck) e tangerinas (Citrus reticulata Blanco) em fase de maturação. Ribeirão Preto, 1979. 186p. Tese (Doutorado) - Faculdade de Ciências Farmacêuticas, Universidade de São Paulo.

DAMIAN, M.T.M.; MONTER, A.V. Aplicación de ácido giberélico y su efecto en la calidad de frutos de naranja 'Valencia Tardia'. Revista Chapingo. Série Horticultura, v.5, n.2, p.103-107, 1999.

DAVIES, F.S.; CAMPBELL, C.A.; ZALMAN, G.R. Gibberellic acid sprays for improving fruit peel quality increasing juice yield of processing oranges. Proceedings of the Florida State for Horticultural Society, v.110, p.16-21, 1997.

DILLEY, D.R. Hormonal control of fruit ripening. HortScience, v.4, p.111-114, 1969.

DONG, L.; LURIE, S.; ZHOU, H. Effect of 1-methylcyclopropene on ripening of 'Canino' apricots and 'Royal Zee' plums. Postharvest Biology and Technology, v.24, p.135-145, 2002.

DONG, L; ZHOU, H; SONEGO, L; LERS, A.; LURIE, S. Ethylene involvement in the cold storage disorder of 'Flavortop' nectarine. Postharvest Biology and Technology, v.23, p.105-115, 2001. 
EL-OTMANI, M.; COGGINS JR., C.W. Growth regulator effects on retention of quality stored citrus fruits. Scientia Horticulturae, v.45, p.261-272, 1991.

FAN, X.; MATTHEIS, J.P. Impact of 1-methylcyclopropene and methyl jasmonate on apple volatile production. Journal of Agriculture and Food Chemistry . v.47, p.2847-2853, 1999.

FAN, X.; MATTHEIS, J.P. Yellowing of brocoli in storage is reduced by 1methylcyclopropene. HortScience, v.35, p.885-887, 2000a.

FAN, X.; MATTHEIS, J.P. Reduction of ethylene-induced physiological disorders of carrots and iceberg by 1-methylcyclopropene. HortScience, v.35, p.1312-1314, $2000 \mathrm{~b}$.

FIGUEIREDO, J.O. Variedades Comerciais. In: RODRIGUES, O.; VIÉGAS, F.; POMPEU JR., J.; AMARO, A.S. (Ed.). Citricultura Brasileira. 2. ed. Campinas: Fundação Cargill, 1991, v.1, 252-254.

FNP CONSULTORIA \& COMÉRCIO. Agrianual 2002: anuário da agricultura brasileira. São Paulo, 2002. p.316-332. Limão/Tangerina - volume comercializado.

FUCHS, Y.; COHEN, A. Degreening of citrus fruit with Ethrel. Journal of the American Society for Horticultural Science, v.94, n.6, p.617-618, 1969.

GARCIA, L.A.; FORNES, F.; GUARDIOLA, J.L. Effects of gibberellin $\mathrm{A}_{3}$ and cytokinins on natural and post-harvest, ethylene-induced pigmentation of 'Satsuma' mandarin peel. Physiologia Plantarum, v.68, p.271-274, 1986. 
GARCIA, L.A.; VILLÉN, A.H.; GUARDIOLA, J.L. Effects of applications of gibberellic acid on late growth, maturation and pigmentation of the Clementine mandarin. Scientia Horticulturae, v.49, p.71-82, 1992.

GARNER, D.; CRISOSTO, C.H.; OTIEZA, E. Controlled atmosphere storage and aminoethoxyvinylglycine postharvest dip delay post storage softening of 'Snow King' peach. HortTechnology, v.11, n.4, p.598-602, 2001.

GOLDSCHMIDT, E.E. Ripening of citrus and other non-climateric fruits: a role for ethylene. Acta Horticulturae, n.463, p.325-334, 1997.

GOLDSCHMIDT, E.E.; AHARONI, Y.; EILATI, S.K.; RIOV, J.W.; MONSELISE, S.P. Differential counteraction of ethylene effects by gibberellin $A_{3}$ and $N_{6-}$ benzyladenine in senescing citrus peel. Plant Physiology, v.59, p.193-195, 1977.

GREENE, G.M. ReTain: the new apple stop drop material. Pensylvania Fruit News, v.77, p.25-28, 1997.

HOFMAN, P.J.; JOBIN-DECOR, M.; MEIBURG, G.F.; MACNISH, A.J.; JOYCE, D.C. Ripening and quality responses of avocado, custard apple, mango and papaya fruit to 1-methylcyclopropene. Australian Journal of Experimental Agriculture, v.41, p.567-572, 2001.

HU, J.F.; FUKUDA, T.; OHARA, H.; TAKAHASHI, E.; MATSUI, H. Effect of AVG application on berry set of 'Kyoho'grape. Journal of the Japanese Society for Horticultural Science, v.68, n.4, p.833-838, 1999.

INSTITUTO ADOLFO LUTZ. Normas analíticas: métodos químicos e físicos para análises de alimentos. 3. ed. São Paulo, 1985. 533p. 
JACOMINO, A.P.; KLUGE, R.A.; BRACKMANN, A.; CASTRO, P.R.C. Amadurecimento e senescência de mamão com 1-metilciclopropeno. Scientia Agricola, v.59, n.2, p.303-308, 2002.

JEONG, J.; HUBER, D.J.; SARGENT, S.A. Influence of 1-methylcyclopropene (1MCP) on ripening and cell-wall matrix polysaccharides of avocado (Persea americana) fruit. Postharvest Biology and Technology, v.25, p.241-364, 2002.

JIANG, Y.; JOYCE, D.C.; MACNISH, A.J. Extension of the shelf life of banana fruit by 1-methylcyclopropene in combination with polyetilene bags. Postharvest Biology and Technology, v.16, p.187-193, 1999.

JU, Z.G.; DUAN, Y.S.; JU, Z.Q. Combinations of $\mathrm{GA}_{3}$ and AVG delay fruit maturation, increase fruit size, and improve storage life of 'Feicheng' peaches. Journal of the Horticultural Science and Biotechnology, v.74, p.579-583, 1999.

KADER, A.A. Postharvest technology of horticultural crops. Oakland: University of California, 1992. 296p.

KANG, F.K.; BYUN, K.K. Effect of aminoethoxyvinylglycine dipping treatment on storability of 'Tsugaru' apple fruits. Journal of the Korean Society for Horticultural Science, v.43, n.3, p.306-308, 2002.

KLUGE, R.A.; JACOMINO, A.P. Shelf life of peaches treated with 1methylcyclopropene. Scientia Agricola, v.59, p.69-72, 2002.

KLUGE, R.A.; NACHTIGAL, J.C.; FACHINELLO, J.C.; BILHALVA, A.B. Fisiologia e manejo pós-colheita de frutas de clima temperado. 2. ed. Campinas: Livraria e Editora Rural, 2002. 214p. 
KLUGE, R.A.; JACOMINO, A.P.; OJEDA, R.M.; BRACKMANN, A. Retenção do amadurecimento de abacate com 1-metilciclopropeno. Pesquisa Agropecuária Brasileira, v.37, n.7, p.895-901, 2002a.

KU, V.V.V.; WILLS, R.B.H.; BEN-YEHOSHUA, S. 1-Methylcyclopropene can differentially affect the postharvest life of strawberries exposed to ethylene. HortScience, v.34, p.119-120, 1999.

LUDFORD, P.L. Postharvest hormone changes in vegetables and fruit. In: DAVIES, P.J. (Ed.). Plant hormones. Dordrecht: Kluwer Academic, 1995. p.725-750.

McGUIRE, R.G. Reporting of objective colour measurements. HortScience, v.27, p.1254-1255, 1992.

MEDINA, P.V.L. Recomendações sobre produtos colhidos. Informe Agropecuário, v.9, p.49-52, 1983.

McMURCHIE, E.J. McGLASSON, W.B.; EAKS, I.L. Treatment of fruit with propylene gives information about the biogenesis of ethylene. Nature, v.237, p.235236, 1972.

MIZOBUTSI, G.P.; BORGES, C.A.M.; SIQUEIRA, D.L. Conservação pós-colheita da lima ácida 'Tahiti' (Citrus latifolia Tanaka), tratada com ácido giberélico e armazenada em três temperaturas. Revista Brasileira de Fruticultura, v.22, p.4247, 2000.

MORETTI, C.L.; CALBO, A.G.; HENS, G.P. Metabolismo respiratório na pós-colheita de frutas e hor taliças. Universa, v.8, n.1, p.259-274, 2000. 
MULlinS, E.D.; McCOLLUM, T.G. McDONALD, R.E. Ethylene: A regulator of stress-induced ACC synthase activity in non-climateric fruit. Physiologia Plantarum, v.107, n.1, p.1-7, 1999.

MUNHOZ, V.; LUIZ, M. Evaluacion de Retain [(AVG) aminoethoxyvinilglycine] como regulador de crescimiento em peras (Pyrus communis) 'Packman's Triumph'. Santiago: Universidad Mayor, Faculdad de Ciências Silvoagropecuárias, 1998. 85p.

OETIKER, J.H.; YANG, S.F. The role of ethylene in fruit ripening. Acta Horticulturae, n.398, p.167-178, 1995.

PORAT, R.; WEISS, B.; COHEN, L; DAUS, A.; GOREN, R.; DROBY, S. Effects of ethylene and 1-methylcyclopropene on the postharvest qualities of 'Shamouti' oranges. Postharvest Biology and Technology, v.15, p.155-163, 1999.

POZO, L.; KENDER, W.J.; BURNS, J.K.; HARTMOND, U.; GRANT, A. Effects of gibberellic acid on ripening and rind puffing in 'Sunburst' mandarin. Proceedings of the Florida State for Horticultural Society, v.113, p.102-105, 2000.

ROBERTS, J.A.; HOOLEY, R. Plant growth regulators . London: Blackie, 1988. 190p.

SCHECHTER, S.; GOLDSCHMIDT, E.E.; GALILI, D. Persistence of $\left({ }^{14} \mathrm{C}\right)$ gibberellin $A_{3}$ and $\left({ }^{3} \mathrm{H}\right)$ gibberellin $A_{1}$ in senescing, ethylene treated citrus and tomate fruit. Plant Growth Regulation, v.8, p.243-253, 1989.

SELVARAJAH, S.; BAUCHOT, A.D.; JOHN, P. Internal browning in cold-stored pineapples is suppressed by a postharvest application of 1-methylcyclopropene. Postharvest Biology and Technology, v.23, p.167-170, 2001. 
SHELLIE, K.C. Muskmelon (Cucumis melo L.) fruit ripening and postharvest quality after a preharvest spray of aminoethoxyvinylglycine. Postharvest Biology and Technology, v.17, n.1, p.55-62, 1999.

SILVA, J.A.A.; DONADIO, L.C. Reguladores vegetais na citricultura. Jaboticabal: Funep, 1997. 38p. (Boletim Citrícola, 3).

SISLER, E.C.; SEREK, M. Inhibitors of ethylene responses in plants at the receptors level: recent developments. Physiologia Plantarum, v.100, n.5, p.577-582, 1997.

SPÓSITO, M.B.; MOURÃO FILHO, F.A.A.; KLUGE, R.A.; JACOMINO, A.P. Armazenamento refrigerado de frutos de limeira-ácida 'Tahiti' tratados com ácido giberélico. Revista Brasileira de Fruticultura, v.22, p.345-348, 2000.

TIAN, M.S.; PRAKASH, S.; ELGAR, H.J.; YOUNG, H.; BURMEISTER, D.M.; ROSS, G.S. Responses of strawberry fruit to 1-methylcyclopropene (1-MCP) end ethylene. Plant Growth Regulation, v.32, p.83-90, 2000.

TING, S.V.; ROUSEFF, R.L. Citrus fruits and their products: analysis y technology. New York: Marcel Dekker, 1986. 293p.

VENDRELL, M.; PALOMER, X. Hormonal control of fruit ripening in climateric fruits. Acta Horticulturae, n.463, p.325-334, 1997.

WENZEL, A.A.; SCHLAUTMANN, H.; JONES, C.A.; KUPPERS, K.; MEHLHORN, H. Aminoethoxyvynilglycine, cobalt and ascorbic acid all reduce ozone toxity in mung beans by inhibition of ethylene biosynthesis. Physiologia Plantarum, v.93, p.286-290, 1995. 
WILLS, R.B.H.; KU, V.V.V. Use of 1-MCP to extend the time to ripen of green tomatoes and postharvest life of ripe tomatoes. Postharvest Biology and Technology, v.26, p.85-90, 2002.

WILLS, R.H.H.; LEE, T.H.; GRAHAM, D.; McGLASSON, W.B.; HALL, E.G. Postharvest. Westport: AYI Publis., 1981. 163p.

YANG, S.F.; HOFFMAN, N.E. Ethylene biosynthesis and its regulation in higher plants. Annual Review of Plant Physiology, v.35, p.155-189, 1984.

ZONTA, E.P.; MACHADO, A.A. Sistema de análise estatística para microcomputadores - SANEST (software). Pelotas: UFPEL, 1984. 109p. 
APÊNDICES 
Tabela 1. Classificação objetiva da lima ácida 'Tahiti' baseada na intensidade $\left(\mathrm{C}^{*}\right)$ e tonalidade $\left(\mathrm{h}^{\mathrm{o}}\right) \mathrm{de}$ coloração da casca, utilizando-se o colorímetro Chroma Meter 300.

\begin{tabular}{crr}
\hline Classe & Croma & Angulo de cor \\
\hline C1 & $\leq 28,00$ & $\geq 120,00$ \\
C2 & $28,00 \leq 38,00$ & $120,00 \geq 117,00$ \\
C3 & $38,00 \leq 48,00$ & $117,00 \geq 114,00$ \\
C4 & $48,00 \leq 53,00$ & $114,00 \geq 106,00$ \\
C5 & $\geq 53,00$ & $\leq 106,00$ \\
\hline
\end{tabular}

* = Os frutos apresentam rugosidades na casca, $\mathrm{C}^{*}=$ croma $\mathrm{e}^{\circ}=$ ângulo de cor.

Tabela 2. Resumo da análise de variância, para as variáveis: croma $\left(\mathrm{C}^{*}\right)$ e ângulo de cor $\left(\mathrm{h}^{\mathrm{o}}\right)$, em casca de tangor 'Murcote' tratado com 1-MCP e armazenado sob refrigeração (mais 3 dias a $25^{\circ} \mathrm{C}$ ).

\begin{tabular}{lccc}
\hline & & \multicolumn{3}{c}{$\begin{array}{c}\text { QUADRADOS MEDIOS } \\
\text { CV }\end{array}$} & GL & $\left(\mathrm{C}^{*}\right)$ & $\left(\mathrm{h}^{\circ}\right)$ \\
\cline { 3 - 4 } \cline { 3 - 4 } & 3 & 14,888 & 387,156 \\
& & $(<0,010)$ & $(<0,010)$ \\
Tratamentos & 4 & 47,229 & 12,077 \\
Período & & $(<0,010)$ & $(<0,010)$ \\
Trat. * Período & 12 & 6,084 & 5,427 \\
& & $(<0,010)$ & $(<0,010)$ \\
Resíduo & 60 & 1,915 & 1,179 \\
\hline
\end{tabular}

Tabela 2A. Resumo da análise de regressão polinomial para a variável croma $\left(\mathrm{C}^{*}\right)$, em casca de tangor 'Murcote', tratado com 1-MCP na concentração de 0; 0,1;0,5 e 1,0 $\mu \mathrm{L} \mathrm{L}^{-1}$ e armazenado sob refrigeração (mais 3 dias a $25^{\circ} \mathrm{C}$ ).

\begin{tabular}{cccccc}
\hline & & \multicolumn{4}{c}{ QUADRADOS MEDIOS } \\
\cline { 3 - 5 } CV & GL & 0 & \multicolumn{4}{c}{ Concentração de 1-MCP $\left(\mu \mathrm{L} \mathrm{L} \mathrm{L}^{-1}\right)$} \\
\cline { 3 - 5 } & & 380,688 & 25,376 & 0,5 & 1,0 \\
\hline Reg. Linear & 1 & $(<0,010)$ & $(<0,010)$ & 48,752 & 32,508 \\
& & 14,200 & 0,306 & $0,010)$ & $(<0,010)$ \\
Reg. Quadr. & 1 & $(<0,010)$ & $(0,693)$ & $(0,828)$ & 17,472 \\
& & 41,967 & 2,959 & 0,424 & $(<0,010)$ \\
Reg. Cúbica & 1 & $(<0,010)$ & $(0,216)$ & $(0,644)$ & $(0,434$ \\
& & 0,969 & 28,878 & 2,275 & 11,356 \\
Reg. Grau 4 & 1 & $(0,513)$ & $(<0,010)$ & $(0,279)$ & $(0,017)$ \\
& & & & & \\
\end{tabular}


Tabela 2B. Resumo da análise de regressão polinomial para a variável ângulo de cor $\left(\mathrm{h}^{\mathrm{o}}\right)$, em casca de tangor 'Murcote', tratado com 1MCP na concentração de $0 ; 0,1 ; 0,5$ e $1,0 \mu \mathrm{L} \mathrm{L}^{-1}$ e armazenado sob refrigeração (mais 3 dias a $25^{\circ} \mathrm{C}$ ).

\begin{tabular}{|c|c|c|c|c|c|}
\hline \multirow{3}{*}{$\mathrm{CV}$} & \multirow{3}{*}{ GL } & \multicolumn{4}{|c|}{$\begin{array}{l}\text { QUADRADOS MÉDIOS } \\
\text { (PROB. > F) }\end{array}$} \\
\hline & & \multicolumn{4}{|c|}{ Concentração de 1-MCP $\left(\mu \mathrm{L} \mathrm{L}^{-1}\right)$} \\
\hline & & 0 & 0,1 & 0,5 & 1,0 \\
\hline \multirow[t]{2}{*}{ Reg. Linear } & 1 & 48,246 & 375,768 & 317,532 & 411,521 \\
\hline & & $(<0,010)$ & $(<0,010)$ & $(<0,010)$ & $(<0,010)$ \\
\hline \multirow[t]{2}{*}{ Reg. Quadr. } & 1 & 0,184 & 5,039 & 0,664 & 1,290 \\
\hline & & $(0,755)$ & $(0,040)$ & $(0,537)$ & $(0,300)$ \\
\hline \multirow[t]{2}{*}{ Reg. Cúbica } & 1 & 11,342 & 1,892 & 5,550 & 62,750 \\
\hline & & $(<0,010)$ & $(0,207)$ & $(0,032)$ & $(<0,010)$ \\
\hline \multirow[t]{2}{*}{ Reg. Grau 4} & 1 & 1,358 & 2,143 & 11,240 & 10,764 \\
\hline & & $(0,287)$ & $(0,179)$ & $(<0,010)$ & $(<0,010)$ \\
\hline
\end{tabular}

Tabela 3. Resumo da análise de variância, para as variáveis: sólidos solúveis totais (SST) e acidez titulável total (ATT), em tangor 'Murcote' tratado com 1-MCP e armazenado sob refrigeração (mais 3 dias a $\left.25^{\circ} \mathrm{C}\right)$.

QUADRADOS MÉDIOS (PROB. > F)

\begin{tabular}{lccc}
\multicolumn{1}{c}{ CV } & GL & SST & ATT \\
\hline Tratamentos & 3 & 0,269 & 0,009 \\
& & $(0,029)$ & $(<0,010)$ \\
Período & 4 & 0,786 & 0,070 \\
& & $(<0,010)$ & $(<0,010)$ \\
Trat. * Período & 12 & 0,176 & 0,006 \\
& & $(0,030)$ & $(<0,010)$ \\
Resíduo & 60 & 0,084 & 0,001 \\
\hline
\end{tabular}

Tabela 3A. Resumo da análise de regressão polinomial para a variável sólidos solúveis totais ( ${ }^{\mathrm{B}}$ Brix), em tangor 'Murcote', tratado com $1 \mathrm{MCP}$ na concentração de $0 ; 0,1 ; 0,5$ e $1,0 \mu \mathrm{L} \mathrm{L} \mathrm{L}^{-1} \mathrm{e}$ armazenado sob refrigeração (mais 3 dias a $25^{\circ} \mathrm{C}$ ).

\begin{tabular}{|c|c|c|c|c|c|}
\hline \multirow{3}{*}{$\mathrm{CV}$} & \multirow{3}{*}{ GL } & \multicolumn{4}{|c|}{$\begin{array}{c}\text { QUADRADOS MÉDIOS } \\
\text { (PROB. > F) }\end{array}$} \\
\hline & & \multicolumn{4}{|c|}{ Concentração de 1-MCP $\left(\mu \mathrm{L} \mathrm{L}^{-1}\right)$} \\
\hline & & 0 & 0,1 & 0,5 & 1,0 \\
\hline \multirow[t]{2}{*}{ Reg. Linear } & 1 & 0,004 & 0,012 & 0,100 & 1,056 \\
\hline & & $(0,822)$ & $(0,705)$ & $(0,279)$ & $(<0,010)$ \\
\hline \multirow[t]{2}{*}{ Reg. Quadr. } & 1 & 0,000 & 2,200 & 0,378 & 0,094 \\
\hline & & $(1,000)$ & $(<0,010)$ & $(0,036)$ & $(0,294)$ \\
\hline \multirow[t]{2}{*}{ Reg. Cúbica } & 1 & 0,196 & 0,420 & 0,156 & 0,025 \\
\hline & & $(0,128)$ & $(0,027)$ & $(0,175)$ & $(0,594)$ \\
\hline \multirow[t]{2}{*}{ Reg. Grau 4} & 1 & 0,028 & 0,100 & 0,282 & 0,206 \\
\hline & & $(0,573)$ & $(0,279)$ & $(0,068)$ & $(0,119)$ \\
\hline
\end{tabular}


Tabela 3B. Resumo da análise de regressão polinomial para a variável acidez titulável total (ATT), em tangor 'Murcote', tratado com 1MCP na concentração de $0 ; 0,1 ; 0,5$ e $1,0 \mu \mathrm{L} \mathrm{L}^{-1}$ e armazenado sob refrigeração (mais 3 dias a $25^{\circ} \mathrm{C}$ ).

\begin{tabular}{|c|c|c|c|c|c|}
\hline \multirow{3}{*}{$\mathrm{CV}$} & \multirow{3}{*}{ GL } & \multicolumn{4}{|c|}{$\begin{array}{c}\text { QUADRADOS MÉDIOS } \\
\text { (PROB. > F) }\end{array}$} \\
\hline & & \multicolumn{4}{|c|}{ Concentração de 1-MCP $\left(\mu \mathrm{L} \mathrm{L}^{-1}\right)$} \\
\hline & & 0 & 0,1 & 0,5 & 1,0 \\
\hline \multirow[t]{2}{*}{ Reg. Linear } & 1 & 0,077 & 0,095 & 0,067 & 0,022 \\
\hline & & $(<0,010)$ & $(<0,010)$ & $(<0,010)$ & $(<0,010)$ \\
\hline \multirow[t]{2}{*}{ Reg. Quadr. } & 1 & 0,001 & 0,022 & 0,004 & 0,008 \\
\hline & & $(0,617)$ & $(<0,010)$ & $(0,054)$ & $(<0,010)$ \\
\hline \multirow[t]{2}{*}{ Reg. Cúbica } & 1 & 0,003 & 0,000 & 0,017 & 0,033 \\
\hline & & $(0,079)$ & $(0,807)$ & $(<0,010)$ & $(<0,010)$ \\
\hline \multirow[t]{2}{*}{ Reg. Grau 4} & 1 & 0,001 & 0,002 & 0,004 & 0,003 \\
\hline & & $(0,573)$ & $(0,118)$ & $(0,040)$ & $(0,065)$ \\
\hline
\end{tabular}

Tabela 4. Resumo da análise de variância, para as variáveis: ratio (SST/ATT) e ácido ascórbico (vit. C), em tangor 'Murcote' tratado com 1-MCP e armazenado sob refrigeração (mais 3 dias a $25^{\circ} \mathrm{C}$ ).

\begin{tabular}{lccc}
\hline & & \multicolumn{3}{c}{$\begin{array}{c}\text { QUADRADOS MÉDIOS } \\
\text { (PROB. }>\text { F) }\end{array}$} \\
\cline { 3 - 4 } CV & GL & Ratio & Vit.C \\
Tratamentos & 3 & 4,104 & 4,345 \\
Período & & $(<0,010)$ & $(<0,010)$ \\
& 4 & 47,066 & 15,794 \\
Trat. * Período & 12 & $(<0,010)$ & $(<0,010)$ \\
& & 3,847 & 1,806 \\
Resíduo & 60 & $(<0,010)$ & $(<0,010)$ \\
\hline
\end{tabular}

Tabela 4A. Resumo da análise de regressão polinomial para a variável Ratio (SST/ATT), em suco de tangor 'Murcote', tratado com $1 \mathrm{MCP}$ na concentração de $0 ; 0,1 ; 0,5$ e $1,0 \mu \mathrm{L} \mathrm{L}^{-1} \mathrm{e}$ armazenado sob refrigeração (mais 3 dias a $25^{\circ} \mathrm{C}$ ).

\begin{tabular}{|c|c|c|c|c|c|}
\hline \multirow{3}{*}{$\mathrm{CV}$} & \multirow{3}{*}{ GL } & \multicolumn{4}{|c|}{$\begin{array}{c}\text { QUADRADOS MÉDIOS } \\
(\text { PROB. > F) }\end{array}$} \\
\hline & & \multicolumn{4}{|c|}{ Concentração de 1-MCP $\left(\mu \mathrm{L} \mathrm{L}^{-1}\right)$} \\
\hline & & 0 & 0,1 & 0,5 & 1,0 \\
\hline \multirow[t]{2}{*}{ Reg. Linear } & 1 & 44,478 & 69,880 & 45,369 & 13,479 \\
\hline & & $(<0,010)$ & $(<0,010)$ & $(<0,010)$ & $(<0,010)$ \\
\hline \multirow[t]{2}{*}{ Reg. Quadr. } & 1 & 0,011 & 10,208 & 7,071 & 7,651 \\
\hline & & $(0,901)$ & $(<0,010)$ & $(<0,010)$ & $(<0,010)$ \\
\hline \multirow[t]{2}{*}{ Reg. Cúbica } & 1 & 1,027 & 0,136 & 11,610 & 12,034 \\
\hline & & $(0,264)$ & $(0,685)$ & $(<0,010)$ & $(<0,010)$ \\
\hline \multirow[t]{2}{*}{ Reg. Grau 4} & 1 & 2,846 & 4,921 & 0,018 & 3,689 \\
\hline & & $(0,062)$ & $(0,015)$ & $(0,876)$ & $(0,034)$ \\
\hline
\end{tabular}


Tabela 4B. Resumo da análise de regressão polinomial para a variável Vitamina C, em suco de tangor 'Murcote', tratado com 1-MCP na concentração de $0 ; 0,1 ; 0,5$ e $1,0 \mu \mathrm{L} \mathrm{L}^{-1}$ e armazenado sob refrigeração (mais 3 dias a $25^{\circ} \mathrm{C}$ ).

\begin{tabular}{|c|c|c|c|c|c|}
\hline \multirow{3}{*}{$\mathrm{CV}$} & \multirow{3}{*}{ GL } & \multicolumn{4}{|c|}{$\begin{array}{c}\text { QUADRADOS MÉDIOS } \\
\text { (PROB. > F) }\end{array}$} \\
\hline & & \multicolumn{4}{|c|}{ Concentração de 1-MCP $\left(\mu \mathrm{L} \mathrm{L}^{-1}\right)$} \\
\hline & & 0 & 0,1 & 0,5 & 1,0 \\
\hline Reg. Linear & 1 & $\begin{array}{c}13,075 \\
(<0,010)\end{array}$ & $\begin{array}{c}4,323 \\
(0,014)\end{array}$ & $\begin{array}{c}15,787 \\
(<0,010)\end{array}$ & $\begin{array}{c}1,814 \\
(0,107)\end{array}$ \\
\hline Reg. Quadr. & 1 & $\begin{array}{l}1,495 \\
(0,143)\end{array}$ & $\begin{array}{c}5,817 \\
(<0,010)\end{array}$ & $\begin{array}{c}12,080 \\
(<0,010)\end{array}$ & $\begin{array}{c}9,153 \\
(<0,010)\end{array}$ \\
\hline Reg. Cúbica & 1 & $\begin{array}{c}0,254 \\
(0,554)\end{array}$ & $\begin{array}{l}1,139 \\
(0,202)\end{array}$ & $\begin{array}{c}7,148 \\
(<0,010)\end{array}$ & $\begin{array}{c}3,214 \\
(0,033)\end{array}$ \\
\hline Reg. Grau 4 & 1 & $\begin{array}{c}1,793 \\
(0,109)\end{array}$ & $\begin{array}{c}1,600 \\
(0,130)\end{array}$ & $\begin{array}{c}4,682 \\
(0,011)\end{array}$ & $\begin{array}{c}1,468 \\
(0,147)\end{array}$ \\
\hline
\end{tabular}

Tabela 5. Resumo da análise de variância para a variável taxa respiratória (TR), em tangor 'Murcote', tratado com 1-MCP e armazenado sob refrigeração a $9{ }^{\circ} \mathrm{C}$ e após 3 dias a $25{ }^{\circ} \mathrm{C}$.

QUADRADOS MÉDIOS

(PROB. > F)

\begin{tabular}{lccc}
\multicolumn{1}{c}{$\mathrm{CV}$} & $\mathrm{GL}$ & $\begin{array}{c}\mathrm{TR}\left(9^{\circ} \mathrm{C}\right) \\
\left(\mathrm{mLCO}_{2} \mathrm{~kg}^{-1} \mathrm{~h}^{-1}\right)\end{array}$ & $\begin{array}{c}\mathrm{TR}\left(25^{\circ} \mathrm{C}\right) \\
\left(\mathrm{mL} \mathrm{CO}_{2} \mathrm{~kg}^{-1} \mathrm{~h}^{-1}\right)\end{array}$ \\
\hline Tratamentos & 3 & 71,185 & 11,325 \\
& & $(<0,010)$ & $(<0,010)$ \\
Período & 4 & 411,734 & 88,052 \\
& & $(<0,010)$ & $(<0,010)$ \\
Trat. * Período & 12 & 8,438 & 3,145 \\
& & $(<0,010)$ & $(0,100)$ \\
Resíduo & 60 & 1,528 & 1,898 \\
\hline
\end{tabular}

Tabela 5A. Resumo da análise de regressão polinomial para a variável taxa respiratória, em tangor 'Murcote', tratado com 1-MCP na concentração de 0; 0,1; 0,5 e 1,0 $\mu \mathrm{L} \mathrm{L}^{-1}$ e armazenado sob refrigeração (mais 3 dias a $25^{\circ} \mathrm{C}$ ).

\begin{tabular}{|c|c|c|c|c|c|}
\hline \multirow{3}{*}{$\mathrm{CV}$} & \multirow{3}{*}{ GL } & \multicolumn{4}{|c|}{$\begin{array}{l}\text { QUADRADOS MÉDIOS } \\
\text { (PROB. > F) }\end{array}$} \\
\hline & & \multicolumn{4}{|c|}{ Concentração de 1-MCP $\left(\mu \mathrm{L} \mathrm{L}^{-1}\right)$} \\
\hline & & 0 & 0,1 & 0,5 & 1,0 \\
\hline \multirow[t]{2}{*}{ Reg. Linear } & 1 & 64,617 & 160,200 & 123,517 & 264,813 \\
\hline & & $(<0,010)$ & $(<0,010)$ & $(<0,010)$ & $(<0,010)$ \\
\hline \multirow[t]{2}{*}{ Reg. Quadr. } & 1 & 30,164 & 232,030 & 192,215 & 155,044 \\
\hline & & $(<0,010)$ & $(<0,010)$ & $(<0,010)$ & $(<0,010)$ \\
\hline \multirow[t]{2}{*}{ Reg. Cúbica } & 1 & 69,090 & 34,875 & 42,066 & 41,330 \\
\hline & & $(<0,010)$ & $(<0,010)$ & $(<0,010)$ & $(<0,010)$ \\
\hline \multirow[t]{2}{*}{ Reg. Grau 4} & 1 & 76,410 & 52,661 & 94,238 & 114,918 \\
\hline & & $(<0,010)$ & $(<0,010)$ & $(<0,010)$ & $(<0,010)$ \\
\hline
\end{tabular}


Tabela 6. Resumo da análise de variância para as variáveis: perda de massa (PM) e quantidade de suco (\% suco), em tangor 'Murcote' tratado com 1-MCP e armazenado sob refrigeração (mais 3 dias a $25^{\circ} \mathrm{C}$ ).

\begin{tabular}{lccc}
\hline & & \multicolumn{3}{c}{$\begin{array}{c}\text { QUADRADOS MEDIOS } \\
\text { (PROB. > F) }\end{array}$} \\
\cline { 3 - 5 } CV & GL & PM & \% de suco \\
\hline Tratamentos & 3 & 10,141 & 15,227 \\
& & $(0,591)$ & $(<0,010)$ \\
Período & 4 & 55,500 & 15,794 \\
& & $(<0,010)$ & $(<0,010)$ \\
Trat. * Período & 12 & 10,443 & 1,806 \\
& & $(0,451)$ & $(<0,010)$ \\
Resíduo & 60 & 10,331 & 0,693 \\
\hline
\end{tabular}

Tabela 6A. Resumo da análise de regressão polinomial para a variável quantidade de suco (\%), em tangor 'Murcote', tratado com 1-MCP na concentração de 0; 0,1;0,5 e 1,0 $\mu \mathrm{L} \mathrm{L}^{-1}$ e armazenado sob refrigeração (mais 3 dias a $25^{\circ} \mathrm{C}$ ).

\begin{tabular}{|c|c|c|c|c|c|}
\hline \multirow{3}{*}{$\mathrm{CV}$} & \multirow{3}{*}{ GL } & \multicolumn{4}{|c|}{$\begin{array}{l}\text { QUADRADOS MÉDIOS } \\
\text { (PROB. > F) }\end{array}$} \\
\hline & & \multicolumn{4}{|c|}{ Concentração de 1-MCP $\left(\mu \mathrm{L} \mathrm{L}^{-1}\right)$} \\
\hline & & 0 & 0,1 & 0,5 & 1,0 \\
\hline \multirow[t]{2}{*}{ Reg. Linear } & 1 & 29,343 & 37,364 & 14,496 & 0,036 \\
\hline & & $(<0,010)$ & $(<0,010)$ & $(<0,010)$ & $(0,881)$ \\
\hline \multirow[t]{2}{*}{ Reg. Quadr. } & 1 & 9,397 & 23,659 & 52,303 & 3,283 \\
\hline & & $(0,023)$ & $(<0,010)$ & $(<0,010)$ & $(0,174)$ \\
\hline \multirow[t]{2}{*}{ Reg. Cúbica } & 1 & 8,299 & 5,162 & 2,299 & 49,617 \\
\hline & & $(0,032)$ & $(0,088)$ & $(0,256)$ & $(<0,010)$ \\
\hline \multirow[t]{2}{*}{ Reg. Grau 4} & 1 & 16,699 & 4,641 & 4,058 & 8,335 \\
\hline & & $(<0,010)$ & $(0,105)$ & $(0,130)$ & $(0,031)$ \\
\hline
\end{tabular}

Tabela 7. Resumo da análise de variância para a variável croma $\left(\mathrm{C}^{*}\right)$ e ângulo de cor $\left(\mathrm{h}^{\circ}\right)$, em casca de tangor 'Murcote', tratado com aminoetoxivinilglicina (AVG) e armazenado sob refrigeração (mais 3 dias a $25^{\circ} \mathrm{C}$ ).

\begin{tabular}{lccc}
\hline & & \multicolumn{3}{c}{$\begin{array}{c}\text { QUADADOS MEDIOS } \\
\text { CV }\end{array}$} & GL & $\left(\mathrm{C}^{*}\right)$ & $\left(\mathrm{h}^{\circ}\right)$ \\
\cline { 3 - 4 } \cline { 3 - 4 } & 3 & 34,210 & 4,441 \\
& & $(<0,010)$ & $(<0,010)$ \\
Pratamentos & 19,128 & 325,295 \\
Período & 4 & $(<0,010)$ & $(<0,010)$ \\
Trat. * Período & 12 & 10,490 & 1,791 \\
& & $(<0,010)$ & $(0,203)$ \\
Resíduo & 60 & 1,287 & 1,303
\end{tabular}


Tabela 7A. Resumo da análise de regressão polinomial para a variável croma $\left(\mathrm{C}^{*}\right)$, em casca de tangor 'Murcote', tratado com AVG na concentração de 0; 10; 50 e $100 \mathrm{mg} \mathrm{L}^{-1}$ e armazenado sob refrigeração (mais 3 dias a $25^{\circ} \mathrm{C}$ ).

\begin{tabular}{|c|c|c|c|c|c|}
\hline \multirow{3}{*}{$\mathrm{CV}$} & \multirow{3}{*}{ GL } & \multicolumn{4}{|c|}{$\begin{array}{c}\text { QUADRADOS MEDIOS } \\
\text { (PROB. > F) }\end{array}$} \\
\hline & & \multicolumn{4}{|c|}{ Concentração de AVG $\left(\mathrm{mg} \mathrm{L}^{-1}\right)$} \\
\hline & & 0 & 10 & 50 & 100 \\
\hline \multirow[t]{2}{*}{ Reg. Linear } & 1 & 49,350 & 37,191 & 2,396 & 0,915 \\
\hline & & $(<0,010)$ & $(<0,010)$ & $(0,174)$ & $(0,592)$ \\
\hline \multirow[t]{2}{*}{ Reg. Quadr. } & 1 & 0,363 & 1,601 & 11,116 & 13,027 \\
\hline & & $(0,603)$ & $(0,268)$ & $(<0,010)$ & $(<0,010)$ \\
\hline \multirow[t]{2}{*}{ Reg. Cúbica } & 1 & 37,713 & 2,621 & 24,071 & 16,256 \\
\hline & & $(<0,010)$ & $(0,155)$ & $(<0,010)$ & $(<0,010)$ \\
\hline \multirow[t]{2}{*}{ Reg. Grau 4} & 1 & 1,468 & 2,232 & 1,519 & 0,550 \\
\hline & & $(0,289)$ & $(0,189)$ & $(0,281)$ & $(0,522)$ \\
\hline
\end{tabular}

Tabela 8. Resumo da análise de variância, para as variáveis: sólidos solúveis totais (SST) e acidez titulável total (ATT), em tangor 'Murcote' tratado com AVG e armazenado sob refrigeração (mais 3 dias a $\left.25^{\circ} \mathrm{C}\right)$.

\begin{tabular}{lccc}
\hline & & \multicolumn{3}{c}{$\begin{array}{c}\text { QUADRADOS MEDIOS } \\
\text { (PROB. }>\text { F) }\end{array}$} \\
\cline { 3 - 4 } \multicolumn{1}{c}{ CV } & GL & SST & ATT \\
\hline Tratamentos & 3 & 3,406 & 0,000 \\
& & $(<0,010)$ & $(0,992)$ \\
Período & 4 & 1,951 & 0,107 \\
& & $(<0,010)$ & $(<0,010)$ \\
Trat. * Período & 12 & 0,448 & 0,001 \\
& & $(<0,010)$ & $0,610)$ \\
Resíduo & 60 & 0,153 & 0,001 \\
\hline
\end{tabular}

Tabela 8A. Resumo da análise de regressão polinomial para a variável sólidos solúveis totais (SST) em tangor 'Murcote', tratado com AVG na concentração de 0; 10; 50 e $100 \mathrm{mg} \mathrm{L}^{-1}$ e armazenado sob refrigeração (mais 3 dias a $25^{\circ} \mathrm{C}$ ).

\begin{tabular}{|c|c|c|c|c|c|}
\hline \multirow{3}{*}{$\mathrm{CV}$} & \multirow{3}{*}{ GL } & \multicolumn{4}{|c|}{$\begin{array}{c}\text { QUADRADOS MEDIOS } \\
\text { (PROB. > F) }\end{array}$} \\
\hline & & \multicolumn{4}{|c|}{ Concentração de AVG $\left(\mathrm{mg} \mathrm{L}^{-1}\right)$} \\
\hline & & 0 & 10 & 50 & 100 \\
\hline \multirow[t]{2}{*}{ Reg. Linear } & 1 & 0,000 & 9,182 & 0,306 & 1,225 \\
\hline & & $(1,000)$ & $(0,023)$ & $(0,155)$ & $(<0,010)$ \\
\hline \multirow[t]{2}{*}{ Reg. Quadr. } & 1 & 0,045 & 0,801 & 5,980 & 2,835 \\
\hline & & $(0,594)$ & $(0,024)$ & $(<0,010)$ & $(<0,010)$ \\
\hline \multirow[t]{2}{*}{ Reg. Cúbica } & 1 & 0,099 & 0,529 & 0,025 & 0,100 \\
\hline & & $(0,571)$ & $(0,064)$ & $(0,650)$ & $(0,572)$ \\
\hline \multirow[t]{2}{*}{ Reg. Grau 4} & 1 & 0,302 & 0,120 & 0,000 & 0,007 \\
\hline & & $(0,162)$ & $(0,616)$ & $(0,950)$ & $(0,826)$ \\
\hline
\end{tabular}


Tabela 9. Resumo da análise de variância, para as variáveis: ratio (SST/ATT) e ácido ascórbico (vit. C), em tangor 'Murcote' tratado com AVG e armazenado sob refrigeração (mais 3 dias a $25^{\circ} \mathrm{C}$ ).

\begin{tabular}{lccc}
\hline & & \multicolumn{3}{c}{$\begin{array}{c}\text { QUADRADOS MEDIOS } \\
\text { (PROB. > F) }\end{array}$} \\
\cline { 3 - 4 } \multicolumn{1}{c}{ CV } & GL & Ratio & Vit. C \\
\hline Tratamentos & 3 & 7,754 & 0,374 \\
& & $(<0,010)$ & $(0,753)$ \\
Período & 4 & 85,155 & 14,718 \\
& & $(<0,010)$ & $(<0,010)$ \\
Trat. * Período & 12 & 1,494 & 2,327 \\
& & $(0,018)$ & $(<0,010)$ \\
Resíduo & 60 & 0,655 & 0,925 \\
\hline
\end{tabular}

Tabela 9A. Resumo da análise de regressão polinomial para a variável ratio (SST/ATT) em tangor 'Murcote', tratado com AVG na concentração de 0; 10; 50 e $100 \mathrm{mg} \mathrm{L}^{-1}$ e armazenado sob refrigeração (mais 3 dias a $25^{\circ} \mathrm{C}$ ).

\begin{tabular}{|c|c|c|c|c|c|}
\hline \multirow{3}{*}{$\mathrm{CV}$} & \multirow{3}{*}{ GL } & \multicolumn{4}{|c|}{$\begin{array}{c}\text { QUADRADOS MÉDIOS } \\
\text { (PROB. > F) }\end{array}$} \\
\hline & & \multicolumn{4}{|c|}{ Concentração de AVG $\left(\mathrm{mg} \mathrm{L}^{-1}\right)$} \\
\hline & & 0 & 10 & 50 & 100 \\
\hline \multirow[t]{2}{*}{ Reg. Linear } & 1 & 44,478 & 96,783 & 109,825 & 80,032 \\
\hline & & $(<0,010)$ & $(<0,010)$ & $(<0,010)$ & $(<0,010)$ \\
\hline \multirow[t]{2}{*}{ Reg. Quadr. } & 1 & 0,011 & 0,754 & 2,036 & 5,760 \\
\hline & & $(0,890)$ & $(0,287)$ & $(0,079)$ & $(<0,010)$ \\
\hline \multirow[t]{2}{*}{ Reg. Cúbica } & 1 & 1,027 & 0,028 & 5,012 & 1,604 \\
\hline & & $(0,213)$ & $(0,831)$ & $(<0,010)$ & $(0,119)$ \\
\hline \multirow[t]{2}{*}{ Reg. Grau 4} & 1 & 2,846 & 1,159 & 3,445 & 3,746 \\
\hline & & $(0,039)$ & $(0,185)$ & $(0,023)$ & $(0,018)$ \\
\hline
\end{tabular}

Tabela 9B. Resumo da análise de regressão polinomial para a variável vitamina $\mathrm{C}$ em tangor 'Murcote', tratado com AVG na concentração de $0 ; 10 ; 50$ e $100 \mathrm{mg} \mathrm{L}^{-1}$ e armazenado sob refrigeração (mais 3 dias a $25^{\circ} \mathrm{C}$ ).

\begin{tabular}{cccccc}
\hline & & \multicolumn{4}{c}{ QUADRADOS MEDIOS } \\
\cline { 3 - 5 } CV & GL & 0 & \multicolumn{4}{c}{ Concentração de AVG $\left(\mathrm{mg} \mathrm{L}^{-1}\right)$} \\
\cline { 3 - 5 } & & 13,075 & 0,625 & 50 & 100 \\
\hline Reg. Linear & 1 & $(<0,010)$ & $(0,580)$ & $(0,155$ & 1,122 \\
& & 1,496 & 9,217 & 13,143 & $(0,274)$ \\
Reg. Quadr. & 1 & $(0,206)$ & $(<0,010)$ & $(<0,010)$ & 10,683 \\
& & 0,254 & 8,145 & 12,354 & $(<0,010)$ \\
Reg. Cúbica & 1 & $(0,608)$ & $(<0,010)$ & $(<0,010)$ & $(0,045)$ \\
& & 1,793 & 5,751 & 3,627 & 1,603 \\
Reg. Grau 4 & 1 & $(0,165)$ & $(0,014)$ & $(0,049)$ & $(0,190)$ \\
& & & &
\end{tabular}


Tabela 10. Resumo da análise de variância para a variável taxa respiratória (TR), em tangor 'Murcote', tratado com AVG e armazenado sob refrigeração a $9{ }^{\circ} \mathrm{C}$ e após 3 dias a $25^{\circ} \mathrm{C}$.

\begin{tabular}{lccc}
\hline & & \multicolumn{2}{c}{$\begin{array}{c}\text { QUADRADOS MEDIOS } \\
\text { (PROB. }>\mathrm{F})\end{array}$} \\
\cline { 3 - 4 } & $\mathrm{GL}$ & $\mathrm{TR}\left(9^{\circ} \mathrm{C}\right)$ & $\mathrm{TR}\left(25^{\circ} \mathrm{C}\right)$ \\
& & $\left(\mathrm{mL} \mathrm{CO}_{2} \mathrm{~kg}^{-1} \mathrm{~h}^{-1}\right)$ & 32,159 \\
& 3 & 57,266 & $\left(\mathrm{~mL} \mathrm{CO}_{2} \mathrm{~kg}^{-1} \mathrm{~h}^{-1}\right)$ \\
\hline Tratamentos & & $(<0,010)$ & 112,124 \\
Período & 4 & 371,115 & $(<0,010)$ \\
& & $(<0,010)$ & 12,816 \\
Trat. * Período & 12 & 12,506 & $(<0,010)$ \\
& & $(<0,010)$ & 1,906 \\
Resíduo & 60 & 1,453 & \\
\hline
\end{tabular}

Tabela 10A. Resumo da análise de regressão polinomial para a variável taxa respiratória em tangor 'Murcote', tratado com AVG na concentração de 0; 10; 50 e $100 \mathrm{mg} \mathrm{L}^{-1}$ e armazenado sob refrigeração a $9 \pm 1^{\circ} \mathrm{C}$.

\begin{tabular}{lccccc}
\hline & & \multicolumn{4}{c}{$\begin{array}{c}\text { QUADRADOS MEDIOS } \\
\text { (PROB. }>\text { F) }\end{array}$} \\
\cline { 3 - 5 } CV & GL & 0 & \multicolumn{4}{c}{ Concentração de AVG (mg L $\left.{ }^{-1}\right)$} \\
& & 64,617 & 65,664 & 50 & 100 \\
\hline Reg. Linear & 1 & $(<0,010)$ & $(<0,010)$ & 113,838 & $(<0,010)$ \\
& & 30,164 & 89,941 & 119,544 & $(<0,010)$ \\
Reg. Quadr. & 1 & $(<0,010)$ & $(<0,010)$ & $(<0,010)$ & 236,201 \\
& & 69,090 & 83,665 & 14,149 & $(<0,010)$ \\
Reg. Cúbica & 1 & $(<0,010)$ & $(<0,010)$ & $(<0,010)$ & 2,171 \\
& & 76,410 & 84,887 & 222,340 & $(0,224)$ \\
Reg. Grau 4 & 1 & $(<0,010)$ & $(<0,010)$ & $(<0,010)$ & $(<0,265$ \\
& & & &
\end{tabular}

Tabela 10B. Resumo da análise de regressão polinomial para a variável taxa respiratória em tangor 'Murcote', tratado com AVG na concentração de 0; 10; 50 e $100 \mathrm{mg} \mathrm{L}^{-1}$ e armazenado sob refrigeração a $25^{\circ} \mathrm{C}$.

\begin{tabular}{lccccc}
\hline & & \multicolumn{4}{c}{ QUADRADOS MEDIOS } \\
\cline { 3 - 5 } CV & GL & 0 & \multicolumn{4}{c}{ Concentração de AVG $\left(\mathrm{mg} \mathrm{L}^{-1}\right)$} \\
\cline { 3 - 5 } & & 0,046 & 10 & 50 & 100 \\
\hline Reg. Linear & 1 & $(0,871)$ & $(0,583)$ & 9,870 & 10,070 \\
& & 17,831 & 164,434 & $40,025)$ & $(0,023)$ \\
Reg. Quadr. & 1 & $(<0,010)$ & $(<0,010)$ & $(<0,010)$ & 23,881 \\
& & 60,934 & 50,153 & 86,112 & $(<0,010)$ \\
Reg. Cúbica & 1 & $(<0,010)$ & $(<0,010)$ & $(<0,010)$ & 29,601 \\
& & 0,444 & 96,444 & 3,905 & $(<0,010)$ \\
Reg. Grau 4 & 1 & $(0,636)$ & $(<0,010)$ & $(0,153)$ & 0,904 \\
& & & & & \\
& & &
\end{tabular}


Tabela 11. Resumo da análise de variância para as variáveis: perda de massa (PM) e quantidade de suco (\% suco), em tangor 'Murcote' tratado com AVG e armazenado sob refrigeração (mais 3 dias a $25^{\circ} \mathrm{C}$ ).

\begin{tabular}{|c|c|c|c|}
\hline \multirow[b]{2}{*}{$\mathrm{CV}$} & \multirow[b]{2}{*}{ GL } & \multicolumn{2}{|c|}{$\begin{array}{c}\text { QUADRADOS MEDIOS } \\
\text { (PROB. > F) }\end{array}$} \\
\hline & & PM & $\%$ de suco \\
\hline Tratamentos & 3 & $\begin{array}{c}0,021 \\
(0,188)\end{array}$ & $\begin{array}{c}18,291 \\
(<0,010)\end{array}$ \\
\hline Período & 4 & $\begin{array}{c}22,496 \\
(<0,010)\end{array}$ & $\begin{array}{l}102,265 \\
(<0,010)\end{array}$ \\
\hline Trat. * Período & 12 & $\begin{array}{c}0,014 \\
(0,394)\end{array}$ & $\begin{array}{c}5,708 \\
(<0,010)\end{array}$ \\
\hline Resíduo & 60 & 0,013 & 1,710 \\
\hline
\end{tabular}

Tabela 11A. Resumo da análise de regressão polinomial para a variável quantidade de suco em tangor 'Murcote', tratado com AVG na concentração de 0; 10; 50 e $100 \mathrm{mg} \mathrm{L}^{-1}$ e armazenado sob refrigeração (mais 3 dias a $25^{\circ} \mathrm{C}$ ).

\begin{tabular}{lccccc}
\hline & & \multicolumn{4}{c}{$\begin{array}{c}\text { QUADRADOS MEDIOS } \\
\text { (PROB. > F) }\end{array}$} \\
\cline { 3 - 5 } CV & GL & 0 & \multicolumn{4}{c}{ Concentração de AVG $\left(\mathrm{mg} \mathrm{L}^{-1}\right)$} \\
& & 29,343 & 75,993 & 10 & 100 \\
\hline Reg. Linear & 1 & $(<0,010)$ & $(<0,010)$ & $(0,011)$ & $(<0,687$ \\
& & 9,397 & 34,870 & 150,093 & 79,063 \\
Reg. Quadr. & 1 & $(0,021)$ & $(<0,010)$ & $(<0,010)$ & $(<0,010)$ \\
& & 8,299 & 0,515 & 2,445 & 4,644 \\
Reg. Cúbica & 1 & $(0,029)$ & $(0,592)$ & $(0,234)$ & $(0,100)$ \\
& & 16,699 & 18,247 & 3,765 & 14,918 \\
Reg. Grau 4 & 1 & $(<0,010)$ & $(<0,010)$ & $(0,139)$ & $(<0,010)$ \\
& & & & &
\end{tabular}

Tabela 12. Resumo da análise de variância, para as variáveis: croma $\left(\mathrm{C}^{*}\right)$ e ângulo de cor $\left(\mathrm{h}^{\mathrm{o}}\right)$, em casca de tangor 'Murcote' tratado com biorreguladores $\left(\mathrm{GA}_{3}, 1-\mathrm{MCP}\right.$ e AVG) e armazenado sob refrigeração (mais 3 dias a $25^{\circ} \mathrm{C}$ ).

\begin{tabular}{lccc}
\hline & & \multicolumn{3}{c}{$\begin{array}{c}\text { QUADRADOS MEDIOS } \\
\text { (PROB. }>\text { F) }\end{array}$} \\
\cline { 3 - 4 } \multicolumn{1}{c}{$\mathrm{CV}$} & $\mathrm{GL}$ & $\left(\mathrm{C}^{*}\right)$ & $\left(\mathrm{h}^{\mathrm{o}}\right)$ \\
\hline Tratamentos & 3 & $(<0,069$ & 4,0126 \\
& & 179,300 & $(<0,010)$ \\
Período & 4 & $(<0,010)$ & 393,049 \\
& & 17,491 & $(<0,010)$ \\
Trat. * Período & 12 & $(<0,010)$ & 3,165 \\
& & 0,472 & 0,368 \\
Resíduo (Trat.) & 9 & & $0,010)$ \\
& & 0,907 & 0,899 \\
Resíduo (Período) & 48 & & \\
\hline
\end{tabular}


Tabela 12A. Resumo da análise de regressão polinomial para a variável croma $\left(\mathrm{C}^{*}\right)$, em casca de tangor 'Murcote', tratado com Biorreguladores e armazenado sob refrigeração (mais 3 dias a $25^{\circ} \mathrm{C}$ ).

\begin{tabular}{|c|c|c|c|c|c|}
\hline \multirow{3}{*}{$\mathrm{CV}$} & \multirow{3}{*}{ GL } & \multicolumn{4}{|c|}{$\begin{array}{l}\text { QUADRADOS MEDIOS } \\
\text { (PROB. > F) }\end{array}$} \\
\hline & & \multicolumn{4}{|c|}{ Biorreguladores } \\
\hline & & Controle & $\mathrm{GA}_{3}$ & $1-\mathrm{MCP}+\mathrm{GA}_{3}$ & $\mathrm{AVG}+\mathrm{GA}_{3}$ \\
\hline \multirow[t]{2}{*}{ Reg. Linear } & 1 & 82,426 & 49,974 & 225,102 & 175,194 \\
\hline & & $(<0,010)$ & $(<0,010)$ & $(<0,010)$ & $(<0,010)$ \\
\hline \multirow[t]{2}{*}{ Reg. Quadr. } & 1 & 106,701 & 98,288 & 0,554 & 5,651 \\
\hline & & $(<0,010)$ & $(<0,010)$ & $(0,555)$ & $(0,015)$ \\
\hline \multirow[t]{2}{*}{ Reg. Cúbica } & 1 & 27,872 & 74,856 & 24,149 & 29,275 \\
\hline & & $(<0,010)$ & $(<0,010)$ & $(<0,010)$ & $(<0,010)$ \\
\hline \multirow[t]{2}{*}{ Reg. Grau 4} & 1 & 0,017 & 5,266 & 13,359 & 8,414 \\
\hline & & $(0,884)$ & $(0,019)$ & $(<0,010)$ & $(<0,010)$ \\
\hline
\end{tabular}

Tabela 12B. Resumo da análise de regressão polinomial para variável ângulo de cor $\left(\mathrm{h}^{\mathrm{o}}\right)$, em casca de tangor 'Murcote', tratado com Biorreguladores e armazenado sob refrigeração (mais 3 dias a $25^{\circ} \mathrm{C}$ ).

\begin{tabular}{|c|c|c|c|c|c|}
\hline \multirow{3}{*}{$\mathrm{CV}$} & \multirow{3}{*}{ GL } & \multicolumn{4}{|c|}{$\begin{array}{l}\text { QUADRADOS MEDIOS } \\
\text { (PROB. }>\text { F) }\end{array}$} \\
\hline & & \multicolumn{4}{|c|}{ Biorreguladores } \\
\hline & & Controle & $\mathrm{GA}_{3}$ & $1-\mathrm{MCP}+\mathrm{GA}_{3}$ & $\mathrm{AVG}+\mathrm{GA}_{3}$ \\
\hline \multirow[t]{2}{*}{ Reg. Linear } & 1 & 401,322 & 299,208 & 429,025 & 310,249 \\
\hline & & $(<0,010)$ & $(<0,010)$ & $(<0,010)$ & $(<0,010)$ \\
\hline \multirow[t]{2}{*}{ Reg. Quadr. } & 1 & 41,650 & 37,131 & 18,514 & 28,571 \\
\hline & & $(<0,010)$ & $(<0,010)$ & $(<0,010)$ & $(<0,010)$ \\
\hline \multirow[t]{2}{*}{ Reg. Cúbica } & 1 & 9,408 & 7,832 & 0,006 & 5,852 \\
\hline & & $(<0,010)$ & $(<0,010)$ & $(0,931)$ & $(0,013)$ \\
\hline \multirow[t]{2}{*}{ Reg. Grau 4} & 1 & 14,175 & 1,840 & 4,915 & 0,472 \\
\hline & & $(<0,010)$ & $(0,155)$ & $(0,022)$ & $(0,521)$ \\
\hline
\end{tabular}

Tabela 13. Resumo da análise de variância para a variável sólidos solúveis totais (SST) e acidez titulável total (ATT), em tangor 'Murcote' tratado com biorreguladores (GA 3 , 1MCP e AVG) e armazenado sob refrigeração (mais 3 dias a $25^{\circ} \mathrm{C}$ ).

\begin{tabular}{lccc}
\hline \multicolumn{1}{c}{ CV } & & \multicolumn{3}{c}{$\begin{array}{c}\text { QUADRADOS MÉDIOS } \\
\text { (PROB. }>\text { F) }\end{array}$} \\
\cline { 3 - 4 } \cline { 3 - 4 } & GL & (SST) & (ATT) \\
Tratamentos & 3 & 3,104 & 0,0017 \\
Período & 4 & $(<0,010)$ & $(0,161)$ \\
& & 1,600 & 0,1009 \\
Trat. * Período & 12 & $(<0,010)$ & $(<0,010)$ \\
& & 0,474 & 0,0004 \\
Resíduo (Trat.) & 9 & $(<0,010)$ & $0,988)$ \\
& & 0,214 & 0,0008 \\
Resíduo (Período) & 48 & & 0,0016 \\
\hline
\end{tabular}


Tabela 13A. Resumo da análise de regressão polinomial para a variável sólidos solúveis totais (SST) em tangor 'Murcote', tratado com Biorreguladores e armazenado sob refrigeração (mais 3 dias a $\left.25^{\circ} \mathrm{C}\right)$.

\begin{tabular}{|c|c|c|c|c|c|}
\hline \multirow{3}{*}{$\mathrm{CV}$} & \multirow{3}{*}{ GL } & \multicolumn{4}{|c|}{$\begin{array}{l}\text { QUADRADOS MÉDIOS } \\
\text { (PROB. > F) }\end{array}$} \\
\hline & & \multicolumn{4}{|c|}{ Biorreguladores } \\
\hline & & Controle & $\mathrm{GA}_{3}$ & $1-\mathrm{MCP}+\mathrm{GA}_{3}$ & $\mathrm{AVG}+\mathrm{GA}_{3}$ \\
\hline \multirow[t]{2}{*}{ Reg. Linear } & 1 & 0,000 & 0,182 & 0,289 & 0,256 \\
\hline & & $(1,000)$ & $(0,261)$ & $(0,156)$ & $(0,181)$ \\
\hline \multirow[t]{2}{*}{ Reg. Quadr. } & 1 & 0,045 & 0,051 & 3,702 & 6,446 \\
\hline & & $(0,579)$ & $(0,555)$ & $(<0,010)$ & $(<0,010)$ \\
\hline \multirow[t]{2}{*}{ Reg. Cúbica } & 1 & 0,099 & 0,030 & 0,072 & 0,020 \\
\hline & & $(0,590)$ & $(0,650)$ & $(0,514)$ & $(0,708)$ \\
\hline \multirow[t]{2}{*}{ Reg. Grau 4} & 1 & 0,302 & 0,048 & 0,078 & 0,472 \\
\hline & & $(0,146)$ & $(0,566)$ & $(0,534)$ & $(0,071)$ \\
\hline
\end{tabular}

Tabela 14. Resumo da análise de variância para a variável ratio (SST/ATT) e ácido ascórbico (vit. C), em tangor 'Murcote' tratado com biorreguladores ( $\mathrm{GA}_{3}, 1-\mathrm{MCP}$ e AVG) e armazenado sob refrigeração (mais 3 dias a $25^{\circ} \mathrm{C}$ ).

\begin{tabular}{lccc}
\hline & & \multicolumn{3}{c}{$\begin{array}{c}\text { QUADRADOS MEDIOS } \\
\text { (PROB. }>\text { F) }\end{array}$} \\
\cline { 3 - 4 } \multicolumn{1}{c}{ CV } & GL & (Ratio) & (vit. C) \\
\hline Tratamentos & 3 & 13,878 & 2,862 \\
& & $(<0,010)$ & $(0,031)$ \\
Período & 4 & 75,228 & 20,590 \\
& & $(<0,010)$ & $(<0,010)$ \\
Trat. * Período & 12 & 2,225 & 1,418 \\
& & $(0,054)$ & $0,187)$ \\
Resíduo (Trat.) & 9 & 1,182 & 0,615 \\
& & & 0,995 \\
Resíduo (Período) & 48 & 1,153 & \\
\hline
\end{tabular}

Tabela 15. Resumo da análise de variância para a variável taxa respiratória (TR), em tangor 'Murcote', tratado com biorreguladores $\left(\mathrm{GA}_{3}, 1-\mathrm{MCP}\right.$ e $\left.\mathrm{AVG}\right)$, sob refrigeração a $9{ }^{\circ} \mathrm{C}$ e após 3 dias a $25^{\circ} \mathrm{C}$.

\begin{tabular}{|c|c|c|c|}
\hline \multirow[b]{2}{*}{$\mathrm{CV}$} & \multirow[b]{2}{*}{ GL } & \multicolumn{2}{|c|}{$\begin{array}{c}\text { QUADRADOS MEDIOS } \\
\text { (PROB. > F) }\end{array}$} \\
\hline & & $\begin{array}{c}\mathrm{TR}\left(9^{\circ} \mathrm{C}\right) \\
\left(\mathrm{mLCO}_{2} \mathrm{~kg}^{-1} \mathrm{~h}^{-1}\right)\end{array}$ & $\begin{array}{c}\operatorname{TR}\left(25^{\circ} \mathrm{C}\right) \\
\left(\mathrm{mL} \mathrm{CO}_{2} \mathrm{~kg}^{-1} \mathrm{~h}^{-1}\right)\end{array}$ \\
\hline Tratamentos & 3 & 10,839 & 12,994 \\
\hline & & $(0,021)$ & $(0,027)$ \\
\hline Período & 4 & 318,275 & 62,278 \\
\hline & & $(<0,010)$ & $(<0,010)$ \\
\hline Trat. * Período & 12 & 7,129 & 9,867 \\
\hline & & $(<0,010)$ & $(<0,010)$ \\
\hline Resíduo (Trat.) & 9 & 2,029 & 2,658 \\
\hline Resíduo (Período) & 48 & 2,072 & 1,924 \\
\hline
\end{tabular}


Tabela 15A. Resumo da análise de regressão polinomial para a variável taxa respiratória (TR), em tangor 'Murcote', tratado com Biorreguladores e armazenado sob refrigeração.

\begin{tabular}{|c|c|c|c|c|c|}
\hline \multirow{3}{*}{$\mathrm{CV}$} & \multirow{3}{*}{ GL } & \multicolumn{4}{|c|}{$\begin{array}{l}\text { QUADRADOS MÉDIOS } \\
\text { (PROB. > F) }\end{array}$} \\
\hline & & \multicolumn{4}{|c|}{ Biorreguladores } \\
\hline & & Controle & $\mathrm{GA}_{3}$ & $1-\mathrm{MCP}+\mathrm{GA}_{3}$ & $\mathrm{AVG}+\mathrm{GA}_{3}$ \\
\hline \multirow[t]{2}{*}{ Reg. Linear } & 1 & 64,617 & 134,835 & 115,294 & 102,048 \\
\hline & & $(<0,010)$ & $(<0,010)$ & $(<0,010)$ & $(<0,010)$ \\
\hline \multirow[t]{2}{*}{ Reg. Quadr. } & 1 & 30,164 & 79,158 & 49,613 & 99,724 \\
\hline & & $(<0,010)$ & $(<0,010)$ & $(<0,010)$ & $(<0,010)$ \\
\hline \multirow[t]{2}{*}{ Reg. Cúbica } & 1 & 69,090 & 36,423 & 1,714 & 2,819 \\
\hline & & $(<0,010)$ & $(<0,010)$ & $(0,629)$ & $(0,247)$ \\
\hline \multirow[t]{2}{*}{ Reg. Grau 4} & 1 & 76,410 & 102,450 & 263,451 & 130,835 \\
\hline & & $(<0,010)$ & $(<0,010)$ & $(<0,010)$ & $(<0,010)$ \\
\hline
\end{tabular}

Tabela 15B. Resumo da análise de regressão polinomial para a variável taxa respiratória (TR), em tangor 'Murcote', tratado com Biorreguladores e armazenado sob refrigeração (mais 3 dias a $25^{\circ} \mathrm{C}$ ).

\begin{tabular}{|c|c|c|c|c|c|}
\hline \multirow{3}{*}{$\mathrm{CV}$} & \multirow{3}{*}{ GL } & \multicolumn{4}{|c|}{$\begin{array}{l}\text { QUADRADOS MEDIOS } \\
\text { (PROB. > F) }\end{array}$} \\
\hline & & \multicolumn{4}{|c|}{ Biorreguladores } \\
\hline & & Controle & $\mathrm{GA}_{3}$ & $1-\mathrm{MCP}+\mathrm{GA}_{3}$ & $\mathrm{AVG}+\mathrm{GA}_{3}$ \\
\hline \multirow[t]{2}{*}{ Reg. Linear } & 1 & 0,718 & 3,648 & 13,294 & 0,891 \\
\hline & & $(0,551)$ & $(0,171)$ & $(0,011)$ & $(0,506)$ \\
\hline \multirow[t]{2}{*}{ Reg. Quadr. } & 1 & 13,602 & 14,606 & 46,546 & 0,492 \\
\hline & & $(<0,010)$ & $(<0,010)$ & $(<0,010)$ & $(0,621)$ \\
\hline \multirow[t]{2}{*}{ Reg. Cúbica } & 1 & 82,282 & 90,420 & 57,768 & 2,596 \\
\hline & & $(<0,010)$ & $(<0,010)$ & $(<0,010)$ & $(0,249)$ \\
\hline \multirow[t]{2}{*}{ Reg. Grau 4} & 1 & 2,632 & 11,931 & 38,621 & 17,465 \\
\hline & & $(0,246)$ & $(0,015)$ & $(<0,010)$ & $(<0,010)$ \\
\hline
\end{tabular}

Tabela 16. Resumo da análise de variância para a variável perda de massa (PM) e quantidade de suco (\% suco), em tangor 'Murcote' tratado com biorreguladores ( $\mathrm{GA}_{3}$, 1-MCP e AVG) e armazenado sob refrigeração (mais 3 dias a $25^{\circ} \mathrm{C}$ ).

\begin{tabular}{lccc}
\hline & & \multicolumn{3}{c}{$\begin{array}{c}\text { QUADADOS MÉEIOS } \\
\text { (PROB. > F) }\end{array}$} \\
\cline { 3 - 4 } \multicolumn{1}{c}{ CV } & GL & $(\mathrm{PM})$ & $(\%$ suco) \\
\cline { 3 - 4 } Tratamentos & 3 & 1,827 & 11,947 \\
& & $(0,560)$ & $(<0,010)$ \\
Período & 4 & 19,991 & 56,791 \\
& & $(<0,010)$ & $(<0,010)$ \\
Trat. * Período & 12 & 2,205 & 11,817 \\
& & $(0,408)$ & 0,625 \\
Resíduo (Trat.) & 9 & 1,835 & 1,712 \\
& & & \\
Resíduo (Período) & 48 & 2,068 & \\
\hline
\end{tabular}


Tabela 16A. Resumo da análise de regressão polinomial para a variável quantidade de suco (\% suco), em tangor 'Murcote', tratado com Biorreguladores e armazenado sob refrigeração (mais 3 dias a $25^{\circ} \mathrm{C}$ ).

\begin{tabular}{|c|c|c|c|c|c|}
\hline \multirow{3}{*}{$\mathrm{CV}$} & \multirow{3}{*}{ GL } & \multicolumn{4}{|c|}{$\begin{array}{c}\text { QUADRADOS MÉDIOS } \\
\text { (PROB. > F) }\end{array}$} \\
\hline & & \multicolumn{4}{|c|}{ Biorreguladores } \\
\hline & & Controle & $\mathrm{GA}_{3}$ & $1-\mathrm{MCP}+\mathrm{GA}_{3}$ & $\mathrm{AVG}+\mathrm{GA}_{3}$ \\
\hline \multirow[t]{2}{*}{ Reg. Linear } & 1 & 29,343 & 39,263 & 11,675 & 38,044 \\
\hline & & $(<0,010)$ & $(<0,010)$ & $(0,011)$ & $(<0,010)$ \\
\hline \multirow[t]{2}{*}{ Reg. Quadr. } & 1 & 9,397 & 2,260 & 145,125 & 45,018 \\
\hline & & $(0,022)$ & $(0,255)$ & $(<0,010)$ & $(<0,010)$ \\
\hline \multirow[t]{2}{*}{ Reg. Cúbica } & 1 & 8,299 & 0,344 & 10,231 & 1,413 \\
\hline & & $(0,030)$ & $(0,660)$ & $(0,017)$ & $(0,628)$ \\
\hline \multirow[t]{2}{*}{ Reg. Grau 4} & 1 & 16,699 & 4,950 & 5,977 & 0,935 \\
\hline & & $(<0,010)$ & $(0,092)$ & $(0,064)$ & $(0,529)$ \\
\hline
\end{tabular}

Tabela 17. Resumo da análise de variância, para as variáveis: croma $\left(\mathrm{C}^{*}\right)$ e ângulo de cor $\left(\mathrm{h}^{\circ}\right)$, em casca de lima ácida 'Tahiti' tratada com 1-MCP e armazenada sob refrigeração (mais 3 dias a $25^{\circ} \mathrm{C}$ ).

\begin{tabular}{lccc}
\hline & & \multicolumn{3}{c}{$\begin{array}{c}\text { QUADRADOS MEDIOS } \\
\text { (PROB. }>\text { F) }\end{array}$} \\
\cline { 3 - 4 } $\begin{array}{c}\text { CV } \\
\text { Tratamentos }\end{array}$ & GL & $\left(\mathrm{C}^{*}\right)$ & $\left(\mathrm{h}^{\circ}\right)$ \\
& 3 & 39,190 & 13,578 \\
Período & & $(<0,010)$ & $(<0,010)$ \\
& 4 & 1547,709 & 919,821 \\
Trat. * Período & 12 & $(<0,010)$ & $(<0,010)$ \\
& & 7,160 & 4,192 \\
Resíduo & 40 & $(<0,010)$ & $(<0,010)$ \\
\hline
\end{tabular}

Tabela 17A. Resumo da análise de regressão polinomial para a variável croma $\left(\mathrm{C}^{*}\right)$, em casca de lima ácida 'Tahiti' tratada com 1-MCP na concentração de $0 ; 0,1 ; 0,5$ e $1,0 \mu \mathrm{L} \mathrm{L}^{-1}$ e armazenada sob refrigeração (mais 3 dias a $25^{\circ} \mathrm{C}$ ).

\begin{tabular}{cccccc}
\hline & & \multicolumn{4}{c}{$\begin{array}{c}\text { QUADRDOS MEDIOS } \\
\text { (PROB. }>\text { F) }\end{array}$} \\
\cline { 3 - 5 } CV & GL & 0 & 0,1 & 0,5 & 1,0 \\
\hline Reg. Linear & 1 & 1717,633 & 1179,637 & 1063,503 & 1045,952 \\
& & $(<0,010)$ & $(<0,010)$ & $(<0,010)$ & $(<0,010)$ \\
Reg. Quadr. & 1 & 319,718 & 265,508 & 363,737 & 256,830 \\
& & $(<0,010)$ & $(<0,010)$ & $(<0,010)$ & $(<0,010)$ \\
Reg. Cúbica & 1 & 3,605 & 7,813 & 0,441 & 0,088 \\
& & $(0,038)$ & $(<0,010)$ & $(0,529)$ & $(0,741)$ \\
Reg. Grau 4 & 1 & 1,508 & 3,453 & 35,366 & 11,966 \\
& & $(0,176)$ & $(0,042)$ & $(<0,010)$ & $(<0,010)$ \\
\hline
\end{tabular}


Tabela 17B. Resumo da análise de regressão polinomial para a variável ângulo de cor $\left(\mathrm{h}^{\mathrm{o}}\right)$, em casca de lima ácida 'Tahiti', tratada com $1 \mathrm{MCP}$ na concentração de $0 ; 0,1 ; 0,5$ e $1,0 \mu \mathrm{L} \mathrm{L} \mathrm{L}^{-1} \mathrm{e}$ armazenada sob refrigeração (mais 3 dias a $25^{\circ} \mathrm{C}$ ).

\begin{tabular}{|c|c|c|c|c|c|}
\hline \multirow{3}{*}{$\mathrm{CV}$} & \multirow{3}{*}{ GL } & \multicolumn{4}{|c|}{$\begin{array}{c}\text { QUADRADOS MEDIOS } \\
\text { (PROB. > F) }\end{array}$} \\
\hline & & \multicolumn{4}{|c|}{ Concentração de 1-MCP $\left(\mu L^{-1}\right)$} \\
\hline & & 0 & 0,1 & 0,5 & 1,0 \\
\hline \multirow[t]{2}{*}{ Reg. Linear } & 1 & 1041,941 & 849,072 & 727,176 & 738,048 \\
\hline & & $(<0,010)$ & $(<0,010)$ & $(<0,010)$ & $(<0,010)$ \\
\hline \multirow[t]{2}{*}{ Reg. Quadr. } & 1 & 57,634 & 141,166 & 68,148 & 78,994 \\
\hline & & $(<0,010)$ & $(<0,010)$ & $(<0,010)$ & $(<0,010)$ \\
\hline \multirow[t]{2}{*}{ Reg. Cúbica } & 1 & 0,005 & 7,301 & 1,452 & 0,507 \\
\hline & & $(0,944)$ & $(0,014)$ & $(0,262)$ & $(0,513)$ \\
\hline \multirow[t]{2}{*}{ Reg. Grau 4} & 1 & 1,475 & 11,433 & 3,680 & 1,560 \\
\hline & & $(0,258)$ & $(<0,010)$ & $(0,075)$ & $(0,245)$ \\
\hline
\end{tabular}

Tabela 18. Resumo da análise de variância, para as variáveis: sólidos solúveis totais (SST) e acidez titulável total (ATT), em lima ácida 'Tahiti' tratada com 1-MCP e armazenada sob refrigeração (mais 3 dias a $25^{\circ} \mathrm{C}$ ).

\begin{tabular}{lccc}
\hline & & \multicolumn{3}{c}{$\begin{array}{c}\text { QUADRADOS MÉtiOS } \\
\text { (PROB. }>\text { F) }\end{array}$} \\
\cline { 3 - 4 } \multicolumn{1}{c}{ CV } & GL & SST & ATT \\
\hline Tratamentos & 3 & 0,000 & 0,043 \\
& & $(0,403)$ & $(<0,010)$ \\
Período & 4 & 0,534 & 0,423 \\
& & $(<0,010)$ & $(<0,010)$ \\
Trat. * Período & 12 & 0,0027 & 0,064 \\
& & $(<0,010)$ & $(<0,010)$ \\
Resíduo & 40 & 0,0007 & 0,005 \\
\hline
\end{tabular}

Tabela 18A. Resumo da análise de regressão polinomial para a variável sólidos solúveis totais $\left({ }^{\circ}\right.$ Brix), em lima ácida 'Tahiti', tratada com $1 \mathrm{MCP}$ na concentração de $0 ; 0,1 ; 0,5$ e $1,0 \mu \mathrm{L} \mathrm{L}^{-1} \mathrm{e}$ armazenada sob refrigeração (mais 3 dias a $25^{\circ} \mathrm{C}$ ).

\begin{tabular}{|c|c|c|c|c|c|}
\hline \multirow{3}{*}{$\mathrm{CV}$} & \multirow{3}{*}{ GL } & \multicolumn{4}{|c|}{$\begin{array}{c}\text { QUADRADOS MÉDIOS } \\
\text { (PROB. > F) }\end{array}$} \\
\hline & & \multicolumn{4}{|c|}{ Concentração de 1-MCP $\left(\mu \mathrm{L} \mathrm{L}^{-1}\right)$} \\
\hline & & 0 & 0,1 & 0,5 & 1,0 \\
\hline \multirow[t]{2}{*}{ Reg. Linear } & 1 & 0,000 & 0,056 & 0,341 & 0,120 \\
\hline & & $(0,945)$ & $(0,056)$ & $(<0,010)$ & $(<0,010)$ \\
\hline \multirow[t]{2}{*}{ Reg. Quadr. } & 1 & 0,349 & 0,619 & 0,746 & 0,720 \\
\hline & & $(<0,010)$ & $(<0,010)$ & $(<0,010)$ & $(<0,010)$ \\
\hline \multirow[t]{2}{*}{ Reg. Cúbica } & 1 & 0,078 & 0,280 & 0,027 & 0,001 \\
\hline & & $(<0,010)$ & $(<0,010)$ & $(0,184)$ & $(0,764)$ \\
\hline \multirow[t]{2}{*}{ Reg. Grau 4} & 1 & 0,003 & 0,344 & 0,189 & 0,000 \\
\hline & & $(0,036)$ & $(<0,010)$ & $(<0,010)$ & $(0,817)$ \\
\hline
\end{tabular}


Tabela 18B. Resumo da análise de regressão polinomial para a variável acidez titulável total (ATT), em lima ácida 'Tahiti', tratada com 1MCP na concentração de $0 ; 0,1 ; 0,5$ e $1,0 \mu \mathrm{L} \mathrm{L}^{-1}$ e armazenada sob refrigeração (mais 3 dias a $25^{\circ} \mathrm{C}$ ).

\begin{tabular}{|c|c|c|c|c|c|}
\hline \multirow{3}{*}{$\mathrm{CV}$} & \multirow{3}{*}{ GL } & \multicolumn{4}{|c|}{$\begin{array}{c}\text { QUADRADOS MÉDIOS } \\
\text { (PROB. > F) }\end{array}$} \\
\hline & & \multicolumn{4}{|c|}{ Concentração de 1-MCP $\left(\mu \mathrm{L} \mathrm{L}^{-1}\right)$} \\
\hline & & 0 & 0,1 & 0,5 & 1,0 \\
\hline \multirow[t]{2}{*}{ Reg. Linear } & 1 & 0,461 & 0,302 & 0,471 & 0,282 \\
\hline & & $(<0,010)$ & $(<0,010)$ & $(<0,010)$ & $(<0,010)$ \\
\hline \multirow[t]{2}{*}{ Reg. Quadr. } & 1 & 0,343 & 0,007 & 0,003 & 0,057 \\
\hline & & $(<0,010)$ & $(0,265)$ & $(0,554)$ & $(<0,010)$ \\
\hline \multirow{2}{*}{ Reg. Cúbica } & 1 & 0,177 & 0,078 & 0,003 & 0,041 \\
\hline & & $(<0,010)$ & $(<0,010)$ & $(0,566)$ & $(<0,010)$ \\
\hline \multirow[t]{2}{*}{ Reg. Grau 4} & 1 & 0,049 & 0,170 & 0,005 & 0,015 \\
\hline & & $(<0,010)$ & $(<0,010)$ & $(0,647)$ & $(0,106)$ \\
\hline
\end{tabular}

Tabela 19. Resumo da análise de variância, para as variáveis: ratio (SST/ATT) e ácido ascórbico (vit. C), em lima ácida 'Tahiti' tratada com 1MCP e armazenada sob refrigeração (mais 3 dias a 25 $\left.{ }^{\circ} \mathrm{C}\right)$.

QUADRADOS MÉDIOS (PROB. > F)

\begin{tabular}{lccc}
\multicolumn{1}{c}{ CV } & GL & Ratio & Vit.C \\
\hline Tratamentos & 3 & 0,002 & 47,331 \\
& & $(0,010)$ & $(0,368)$ \\
Período & 4 & 0,025 & 498,744 \\
& & $(<0,010)$ & $(<0,010)$ \\
Trat. * Período & 12 & 0,001 & 39,566 \\
& & $(<0,010)$ & $(0,550)$ \\
Resíduo & 40 & 0,0005 & 43,726 \\
\hline
\end{tabular}

Tabela 19A. Resumo da análise de regressão polinomial para a variável Ratio (SST/ATT), em suco de lima ácida 'Tahiti', tratada com $1 \mathrm{MCP}$ na concentração de $0 ; 0,1 ; 0,5$ e $1,0 \mu \mathrm{L} \mathrm{L}^{-1} \mathrm{e}$ armazenada sob refrigeração (mais 3 dias a $25^{\circ} \mathrm{C}$ ).

\begin{tabular}{cccccc}
\hline & & \multicolumn{4}{c}{ QUADRADOS MÉDIOS } \\
& \multirow{2}{*}{ CL } & \multicolumn{4}{c}{ PROB. > F) } \\
\cline { 3 - 5 } & & 0 & 0,1 & 0,5 & 1,0 \\
\hline Reg. Linear & 1 & 0,013 & 0,006 & 0,003 & $(0,004$ \\
& & $(<0,010)$ & $(<0,010)$ & $(0,017)$ & $0,014)$ \\
Reg. Quadr. & 1 & 0,044 & 0,017 & 0,014 & 0,006 \\
& & $(<0,010)$ & $(<0,010)$ & $(<0,010)$ & $(<0,010)$ \\
Reg. Cúbica & 1 & 0,005 & 0,000 & 0,002 & 0,002 \\
& & $(<0,010)$ & $(0,661)$ & $(0,077)$ & $(0,089)$ \\
Reg. Grau 4 & 1 & 0,000 & 0,000 & 0,002 & 0,000 \\
& & $(0,796)$ & $(0,838)$ & $(0,052)$ & $(0,509)$ \\
\hline
\end{tabular}


Tabela 20. Resumo da análise de variância para a variável taxa respiratória (TR), em lima ácida 'Tahiti' tratada com 1-MCP e armazenada com 1MCP e armazenado sob refrigeração a $9{ }^{\circ} \mathrm{C}$ e após 3 dias a $25^{\circ} \mathrm{C}$.

\begin{tabular}{|c|c|c|c|}
\hline \multirow[b]{2}{*}{$\mathrm{CV}$} & \multirow[b]{2}{*}{ GL } & \multicolumn{2}{|c|}{$\begin{array}{l}\text { QUADRADOS MEDIOS } \\
\text { (PROB. > F) }\end{array}$} \\
\hline & & $\begin{array}{c}\mathrm{TR}\left(9^{\circ} \mathrm{C}\right) \\
\left(\mathrm{mL} \mathrm{CO}_{2} \mathrm{~kg}^{-1} \mathrm{~h}^{-1}\right)\end{array}$ & $\begin{array}{c}\mathrm{TR}\left(25^{\circ} \mathrm{C}\right) \\
\left(\mathrm{mLCO}_{2} \mathrm{~kg}^{-1} \mathrm{~h}^{-1}\right)\end{array}$ \\
\hline Tratamentos & 3 & $\begin{array}{l}47,331 \\
(0,368)\end{array}$ & $\begin{array}{c}3,643 \\
(<0,010)\end{array}$ \\
\hline Período & 4 & $\begin{array}{l}198,744 \\
(<0,010)\end{array}$ & $\begin{array}{l}347,380 \\
(<0,010)\end{array}$ \\
\hline Trat. * Período & 12 & $\begin{array}{l}39,566 \\
(0,550)\end{array}$ & $\begin{array}{c}3,911 \\
(<0,010)\end{array}$ \\
\hline Resíduo & 40 & 43,726 & 0,222 \\
\hline
\end{tabular}

Tabela 20A. Resumo da análise de regressão polinomial para a variável taxa respiratória, em lima ácida 'Tahiti', tratada com 1-MCP na concentração de $0 ; 0,1 ; 0,5$ e $1,0 \mu \mathrm{L} \mathrm{L}^{-1}$ e armazenada sob refrigeração a $9 \pm 1^{\circ} \mathrm{C}$ ).

\begin{tabular}{|c|c|c|c|c|c|}
\hline \multirow{3}{*}{$\mathrm{CV}$} & \multirow{3}{*}{ GL } & \multicolumn{4}{|c|}{$\begin{array}{c}\text { QUADRADOS MEDIOS } \\
\text { (PROB. > F) }\end{array}$} \\
\hline & & \multicolumn{4}{|c|}{ Concentração de 1-MCP $\left(\mu \mathrm{L} \mathrm{L}^{-1}\right)$} \\
\hline & & 0 & 0,1 & 0,5 & 1,0 \\
\hline \multirow[t]{2}{*}{ Reg. Linear } & 1 & 117,651 & 148,074 & 109,748 & 139,234 \\
\hline & & $(<0,010)$ & $(<0,010)$ & $(<0,010)$ & $(<0,010)$ \\
\hline \multirow[t]{2}{*}{ Reg. Quadr. } & 1 & 116,300 & 87,408 & 117,869 & 98,838 \\
\hline & & $(<0,010)$ & $(<0,010)$ & $(<0,010)$ & $(<0,010)$ \\
\hline \multirow[t]{2}{*}{ Reg. Cúbica } & 1 & 8,247 & 1,408 & 8,049 & 15,465 \\
\hline & & $(<0,010)$ & $(0,019)$ & $(<0,010)$ & $(<0,010)$ \\
\hline \multirow[t]{2}{*}{ Reg. Grau 4} & 1 & 15,109 & 11,573 & 14,144 & 2,853 \\
\hline & & $(<0,010)$ & $(<0,010)$ & $(<0,010)$ & $(<0,010)$ \\
\hline
\end{tabular}

Tabela 20B. Resumo da análise de regressão polinomial para a variável taxa respiratória, em lima ácida 'Tahiti', tratada com 1-MCP na concentração de $0 ; 0,1 ; 0,5$ e $1,0 \mu \mathrm{L} \mathrm{L}^{-1}$ e armazenada sob refrigeração (mais 3 dias a $25^{\circ} \mathrm{C}$ ).

\begin{tabular}{|c|c|c|c|c|c|}
\hline \multirow{3}{*}{$\mathrm{CV}$} & \multirow{3}{*}{ GL } & \multicolumn{4}{|c|}{$\begin{array}{c}\text { QUADRADOS MEDIOS } \\
\text { (PROB. > F) }\end{array}$} \\
\hline & & \multicolumn{4}{|c|}{ Concentração de 1-MCP $\left(\mu \mathrm{L} \mathrm{L}^{-1}\right)$} \\
\hline & & 0 & 0,1 & 0,5 & 1,0 \\
\hline \multirow[t]{2}{*}{ Reg. Linear } & 1 & 6,486 & 19,136 & 23,567 & 63,831 \\
\hline & & $(<0,010)$ & $(<0,010)$ & $(<0,010)$ & $(<0,010)$ \\
\hline \multirow[t]{2}{*}{ Reg. Quadr. } & 1 & 252,938 & 298,559 & 311,222 & 424,466 \\
\hline & & $(<0,010)$ & $(<0,010)$ & $(<0,010)$ & $(<0,010)$ \\
\hline \multirow[t]{2}{*}{ Reg. Cúbica } & 1 & 8,480 & 0,002 & 14,324 & 0,220 \\
\hline & & $(<0,010)$ & $(0,913)$ & $(<0,010)$ & $(0,673)$ \\
\hline \multirow[t]{2}{*}{ Reg. Grau 4} & 1 & 7,868 & 2,855 & 2,098 & 0,398 \\
\hline & & $(<0,010)$ & $(<0,010)$ & $(<0,010)$ & $(0,184)$ \\
\hline
\end{tabular}


Tabela 21. Resumo da análise de variância para as variáveis: perda de massa (PM) e quantidade de suco (\% suco), em lima ácida 'Tahiti' tratada com 1 MCP e armazenada sob refrigeração (mais 3 dias a $\left.25^{\circ} \mathrm{C}\right)$.

\begin{tabular}{lccc}
\hline & & \multicolumn{3}{c}{$\begin{array}{c}\text { QUADRADOS MEDIOS } \\
\text { (PROB. }>\text { F) }\end{array}$} \\
\cline { 3 - 4 } \multicolumn{1}{c}{ CV } & GL & PM & \% de suco \\
\hline Tratamentos & 3 & 0,092 & 4,292 \\
& & $(0,141)$ & $(0,392)$ \\
Período & 4 & 27,157 & 263,392 \\
& & $(<0,010)$ & $(<0,010)$ \\
Trat. * Período & 12 & 0,130 & 3,499 \\
& & $(<0,010)$ & $(0,614)$ \\
Resíduo & 40 & 0,048 & 4,181 \\
\hline
\end{tabular}

Tabela 22. Resumo da análise de variância para a variável croma $\left(\mathrm{C}^{*}\right)$ e ângulo de cor $\left(\mathrm{h}^{\mathrm{o}}\right)$, em casca de lima ácida 'Tahiti', tratada com aminoetoxivinilglicina (AVG) e armazenada sob refrigeração (mais 3 dias a $25^{\circ} \mathrm{C}$ ).

\begin{tabular}{lccc}
\hline & & \multicolumn{3}{c}{$\begin{array}{c}\text { QUADRADOS MEDIOS } \\
\text { (PROB. > F) }\end{array}$} \\
\cline { 3 - 4 } \multicolumn{1}{c}{$\mathrm{CV}$} & $\mathrm{GL}$ & $\left(\mathrm{C}^{*}\right)$ & $\left(\mathrm{h}^{\circ}\right)$ \\
\hline Tratamentos & 3 & 51,679 & 1,523 \\
& & $(<0,010)$ & $(0,050)$ \\
Período & 4 & 1528,217 & 1043,686 \\
& & $(<0,010)$ & $(<0,010)$ \\
Trat. * Período & 12 & 14,900 & 2,479 \\
& & $(<0,010)$ & $(<0,010)$ \\
Resíduo & 40 & 0,519 & 0,542 \\
\hline
\end{tabular}

Tabela 22A. Resumo da análise de regressão polinomial para a variável croma $\left(\mathrm{C}^{*}\right)$, em casca de lima ácida 'Tahiti', tratada com AVG na concentração de 0; 10; 50 e $100 \mathrm{mg} \mathrm{L}^{-1}$ e armazenada sob refrigeração (mais 3 dias a $25^{\circ} \mathrm{C}$ ).

\begin{tabular}{|c|c|c|c|c|c|}
\hline \multirow{3}{*}{$\mathrm{CV}$} & \multirow{3}{*}{ GL } & \multicolumn{4}{|c|}{$\begin{array}{c}\text { QUADRADOS MEEDIOS } \\
\text { (PROB. }>\text { F) }\end{array}$} \\
\hline & & \multicolumn{4}{|c|}{ Concentração de AVG (mg L $\left.{ }^{-1}\right)$} \\
\hline & & 0 & 10 & 50 & 100 \\
\hline \multirow[t]{2}{*}{ Reg. Linear } & 1 & 1672,533 & 995,443 & 948,544 & 846,945 \\
\hline & & $(<0,010)$ & $(<0,010)$ & $(<0,010)$ & $(<0,010)$ \\
\hline \multirow[t]{2}{*}{ Reg. Quadr. } & 1 & 336,487 & 384,810 & 428,481 & 365,858 \\
\hline & & $(<0,010)$ & $(<0,010)$ & $(<0,010)$ & $(<0,010)$ \\
\hline \multirow{2}{*}{ Reg. Cúbica } & 1 & 0,645 & 0,714 & 3,794 & 6,640 \\
\hline & & $(0,271)$ & $(0,246)$ & $(<0,010)$ & $(<0,010)$ \\
\hline \multirow[t]{2}{*}{ Reg. Grau 4} & 1 & 0,160 & 99,829 & 39,754 & 161,219 \\
\hline & & $(0,588)$ & $(<0,010)$ & $(<0,010)$ & $(<0,010)$ \\
\hline
\end{tabular}


Tabela 22B. Resumo da análise de regressão polinomial para a variável ângulo de cor $\left(\mathrm{h}^{\mathrm{o}}\right)$, em casca de lima ácida 'Tahiti', tratada com AVG na concentração de 0;10; 50 e $100 \mathrm{mg} \mathrm{L}^{-1}$ e armazenada sob refrigeração (mais 3 dias a $25^{\circ} \mathrm{C}$ ).

\begin{tabular}{|c|c|c|c|c|c|}
\hline \multirow{3}{*}{$\mathrm{CV}$} & \multirow{3}{*}{ GL } & \multicolumn{4}{|c|}{$\begin{array}{c}\text { QUADRADOS MEDIOS } \\
\text { (PROB. > F) }\end{array}$} \\
\hline & & \multicolumn{4}{|c|}{ Concentração de AVG $\left(\mathrm{mg} \mathrm{L}^{-1}\right)$} \\
\hline & & 0 & 10 & 50 & 100 \\
\hline \multirow{2}{*}{ Reg. Linear } & 1 & 1041,941 & 926,296 & 993,025 & 921,856 \\
\hline & & $(<0,010)$ & $(<0,010)$ & $(<0,010)$ & $(<0,010)$ \\
\hline \multirow[t]{2}{*}{ Reg. Quadr. } & 1 & 57,634 & 73,868 & 76,275 & 72,811 \\
\hline & & $(<0,010)$ & $(<0,010)$ & $(<0,010)$ & $(<0,010)$ \\
\hline \multirow[t]{2}{*}{ Reg. Cúbica } & 1 & 0,005 & 10,325 & 3,201 & 4,720 \\
\hline & & $(0,918)$ & $(<0,010)$ & $(0,018)$ & $(<0,010)$ \\
\hline \multirow[t]{2}{*}{ Reg. Grau 4} & 1 & 1,475 & 11,526 & 9,135 & 0,394 \\
\hline & & $(0,103)$ & $(<0,010)$ & $(<0,010)$ & $(0,596)$ \\
\hline
\end{tabular}

Tabela 23. Resumo da análise de variância, para as variáveis: sólidos solúveis totais (SST) e acidez titulável total (ATT), em lima ácida 'Tahiti', tratada com aminoetoxivinilglicina (AVG) e armazenada sob refrigeração (mais 3 dias a $25^{\circ} \mathrm{C}$ ).

\begin{tabular}{lccc}
\hline & & \multicolumn{3}{c}{$\begin{array}{c}\text { QUADRADOS MEDIOS } \\
\text { (PROB. }>\text { F) }\end{array}$} \\
\cline { 3 - 4 } CV & GL & SST & ATT \\
\cline { 3 - 4 } Tratamentos & 3 & 0,084 & 0,027 \\
Período & & $(<0,010)$ & $(<0,010)$ \\
& 4 & 0,777 & 0,604 \\
Trat. * Período & 12 & $(<0,010)$ & $(<0,010)$ \\
& & 0,065 & 0,054 \\
Resíduo & 40 & $(<0,010)$ & $(<0,010)$ \\
\hline
\end{tabular}

Tabela 23A. Resumo da análise de regressão polinomial para a variável sólidos solúveis totais (SST) em lima ácida 'Tahiti', tratada com AVG na concentração de 0;10; 50 e $100 \mathrm{mg} \mathrm{L}^{-1}$ e armazenada sob refrigeração (mais 3 dias a $25^{\circ} \mathrm{C}$ ).

\begin{tabular}{|c|c|c|c|c|c|}
\hline \multirow{3}{*}{$\mathrm{CV}$} & \multirow{3}{*}{ GL } & \multicolumn{4}{|c|}{$\begin{array}{l}\text { QUADRADOS MEDIOS } \\
\text { (PROB. > F) }\end{array}$} \\
\hline & & \multicolumn{4}{|c|}{ Concentração de AVG $\left(\mathrm{mg} \mathrm{L}^{-1}\right)$} \\
\hline & & 0 & 10 & 50 & 100 \\
\hline \multirow[t]{2}{*}{ Reg. Linear } & 1 & 0,056 & 0,208 & 0,096 & 0,176 \\
\hline & & $(0,030)$ & $(<0,010)$ & $(<0,010)$ & $(<0,010)$ \\
\hline \multirow[t]{2}{*}{ Reg. Quadr. } & 1 & 0,400 & 0,440 & 0,571 & 0,200 \\
\hline & & $(<0,010)$ & $(<0,010)$ & $(<0,010)$ & $(<0,010)$ \\
\hline \multirow[t]{2}{*}{ Reg. Cúbica } & 1 & 1,160 & 0,033 & 0,147 & 0,027 \\
\hline & & $(<0,010)$ & $(0,092)$ & $(<0,010)$ & $(0,129)$ \\
\hline \multirow[t]{2}{*}{ Reg. Grau 4} & 1 & 0,096 & 0,260 & 0,021 & 0,000 \\
\hline & & $(<0,010)$ & $(<0,010)$ & $(0,181)$ & $(0,842)$ \\
\hline
\end{tabular}


Tabela 23B. Resumo da análise de regressão polinomial para a variável acidez titulável total (ATT), em lima ácida 'Tahiti' tratada com AVG na concentração de 0; 10; 50 e $100 \mathrm{mg} \mathrm{L}^{-1}$ e armazenada sob refrigeração (mais 3 dias a $25^{\circ} \mathrm{C}$ ).

\begin{tabular}{|c|c|c|c|c|c|}
\hline \multirow{3}{*}{$\mathrm{CV}$} & \multirow{3}{*}{ GL } & \multicolumn{4}{|c|}{$\begin{array}{c}\text { QUADRADOS MÉDIOS } \\
\text { (PROB. > F) }\end{array}$} \\
\hline & & \multicolumn{4}{|c|}{ Concentração de AVG $\left(\mathrm{mg} \mathrm{L}^{-1}\right)$} \\
\hline & & 0 & 10 & 50 & 100 \\
\hline \multirow[t]{2}{*}{ Reg. Linear } & 1 & 0,461 & 0,328 & 0,308 & 0,571 \\
\hline & & $(<0,010)$ & $(<0,010)$ & $(<0,010)$ & $(<0,010)$ \\
\hline \multirow[t]{2}{*}{ Reg. Quadr. } & 1 & 0,343 & 0,006 & 0,095 & 0,016 \\
\hline & & $(<0,010)$ & $(0,667)$ & $(<0,010)$ & $(0,110)$ \\
\hline \multirow[t]{2}{*}{ Reg. Cúbica } & 1 & 0,178 & 0,002 & 0,378 & 0,006 \\
\hline & & $(<0,010)$ & $(0,525)$ & $(<0,010)$ & $(0,324)$ \\
\hline \multirow[t]{2}{*}{ Reg. Grau 4} & 1 & 0,049 & 0,183 & 0,097 & 0,045 \\
\hline & & $(<0,010)$ & $(<0,010)$ & $(0,181)$ & $(<0,010)$ \\
\hline
\end{tabular}

Tabela 24. Resumo da análise de variância, para as variáveis: ratio (SST/ATT) e ácido ascórbico (vit. C), em lima ácida 'Tahiti', tratada com aminoetoxivinilglicina (AVG) e armazenada sob refrigeração (mais 3 dias a $25^{\circ} \mathrm{C}$ ).

\begin{tabular}{lccc}
\hline & & \multicolumn{3}{c}{$\begin{array}{c}\text { QUADRADOS MEDIOS } \\
\text { (PROB. }>\text { F) }\end{array}$} \\
\cline { 3 - 4 } CV & GL & Ratio & Vit. C \\
Tratamentos & 3 & 0,005 & 20,336 \\
& & $(<0,010)$ & $(0,304)$ \\
Período & 4 & 0,029 & 102,007 \\
& & $(<0,010)$ & $(<0,010)$ \\
Trat. * Período & 12 & 0,002 & 24,846 \\
& & $(<0,010)$ & $(0,154)$ \\
Resíduo & 40 & 0,0006 & 16,262 \\
\hline
\end{tabular}

Tabela 24A. Resumo da análise de regressão polinomial para a variável ratio (SST/ATT) em lima ácida 'Tahiti', tratada com AVG na concentração de 0; 10; 50 e $100 \mathrm{mg} \mathrm{L}^{-1}$ e armazenada sob refrigeração (mais 3 dias a $25^{\circ} \mathrm{C}$ ).

\begin{tabular}{cccccc}
\hline & & \multicolumn{4}{c}{$\begin{array}{c}\text { QUADRADOS MEDIOS } \\
\text { (PROB. }>\text { F) }\end{array}$} \\
\cline { 3 - 5 } CV & GL & 0 & 10 & 50 & 100 \\
\hline Reg. Linear & 1 & 0,013 & 0,001 & 0,006 & 0,009 \\
& & $(<0,010)$ & $(0,166)$ & $(<0,010)$ & $(<0,010)$ \\
Reg. Quadr. & 1 & 0,044 & 0,009 & 0,031 & 0,008 \\
& & $(<0,010)$ & $(<0,010)$ & $(<0,010)$ & $(<0,010)$ \\
Reg. Cúbica & 1 & 0,005 & 0,000 & 0,005 & 0,001 \\
& & $(<0,010)$ & $(0,878)$ & $(<0,010)$ & $(0,190)$ \\
Reg. Grau 4 & 1 & 0,000 & 0,007 & 0,001 & 0,002 \\
& & $(0,799)$ & $(<0,010)$ & $(0,130)$ & $(0,038)$ \\
\hline
\end{tabular}


Tabela 25. Resumo da análise de variância para a variável taxa respiratória (TR), em lima ácida 'Tahiti', tratada com aminoetoxivinilglicina (AVG) e armazenada sob refrigeração a $9{ }^{\circ} \mathrm{C}$ e após 3 dias a $25^{\circ} \mathrm{C}$.

\begin{tabular}{lccc}
\hline & & \multicolumn{3}{c}{$\begin{array}{c}\text { QUADRADOS MEDIOS } \\
\text { (PROB. }>\mathrm{F})\end{array}$} \\
\cline { 3 - 4 } & $\mathrm{GL}$ & $\mathrm{TR}\left(9^{\circ} \mathrm{C}\right)$ & $\mathrm{TR}\left(25^{\circ} \mathrm{C}\right)$ \\
& & 5,645 & $\left(\mathrm{~mL} \mathrm{CO}_{2} \mathrm{~kg}^{-1} \mathrm{~h}^{-1}\right)$ \\
\hline Tratamentos & 3 & $(<0,010)$ & 5,706 \\
& & 209,004 & $(<0,010)$ \\
Período & 4 & $(<0,010)$ & 320,270 \\
& & 1,930 & $(<0,010)$ \\
Trat. * Período & 12 & $(<0,010)$ & 3,581 \\
& & 0,428 & $(<0,010)$ \\
Resíduo & 40 & & 0,958 \\
\hline
\end{tabular}

Tabela 25A. Resumo da análise de regressão polinomial para a variável taxa respiratória em lima ácida 'Tahiti', tratada com AVG na concentração de 0; 10; 50 e $100 \mathrm{mg} \mathrm{L}^{-1}$ e armazenada sob refrigeração a $9+1{ }^{\circ} \mathrm{C}$.

\begin{tabular}{|c|c|c|c|c|c|}
\hline \multirow{3}{*}{$\mathrm{CV}$} & \multirow{3}{*}{ GL } & \multicolumn{4}{|c|}{$\begin{array}{c}\text { QUADRADOS MÉDIOS } \\
\text { (PROB. > F) }\end{array}$} \\
\hline & & \multicolumn{4}{|c|}{ Concentração de AVG $\left(\mathrm{mg} \mathrm{L}^{-1}\right)$} \\
\hline & & 0 & 10 & 50 & 100 \\
\hline \multirow[t]{2}{*}{ Reg. Linear } & 1 & 117,651 & 123,748 & 139,019 & 130,124 \\
\hline & & $(<0,010)$ & $(<0,010)$ & $(<0,010)$ & $(<0,010)$ \\
\hline \multirow[t]{2}{*}{ Reg. Quadr. } & 1 & 114,510 & 67,007 & 79,709 & 38,899 \\
\hline & & $(<0,010)$ & $(<0,010)$ & $(<0,010)$ & $(<0,010)$ \\
\hline \multirow[t]{2}{*}{ Reg. Cúbica } & 1 & 8,247 & 7,340 & 5,976 & 4,555 \\
\hline & & $(<0,010)$ & $(<0,010)$ & $(<0,010)$ & $(<0,010)$ \\
\hline \multirow[t]{2}{*}{ Reg. Grau 4} & 1 & 15,991 & 3,538 & 0,813 & 2,054 \\
\hline & & $(<0,010)$ & $(<0,010)$ & $(0,172)$ & $(0,032)$ \\
\hline
\end{tabular}

Tabela 25B. Resumo da análise de regressão polinomial para a variável taxa respiratória em lima ácida 'Tahiti', tratada com AVG na concentração de 0; 10; 50 e $100 \mathrm{mg} \mathrm{L}^{-1}$ e armazenada sob refrigeração (mais 3 dia a $25^{\circ} \mathrm{C}$ ).

\begin{tabular}{cccccc}
\hline & & \multicolumn{4}{c}{$\begin{array}{c}\text { QUDRADOS MEDIOS } \\
\text { (PROB. }>\text { F) }\end{array}$} \\
\cline { 3 - 5 } CV & GL & 0 & \multicolumn{4}{c}{ Concentração de AVG $\left(\mathrm{mg} \mathrm{L}^{-1}\right)$} \\
& & 6,486 & 41,184 & 50 & 100 \\
\hline Reg. Linear & 1 & $(0,012)$ & $(<0,010)$ & $(<0,3910)$ & 52,272 \\
& & 252,938 & 346,926 & 247,859 & $(<0,010)$ \\
Reg. Quadr. & 1 & $(<0,010)$ & $(<0,010)$ & $(<0,010)$ & 293,462 \\
& & 8,480 & 1,408 & 15,165 & $(<0,010)$ \\
Reg. Cúbica & 1 & $(<0,010)$ & $(0,231)$ & $(<0,010)$ & $(<0,010)$ \\
& & 7,868 & 1,132 & 0,177 & 8,288 \\
Reg. Grau 4 & 1 & $(<0,010)$ & $(0,283)$ & $(0,672)$ & $(<0,010)$ \\
& & & & & \\
\hline
\end{tabular}


Tabela 26. Resumo da análise de variância para as variáveis: perda de massa (PM) e quantidade de suco (\% suco), em lima ácida 'Tahiti', tratada com aminoetoxivinilglicina (AVG) e armazenada sob refrigeração (mais 3 dias a $25^{\circ} \mathrm{C}$ ).

\begin{tabular}{lccc}
\hline & & \multicolumn{3}{c}{$\begin{array}{c}\text { QUADRADOS MEDIOS } \\
\text { (PROB. > F) }\end{array}$} \\
\cline { 3 - 4 } \multicolumn{1}{c}{ CV } & GL & PM & \% de suco \\
\cline { 3 - 4 } Tratamentos & 3 & 0,128 & 2,066 \\
& & $(0,199)$ & $(0,747)$ \\
Período & 4 & 27,452 & 198,683 \\
& & $(<0,010)$ & $(<0,010)$ \\
Trat. * Período & 12 & 0,038 & 3,082 \\
& & $(0,912)$ & $(0,814)$ \\
Resíduo & 40 & 0,079 & 4,983 \\
\hline
\end{tabular}

Tabela 27. Resumo da análise de variância para a variável croma $\left(\mathrm{C}^{*}\right)$ e ângulo de cor $\left(\mathrm{h}^{\mathrm{o}}\right)$, em casca de lima ácida 'Tahiti', tratada com reguladores vegetais e armazenada sob refrigeração (mais 3 dias a $25^{\circ} \mathrm{C}$ ).

\begin{tabular}{|c|c|c|c|}
\hline \multirow[b]{2}{*}{$\mathrm{CV}$} & \multirow[b]{2}{*}{ GL } & \multicolumn{2}{|c|}{$\begin{array}{c}\text { QUADRADOS MEDIOS } \\
\text { (PROB. > F) }\end{array}$} \\
\hline & & $\left(\mathrm{C}^{*}\right)$ & $\left(\mathrm{h}^{0}\right)$ \\
\hline \multirow[t]{2}{*}{ Tratamentos } & 3 & 273,393 & 124,027 \\
\hline & & $(<0,010)$ & $(<0,010)$ \\
\hline \multirow{2}{*}{ Período } & 4 & 991,611 & 513,485 \\
\hline & & $(<0,010)$ & $(<0,010)$ \\
\hline \multirow[t]{2}{*}{ Trat. * Período } & 12 & 35,313 & 21,988 \\
\hline & & $(<0,010)$ & $(<0,010)$ \\
\hline Resíduo (Trat.) & 6 & 1,554 & 0,247 \\
\hline Resíduo (Período) & 32 & 0,766 & 0,455 \\
\hline
\end{tabular}

Tabela 27A. Resumo da análise de regressão polinomial para a variável croma $\left(\mathrm{C}^{*}\right)$, em casca de lima ácida 'Tahiti', tratada com reguladores vegetais e armazenada sob refrigeração (mais 3 dias a $25^{\circ} \mathrm{C}$ ).

\begin{tabular}{|c|c|c|c|c|c|}
\hline \multirow{3}{*}{$\mathrm{CV}$} & \multirow{3}{*}{ GL } & \multicolumn{4}{|c|}{$\begin{array}{l}\text { QUADRADOS MÉDIOS } \\
\text { (PROB. > F) }\end{array}$} \\
\hline & & \multicolumn{4}{|c|}{ Biorreguladores } \\
\hline & & Controle & $\mathrm{GA}_{3}$ & $1-\mathrm{MCP}+\mathrm{GA}_{3}$ & $\mathrm{AVG}+\mathrm{GA}_{3}$ \\
\hline \multirow[t]{2}{*}{ Reg. Linear } & 1 & 1672,533 & 759,630 & 361,157 & 490,537 \\
\hline & & $(<0,010)$ & $(<0,010)$ & $(<0,010)$ & $(<0,010)$ \\
\hline \multirow[t]{2}{*}{ Reg. Quadr. } & 1 & 306,487 & 248,686 & 195,739 & 111,622 \\
\hline & & $(<0,010)$ & $(<0,010)$ & $(<0,010)$ & $(<0,010)$ \\
\hline \multirow[t]{2}{*}{ Reg. Cúbica } & 1 & 0,645 & 4,354 & 6,274 & 26,942 \\
\hline & & $(0,631)$ & $(0,022)$ & $(<0,010)$ & $(<0,010)$ \\
\hline \multirow[t]{2}{*}{ Reg. Grau 4} & 1 & 0,160 & 0,247 & 24,603 & 150,588 \\
\hline & & $(0,655)$ & $(0,580)$ & $(<0,010)$ & $(<0,010)$ \\
\hline
\end{tabular}


Tabela 27B. Resumo da análise de regressão polinomial para a variável, ângulo de cor $\left(\mathrm{h}^{\mathrm{o}}\right)$, em casca de lima ácida 'Tahiti', tratada com reguladores vegetais e armazenada sob refrigeração (mais 3 dias a $\left.25^{\circ} \mathrm{C}\right)$.

\begin{tabular}{|c|c|c|c|c|c|}
\hline \multirow{3}{*}{$\mathrm{CV}$} & \multirow{3}{*}{ GL } & \multicolumn{4}{|c|}{$\begin{array}{l}\text { QUADRADOS MEDIOS } \\
\text { (PROB. > F) }\end{array}$} \\
\hline & & \multicolumn{4}{|c|}{ Biorreguladores } \\
\hline & & Controle & $\mathrm{GA}_{3}$ & $1-\mathrm{MCP}+\mathrm{GA}_{3}$ & $\mathrm{AVG}+\mathrm{GA}_{3}$ \\
\hline \multirow[t]{2}{*}{ Reg. Linear } & 1 & 1041,941 & 352,947 & 124,847 & 465,707 \\
\hline & & $(<0,010)$ & $(<0,010)$ & $(<0,010)$ & $(<0,010)$ \\
\hline \multirow[t]{2}{*}{ Reg. Quadr. } & 1 & 57,634 & 79,819 & 35,843 & 114,675 \\
\hline & & $(<0,010)$ & $(<0,010)$ & $(<0,010)$ & $(<0,010)$ \\
\hline \multirow[t]{2}{*}{ Reg. Cúbica } & 1 & 0,005 & 11,041 & 0,867 & 23,585 \\
\hline & & $(0,910)$ & $(<0,010)$ & $(0,174)$ & $(<0,010)$ \\
\hline \multirow[t]{2}{*}{ Reg. Grau 4} & 1 & 1,475 & 4,695 & 2,585 & 0,128 \\
\hline & & $(0,078)$ & $(<0,010)$ & $(0,022)$ & $(0,604)$ \\
\hline
\end{tabular}

Tabela 28. Resumo da análise de variância, para as variáveis: sólidos solúveis totais (SST) e acidez titulável total (ATT), em lima ácida 'Tahiti', tratada com reguladores vegetais e armazenada sob refrigeração (mais 3 dias a $25^{\circ} \mathrm{C}$ ).

\begin{tabular}{lccc}
\hline & & \multicolumn{3}{c}{$\begin{array}{c}\text { QUADRADOS MEDIOS } \\
\text { (PROB. > F) }\end{array}$} \\
\cline { 3 - 5 } \multicolumn{1}{c}{ CV } & GL & SST & ATT \\
\hline Tratamentos & 3 & 0,016 & 0,055 \\
& & $(0,323)$ & $(<0,010)$ \\
Período & 4 & 1,183 & 0,664 \\
& & $(<0,010)$ & $(<0,010)$ \\
Trat. * Período & 12 & 0,149 & 0,030 \\
& & $(<0,010)$ & $(<0,010)$ \\
Resíduo (Trat.) & 6 & 0,011 & 0,003 \\
Resíduo (Período) & 32 & 0,012 & 0,005 \\
\hline
\end{tabular}

Tabela 28A. Resumo da análise de regressão polinomial para a variável sólidos solúveis totais (SST) em lima ácida 'Tahiti', tratada com reguladores vegetais e armazenada sob refrigeração (mais 3 dias a $\left.25^{\circ} \mathrm{C}\right)$.

\begin{tabular}{cccccc}
\hline & & \multicolumn{3}{c}{$\begin{array}{c}\text { QUARADOS MEDIOS } \\
\text { (PROB. }>\text { F) }\end{array}$} \\
\cline { 3 - 6 } CV & GL & Controle & $\mathrm{GA}_{3}$ & $\begin{array}{c}\text { Biorreguladores } \\
\text { 1-MCP + GA }\end{array}$ & AVG + GA $_{3}$ \\
\hline Reg. Linear & 1 & 0,056 & 0,056 & 0,016 & 0,408 \\
& & $(0,036)$ & $(0,036)$ & $(0,252)$ & $(<0,010)$ \\
Reg. Quadr. & 1 & 0,400 & 2,240 & 1,005 & 0,228 \\
& & $(<0,010)$ & $(<0,010)$ & $(<0,010)$ & $(<0,010)$ \\
Reg. Cúbica & 1 & 1,160 & 0,000 & 0,225 & 0,208 \\
& & $(<0,010)$ & $(0,863)$ & $(<0,010)$ & $(<0,010)$ \\
Reg. Grau 4 & 1 & 0,096 & 0,360 & 0,061 & 0,004 \\
& & $(<0,010)$ & $(<0,010)$ & $(0,029)$ & $(0,582)$ \\
\hline
\end{tabular}


Tabela 28B. Resumo da análise de regressão polinomial para a variável acidez titulável total (ATT), em lima ácida 'Tahiti' tratada com reguladores vegetais e armazenada sob refrigeração (mais 3 dias a $\left.25^{\circ} \mathrm{C}\right)$.

\begin{tabular}{|c|c|c|c|c|c|}
\hline \multirow{3}{*}{$\mathrm{CV}$} & \multirow{3}{*}{ GL } & \multicolumn{4}{|c|}{$\begin{array}{l}\text { QUADRADOS MEDIOS } \\
\text { (PROB. > F) }\end{array}$} \\
\hline & & \multicolumn{4}{|c|}{ Biorreguladores } \\
\hline & & Controle & $\mathrm{GA}_{3}$ & $1-\mathrm{MCP}+\mathrm{GA}_{3}$ & $\mathrm{AVG}+\mathrm{GA}_{3}$ \\
\hline \multirow[t]{2}{*}{ Reg. Linear } & 1 & 0,461 & 9,964 & 0,341 & 0,205 \\
\hline & & $(<0,010)$ & $(<0,010)$ & $(<0,010)$ & $(<0,010)$ \\
\hline \multirow[t]{2}{*}{ Reg. Quadr. } & 1 & 0,343 & 0,103 & 0,099 & 0,014 \\
\hline & & $(<0,010)$ & $(<0,010)$ & $(<0,010)$ & $(0,122)$ \\
\hline \multirow[t]{2}{*}{ Reg. Cúbica } & 1 & 0,177 & 0,004 & 0,008 & 0,089 \\
\hline & & $(<0,010)$ & $(0,570)$ & $(0,241)$ & $(<0,010)$ \\
\hline \multirow[t]{2}{*}{ Reg. Grau 4} & 1 & 0,049 & 0,047 & 0,099 & 0,017 \\
\hline & & $(<0,010)$ & $(<0,010)$ & $(<0,010)$ & $(0,090)$ \\
\hline
\end{tabular}

Tabela 29. Resumo da análise de variância, para as variáveis: ratio (SST/ATT) e ácido ascórbico (vit. C), em lima ácida 'Tahiti', tratada com reguladores vegetais e armazenada sob refrigeração (mais 3 dias a $\left.25^{\circ} \mathrm{C}\right)$.

\begin{tabular}{lccc}
\hline \multicolumn{1}{c}{ CV } & & \multicolumn{3}{c}{$\begin{array}{c}\text { QUADRADOS MEDIOS } \\
\text { (PROB. }>\text { F) }\end{array}$} \\
\cline { 3 - 4 } & GL & Ratio & Vit. C \\
Tratamentos & 3 & 0,007 & 17,541 \\
Período & & $(<0,010)$ & $(<0,010)$ \\
& 4 & 0,040 & 69,354 \\
Trat. * Período & 12 & $(<0,010)$ & $(<0,010)$ \\
& & 0,010 & 8,088 \\
Resíduo (Trat.) & 6 & $(<0,010)$ & $(<0,010)$ \\
Resíduo (Período) & 32 & 0,001 & 0,287 \\
\end{tabular}

Tabela 29A. Resumo da análise de regressão polinomial para a variável ratio (SST/ATT) em lima ácida 'Tahiti', tratada com reguladores vegetais e armazenada sob refrigeração (mais 3 dias a 25 $\left.{ }^{\mathrm{o}} \mathrm{C}\right)$.

\begin{tabular}{|c|c|c|c|c|c|}
\hline \multirow{3}{*}{$\mathrm{CV}$} & \multirow{3}{*}{ GL } & \multicolumn{4}{|c|}{$\begin{array}{c}\text { QUADRADOS MÉDIOS } \\
\text { (PROB. > F) }\end{array}$} \\
\hline & & \multicolumn{4}{|c|}{ Biorreguladores } \\
\hline & & Controle & $\mathrm{GA}_{3}$ & $1-\mathrm{MCP}+\mathrm{GA}_{3}$ & $\mathrm{AVG}+\mathrm{GA}_{3}$ \\
\hline \multirow[t]{2}{*}{ Reg. Linear } & 1 & 0,013 & 0,059 & 0,003 & 0,002 \\
\hline & & $(<0,010)$ & $(<0,010)$ & $(0,029)$ & $(0,056)$ \\
\hline \multirow[t]{2}{*}{ Reg. Quadr. } & 1 & 0,044 & 0,093 & 0,027 & 0,000 \\
\hline & & $(<0,010)$ & $(<0,010)$ & $(<0,010)$ & $(0,537)$ \\
\hline \multirow[t]{2}{*}{ Reg. Cúbica } & 1 & 0,005 & 0,003 & 0,005 & 0,020 \\
\hline & & $(<0,010)$ & $(0,021)$ & $(<0,010)$ & $(<0,010)$ \\
\hline \multirow[t]{2}{*}{ Reg. Grau 4} & 1 & 0,000 & 0,000 & 0,001 & 0,003 \\
\hline & & $(0,795)$ & $(0,860)$ & $(0,218)$ & $(0,025)$ \\
\hline
\end{tabular}


Tabela 29B. Resumo da análise de regressão polinomial para a variável ácido ascórbico (vit. C), em lima ácida 'Tahiti' tratada com reguladores vegetais e armazenada sob refrigeração (mais 3 dias a $\left.25^{\circ} \mathrm{C}\right)$.

\begin{tabular}{|c|c|c|c|c|c|}
\hline \multirow{3}{*}{$\mathrm{CV}$} & \multirow{3}{*}{ GL } & \multicolumn{4}{|c|}{$\begin{array}{l}\text { QUADRADOS MEDIOS } \\
\text { (PROB. > F) }\end{array}$} \\
\hline & & \multicolumn{4}{|c|}{ Biorreguladores } \\
\hline & & Controle & $\mathrm{GA}_{3}$ & $1-\mathrm{MCP}+\mathrm{GA}_{3}$ & $\mathrm{AVG}+\mathrm{GA}_{3}$ \\
\hline \multirow[t]{2}{*}{ Reg. Linear } & 1 & 7,977 & 69,555 & 74,198 & 9,517 \\
\hline & & $(<0,010)$ & $(<0,010)$ & $(<0,010)$ & $(<0,010)$ \\
\hline \multirow[t]{2}{*}{ Reg. Quadr. } & 1 & 46,074 & 6,202 & 29,467 & 3,013 \\
\hline & & $(<0,010)$ & $(<0,010)$ & $(<0,010)$ & $(<0,010)$ \\
\hline \multirow[t]{2}{*}{ Reg. Cúbica } & 1 & 2,154 & 16,265 & 2,263 & 3,353 \\
\hline & & $(0,014)$ & $(<0,010)$ & $(0,012)$ & $(<0,010)$ \\
\hline \multirow[t]{2}{*}{ Reg. Grau 4} & 1 & 4,761 & 4,450 & 1,966 & 6,257 \\
\hline & & $(<0,010)$ & $(<0,010)$ & $(0,018)$ & $(<0,010)$ \\
\hline
\end{tabular}

Tabela 30. Resumo da análise de variância para a variável taxa respiratória (TR), em lima ácida 'Tahiti', tratada com reguladores vegetais e armazenada sob refrigeração a $9{ }^{\circ} \mathrm{C}$ e após 3 dias a $25^{\circ} \mathrm{C}$.

\begin{tabular}{|c|c|c|c|}
\hline \multirow[b]{2}{*}{$\mathrm{CV}$} & \multirow[b]{2}{*}{ GL } & \multicolumn{2}{|c|}{$\begin{array}{c}\text { QUADRADOS MEDIOS } \\
\text { (PROB. > F) }\end{array}$} \\
\hline & & $\begin{array}{c}\mathrm{TR}\left(9^{\circ} \mathrm{C}\right) \\
\left(\mathrm{mLCO} \mathrm{kg}^{-1} \mathrm{~h}^{-1}\right)\end{array}$ & $\begin{array}{c}\mathrm{TR}\left(25^{\circ} \mathrm{C}\right) \\
\left(\mathrm{mLCO}_{2} \mathrm{~kg}^{-1} \mathrm{~h}^{-1}\right)\end{array}$ \\
\hline Tratamentos & 3 & $\begin{array}{c}10,026 \\
(<0,010)\end{array}$ & $\begin{array}{c}9,308 \\
(<0,010)\end{array}$ \\
\hline Período & 4 & $\begin{array}{l}248,938 \\
(<0,010)\end{array}$ & $\begin{array}{l}348,594 \\
(<0,010)\end{array}$ \\
\hline Trat. * Período & 12 & $\begin{array}{c}1,502 \\
(<0,010)\end{array}$ & $\begin{array}{c}4,025 \\
(<0,010)\end{array}$ \\
\hline Resíduo (Trat.) & 6 & 0,179 & 0,173 \\
\hline Resíduo (Período) & 32 & 0,236 & 0,206 \\
\hline
\end{tabular}

Tabela 30A. Resumo da análise de regressão polinomial para a variável taxa respiratória em lima ácida 'Tahiti', tratada com reguladores vegetais e armazenada sob refrigeração a $9 \pm 1^{\circ} \mathrm{C}$.

\begin{tabular}{|c|c|c|c|c|c|}
\hline \multirow{3}{*}{$\mathrm{CV}$} & \multirow{3}{*}{ GL } & \multicolumn{4}{|c|}{$\begin{array}{l}\text { QUADRADOS MÉDIOS } \\
\text { (PROB. > F) }\end{array}$} \\
\hline & & \multicolumn{4}{|c|}{ Biorreguladores } \\
\hline & & Controle & $\mathrm{GA}_{3}$ & $1-\mathrm{MCP}+\mathrm{GA}_{3}$ & $\mathrm{AVG}+\mathrm{GA}_{3}$ \\
\hline \multirow[t]{2}{*}{ Reg. Linear } & 1 & 117,651 & 154,632 & 143,707 & 120,400 \\
\hline & & $(<0,010)$ & $(<0,010)$ & $(<0,010)$ & $(<0,010)$ \\
\hline \multirow[t]{2}{*}{ Reg. Quadr. } & 1 & 114,510 & 109,222 & 121,108 & 65,825 \\
\hline & & $(<0,010)$ & $(<0,010)$ & $(<0,010)$ & $(<0,010)$ \\
\hline \multirow[t]{2}{*}{ Reg. Cúbica } & 1 & 8,847 & 2,203 & 17,910 & 1,610 \\
\hline & & $(<0,010)$ & $(<0,010)$ & $(<0,010)$ & $(0,013)$ \\
\hline \multirow[t]{2}{*}{ Reg. Grau 4} & 1 & 15,991 & 2,879 & 15,287 & 2,596 \\
\hline & & $(<0,010)$ & $(<0,010)$ & $(<0,010)$ & $(<0,010)$ \\
\hline
\end{tabular}


Tabela 30B. Resumo da análise de regressão polinomial para a variável taxa respiratória em lima ácida 'Tahiti', tratada com reguladores vegetais e armazenada sob refrigeração (mais 3 dia a 25 ${ }^{\circ} \mathrm{C}$ ).

\begin{tabular}{|c|c|c|c|c|c|}
\hline \multirow{3}{*}{$\mathrm{CV}$} & \multirow{3}{*}{ GL } & \multicolumn{4}{|c|}{$\begin{array}{l}\text { QUADRADOS MEDIOS } \\
\text { (PROB. > F) }\end{array}$} \\
\hline & & \multicolumn{4}{|c|}{ Biorreguladores } \\
\hline & & Controle & $\mathrm{GA}_{3}$ & $1-\mathrm{MCP}+\mathrm{GA}_{3}$ & $\mathrm{AVG}+\mathrm{GA}_{3}$ \\
\hline \multirow{2}{*}{ Reg. Linear } & 1 & 6,486 & 11,706 & 28,479 & 29,264 \\
\hline & & $(<0,010)$ & $(<0,010)$ & $(<0,010)$ & $(<0,010)$ \\
\hline \multirow[t]{2}{*}{ Reg. Quadr. } & 1 & 252,938 & 347,789 & 408,657 & 323,204 \\
\hline & & $(<0,010)$ & $(<0,010)$ & $(<0,010)$ & $(<0,010)$ \\
\hline \multirow[t]{2}{*}{ Reg. Cúbica } & 1 & 8,480 & 0,257 & 0,029 & 7,193 \\
\hline & & $(<0,010)$ & $(0,272)$ & $(0,709)$ & $(<0,010)$ \\
\hline \multirow[t]{2}{*}{ Reg. Grau 4} & 1 & 7,868 & 2,152 & 6,171 & 2,007 \\
\hline & & $(<0,010)$ & $(<0,010)$ & $(<0,010)$ & $(<0,010)$ \\
\hline
\end{tabular}

Tabela 31. Resumo da análise de variância para as variáveis: perda de massa (PM) e quantidade de suco (\% suco), em lima ácida 'Tahiti', tratada com reguladores vegetais e armazenada sob refrigeração (mais 3 dias a $25^{\circ} \mathrm{C}$ ).

\begin{tabular}{lccc}
\hline & & \multicolumn{3}{c}{$\begin{array}{c}\text { QUADADOS MEDIOS } \\
\text { (PROB. > F) }\end{array}$} \\
\cline { 3 - 4 } \multicolumn{1}{c}{ CV } & GL & PM & \% de suco \\
\hline Tratamentos & 3 & 0,492 & 5,535 \\
& & $(0,041)$ & $(0,393)$ \\
Período & 4 & 30,391 & 235,822 \\
& & $(<0,010)$ & $(<0,010)$ \\
Trat. * Período & 12 & 0,222 & 2,912 \\
& & $(<0,010)$ & $(0,456)$ \\
Resíduo (Trat.) & 6 & 0,094 & 4,691 \\
Resíduo (Período) & 32 & 0,048 & 2,861 \\
\hline
\end{tabular}

Tabela 31A. Resumo da análise de regressão polinomial para a variável perda de massa (PM), em lima ácida 'Tahiti' tratada com reguladores vegetais e armazenada sob refrigeração (mais 3 dias a $\left.25^{\circ} \mathrm{C}\right)$.

\begin{tabular}{|c|c|c|c|c|c|}
\hline \multirow{3}{*}{$\mathrm{CV}$} & \multirow{3}{*}{ GL } & \multicolumn{4}{|c|}{$\begin{array}{l}\text { QUADRADOS MEDIOS } \\
\text { (PROB. > F) }\end{array}$} \\
\hline & & \multicolumn{4}{|c|}{ Biorreguladores } \\
\hline & & Controle & $\mathrm{GA}_{3}$ & $1-\mathrm{MCP}+\mathrm{GA}_{3}$ & $\mathrm{AVG}+\mathrm{GA}_{3}$ \\
\hline \multirow[t]{2}{*}{ Reg. Linear } & 1 & 1,164 & 2,133 & 3,974 & 2,075 \\
\hline & & $(<0,010)$ & $(<0,010)$ & $(<0,010)$ & $(<0,010)$ \\
\hline \multirow[t]{2}{*}{ Reg. Quadr. } & 1 & 18,680 & 18,480 & 22,177 & 19,598 \\
\hline & & $(<0,010)$ & $(<0,010)$ & $(<0,010)$ & $(<0,010)$ \\
\hline \multirow[t]{2}{*}{ Reg. Cúbica } & 1 & 5,067 & 5,764 & 2,706 & 3,481 \\
\hline & & $(<0,010)$ & $(<0,010)$ & $(<0,010)$ & $(<0,010)$ \\
\hline \multirow[t]{2}{*}{ Reg. Grau 4} & 1 & 0,892 & 7,135 & 5,176 & 1,559 \\
\hline & & $(<0,010)$ & $(<0,010)$ & $(<0,010)$ & $(<0,010)$ \\
\hline
\end{tabular}




\section{CLASSIFICAÇÃO}

Classificacăo é a separação do produto por cor, tamanho, formato e qualidade. Usizar a classificacâo da LIMAO TAHITI e unificar a linousgem do mercado.

Produtores, atacadistas, industries, varejistas e consumidores devem ter

os mesmos padrbes para determinar a qualidade do produto. So assim.

obteremos transparencia na comercializaçäo, melhores preços para

produtores e consumidcres, menores perdas e melhor qualidade.

\section{COLORAÇÃO}

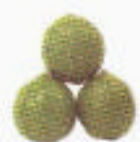

C1

(rugoso)

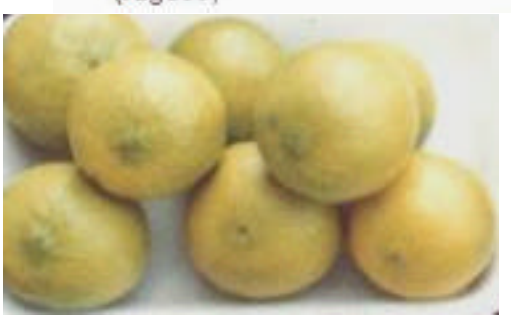

CONTROLE

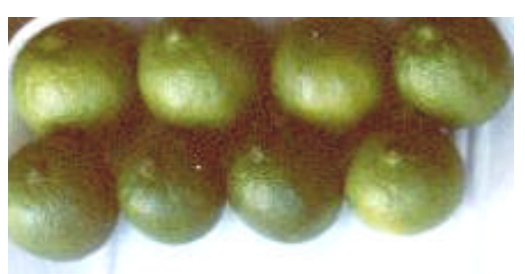

1-MCP+GA $3\left(0,5 \mu \mathrm{L} \mathrm{L}^{-1}+20 \mathrm{mgL}^{-1}\right)$

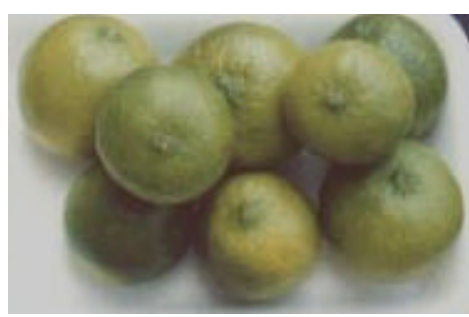

$\mathbf{A V G}_{\mathbf{6}} \mathbf{G A}_{3}\left(50+20 \mathrm{mg} \mathrm{L}^{-1}\right)$

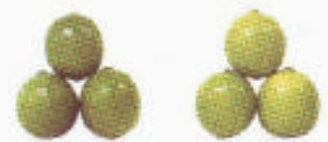

$\mathrm{C} 3$

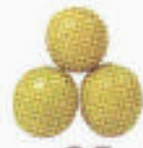

C5

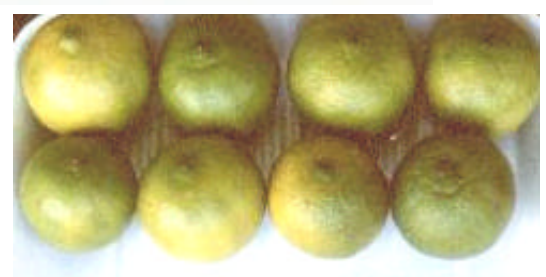

$\mathbf{G A}_{\mathbf{3}}\left(20 \mathrm{mg} \mathrm{L}^{-1}\right)$

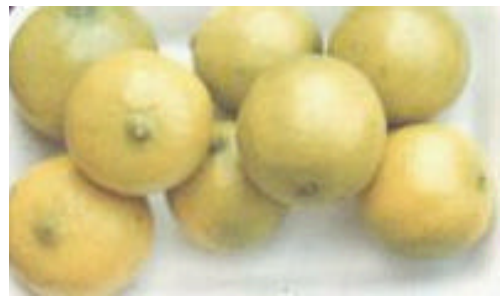

AVG $50 \mathrm{mg} \mathrm{L}^{-1}$ )

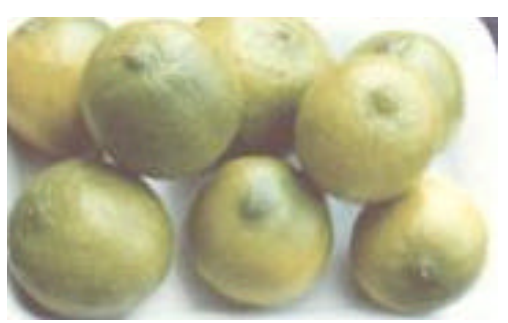

1-MCP $0,5 \mu \mathrm{L} \mathrm{L}^{-1}$

Figura 7 - Resultados da aplicação do regulador vegetal: $\mathrm{GA}_{3} 20 \mathrm{mg} \mathrm{L}^{-1}$; AVG $50 \mathrm{mg} \mathrm{L} \mathrm{L}^{-1}$; 1MCP $0,5 \mu \mathrm{L} \mathrm{L}^{-1} ; \mathrm{AVG} \mathrm{GA}_{3} 50+20 \mathrm{mg} \mathrm{L}^{-1}$ e 1-MCP+GA $0,5 \mu \mathrm{L} \mathrm{L}^{-1}+20 \mathrm{mg} \mathrm{L}^{-1}$, respectivamente, após 60 dias de armazenamento a $9{ }^{\circ} \mathrm{C}$, da lima ácida 'Tahiti'. 